\title{
Adolescent Girls Empowerment Programme in Zambia: Qualitative evaluation report
}

Zoe Duby

Chipo Natasha Zulu

Karen Austrian

Population Council

Follow this and additional works at: https://knowledgecommons.popcouncil.org/departments_sbsr-pgy

Part of the Demography, Population, and Ecology Commons, Family, Life Course, and Society Commons, International Public Health Commons, and the Women's Health Commons How does access to this work benefit you? Let us know!

\section{Recommended Citation}

Duby, Zoe, Chipo Natasha Zulu, and Karen Austrian. 2016. "Adolescent Girls Empowerment Programme in Zambia: Qualitative evaluation report." Lusaka: Population Council. 


\section{Adolescent Cirls Empowerment Programme in Zambla: Qualitative Evaluation Report}




\section{POPULATION}

COUNCIL

Ideas. Evidence. Impact.

The Population Council confronts critical health and development issues-from stopping the spread of HIV to improving reproductive health and ensuring that young people lead full and productive lives. Through biomedical, social science, and public health research in 50 countries, we work with our partners to deliver solutions that lead to more effective policies, programs, and technologies that improve lives around the world. Established in 1952 and headquartered in New York, the Council is a nongovernmental, nonprofit organization governed by an international board of trustees.

Population Council, Zambia

Plot 3670, No. 4

Mwaleshi Road, Olympia Park

Lusaka, Zambia

Tel: $\quad+260211295925$

email:info.zambia@popcouncil.org

Suggested citation: Duby, Zoe, Chipo Natasha Zulu, and Karen Austrian. 2016. "Adolescent Girls Empowerment Programme in Zambia: Qualitative Evaluation Report." Lusaka: Population Council.

(C) 2016 The Population Council, Inc.

popcouncil.org 


\section{Table of Contents}

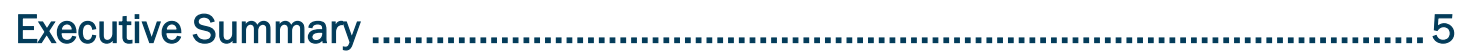

Background and Introduction ........................................................................... 9

1. Situational Context...................................................................................... 9

2. The AGEP Programme ...........................................................................................10

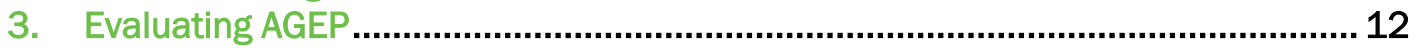

Evaluation Methodology ….........................................................................13

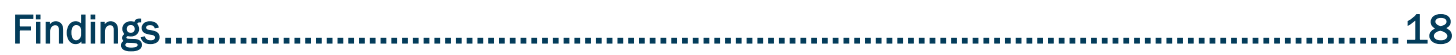

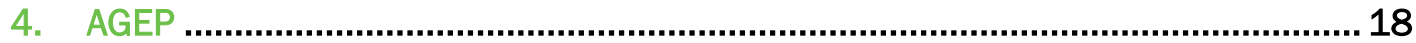

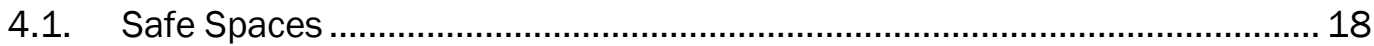

4.1.1. Motivating factors for attending Safe Spaces meetings ........................................18

4.1.2. Demotivating Factors / Discouragement to Attend ……………………..............20

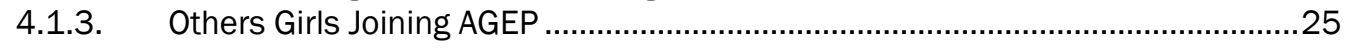

4.2. Control Group Girls: Non-AGEP Program Participation .................................. 25

4.3. Mentoring …………………………………………………………. 26

4.3.1. Mentors benefited from AGEP..................................................................................26

4.3.2. Motivation to become a mentor …………………………………………………………......29

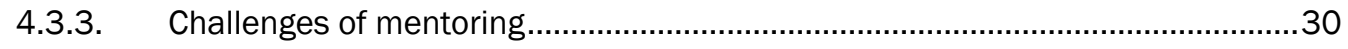

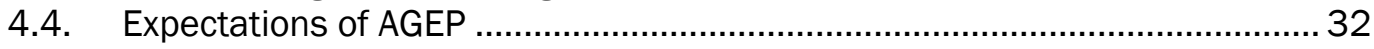

4.5. Concerns about AGEP ............................................................................. 33

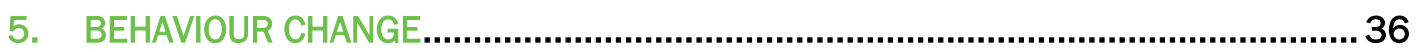

5.1. Behaviour Change ............................................................................ 36

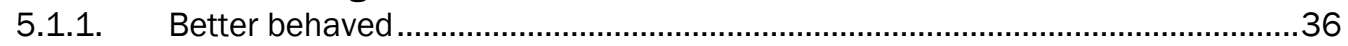

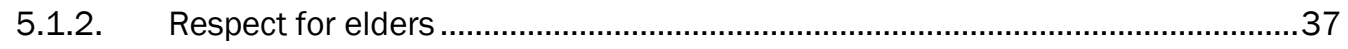

5.1.3. Behaviour of AGEP girls compared to non-AGEP girls ............................................39

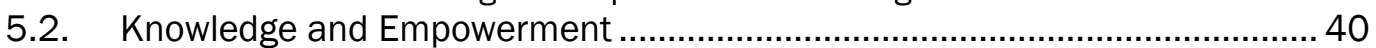

5.2.1. Self-care and safety ................................................................................................40

5.2.2. Physical and sexual abuse ………………………………………………...41

5.2.3. Bodily integrity and rights awareness ...................................................................42

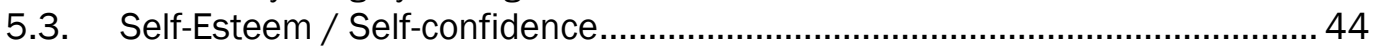

5.3.1. Improved self-esteem / self-confidence ............................................................44

5.3.2. Control group girls: Self-confidence, agency \& decision-making .........................47

5.3.3. Life goals and 'Dreaming Big' .....................................................................4 4

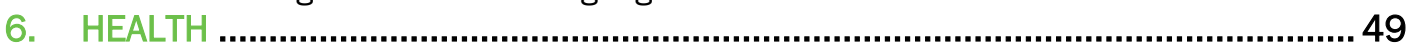

6.1. Health Knowledge............................................................................ 49

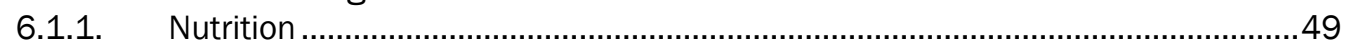

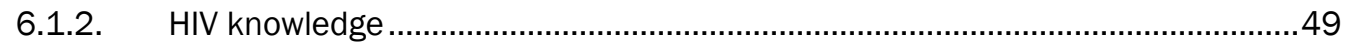

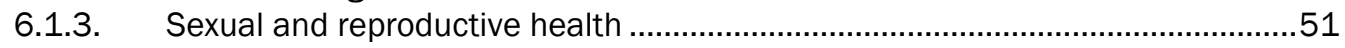

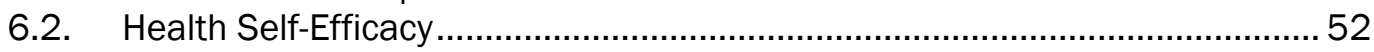

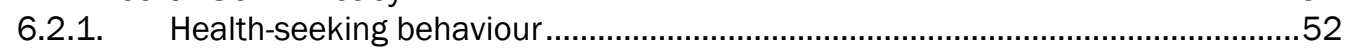

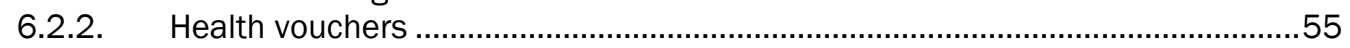

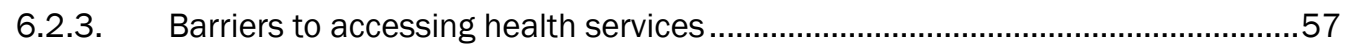

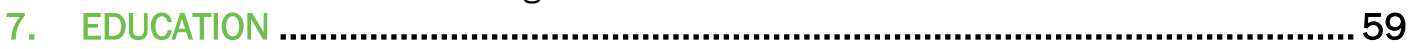

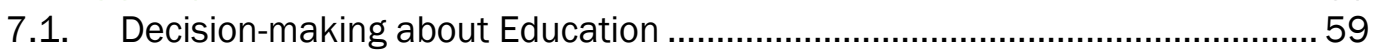

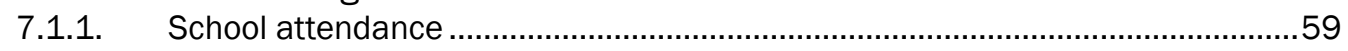

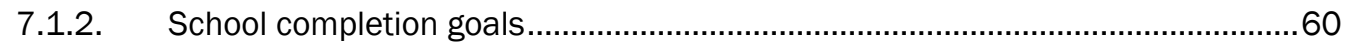

7.2. Effects of AGEP on Education ........................................................... 66

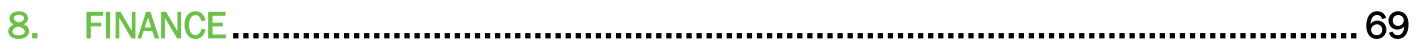

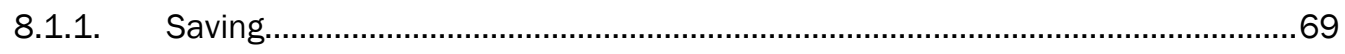

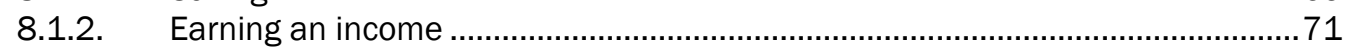

8.1.3. Financial Decision-Making....................................................................... 73 


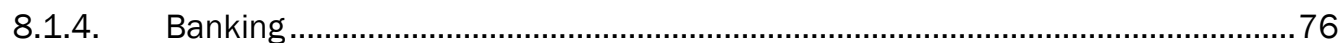

8.1.5. Savings groups ........................................................................................ 78

8.1.6. Effect of saving on interpersonal relationships ............................................... 79

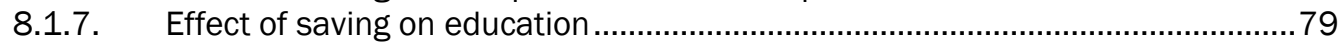

9. SOCIAL NETWORKS AND RELATIONSHIPS .......................................................... 81

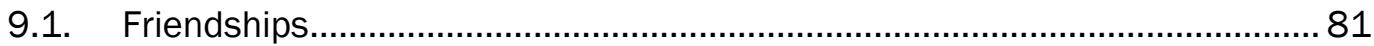

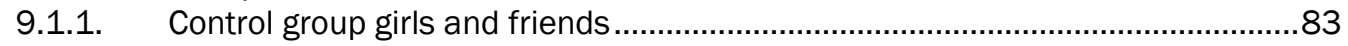

9.2. Sexual Relationships \& Sexual Behaviour ......................................... 83

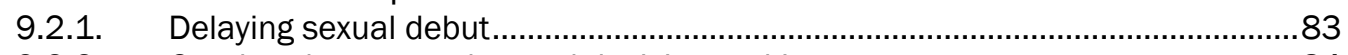

9.2.2. Gendered power and sexual decision-making .................................................84

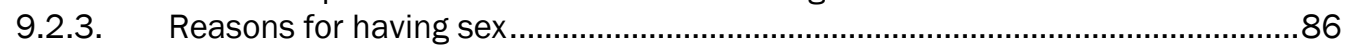

9.2.4. Effect of safe spaces on sexual behaviour........................................................ 87

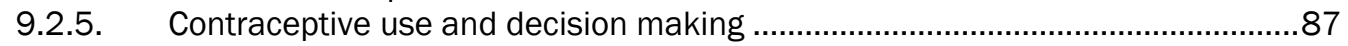

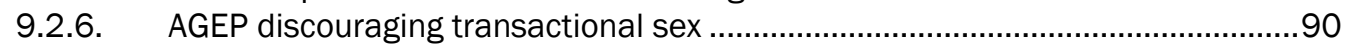

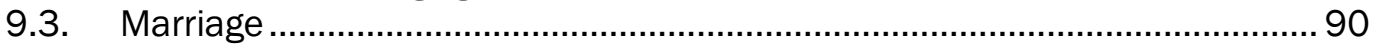

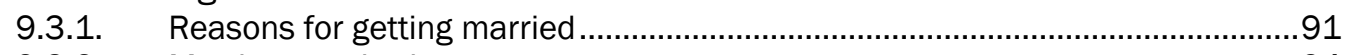

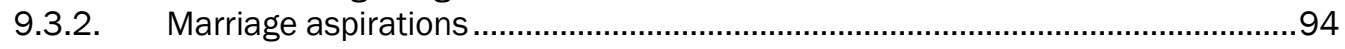

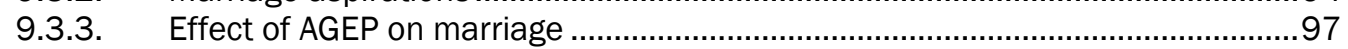

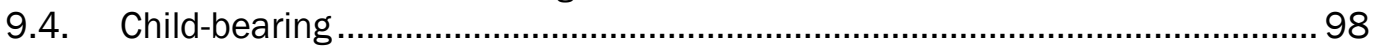

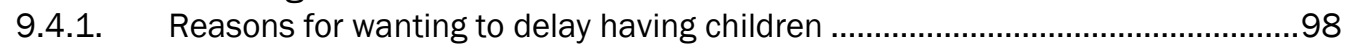

9.4.2. Child-bearing aspirations ............................................................................ 101

9.4.3. Effect of AGEP on delaying child-bearing..................................................... 102

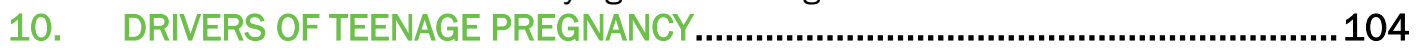

10.1. Transactional Sex......................................................................... 104

10.2. Peer Pressure ................................................................................... 115

10.3. Bad behaviour / Being naughty ................................................. 117

10.4. Culture / Tradition....................................................................... 118

10.5. Substance Use: Drinking Alcohol ...................................................... 119

10.6. Lack of Information / Education ........................................................120

10.7. Not listening to advice .................................................................. 120

10.8. Abuse...................................................................................... 122

10.9. Boredom / Lack of Entertainment / Dropping Out of School ...................122

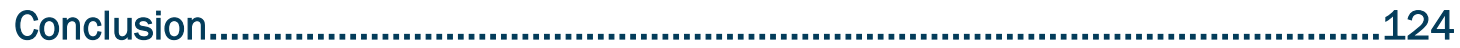

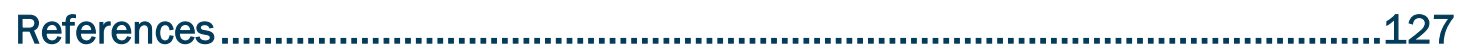




\section{Executive Summary}

The Adolescent Girls Empowerment Program (AGEP) reaches over 10,000 vulnerable girls 10-19 years old in five urban and five rural sites spread across four provinces in Zambia. The programme works to build adolescent girls' social, health and economic assets, providing them with key skills and opportunities to help them transition from adolescence to adulthood in a healthy way. AGEP is comprised of three major components:

1) Safe Spaces groups in which girls meet once a week over the course of two years for training on sexual and reproductive health, life skills and financial education. Groups are facilitated by a mentor, a young female from the same community as the girls;

2) A health voucher that girls can use at contracted private and public facilities for general wellness and sexual and reproductive health services; and

3) A savings account that has been designed to be girl-friendly.

A randomized control trial (RCT) using a cluster design is being used to evaluate the impact of AGEP. The research aims to identify the impact of the intervention on the following key indicators: HIV prevalence, HSV-2 prevalence, age at first sex, age at first birth, contraceptive use, experience of gender-based violence, and educational attainment. The programme is being implemented in three versions to assess the added effect of each programme component:
1) Safe Spaces only (SS Only)
2) Safe Spaces + Health Voucher (SS + HV)
3) Safe Spaces + Health Voucher + Savings Account (SS + HV + SA)

In addition to the quantitative data, qualitative data is also being collected in four of the ten study sites (two urban and two rural). This report presents findings from the second round of data collection. The qualitative data collected in this round is comprised of a total of 144 in-depth interviews (IDIs) conducted from September to November 2015. Ninety-six IDIs were conducted with adolescent girls (girls who had been included in the intervention and girls in the control group) and 48 IDIs with adult stakeholders (parents, community leaders and mentors). Interviews were conducted in the preferred language of the respondent. There was representation of parents and mentors from each of the three study arms.

Qualitative data were analysed using an integrated approach, employing a deductive organising framework for code types (start list), as determined by the content of the interview guides, combined with an inductive (ground-up) development of codes as they emerged from the data (Bradley et al., 2007). A codebook was developed reflecting the key research questions and the topics covered in the interview guides. Qualitative data were coded and thematically analysed using the Atlas.ti software package by two data analysts concurrently. The data analysts double-coded $>10 \%$ of the transcripts to ensure consistency in coding application. Once all the transcripts had been coded, the data was divided into sections and allocated for the next phase of analysis between the two analysts. On-going communication and discussion between the two analysts occurred throughout the process. The final report was compiled by the lead analyst.

The report is structured according to the key themes that emerged through the analysis of the data, and then arranged under seven overarching topic areas:

1) AGEP (including AGEP girls' experiences of Safe Spaces meetings, community expectations of the programme, positive and negative views of the programme and mentors' experiences); 
2) Behaviour Change (relating to changes in behaviour in AGEP girls as a result of programme participation, and as compared to non-programme girls);

3) Health (including health seeking behaviour and health self-efficacy, health knowledge and experiences of AGEP girls who received health vouchers);

4) Education (including the educational benefits of AGEP, decision-making around education, school attendance behaviour and school aspirations);

5) Finance (including financial literacy, financial decision-making, earning, saving and spending behaviour, experiences of AGEP girls who opened bank account, and the effects of saving on relationships);

6) Social Networks and Relationships (including friendships, sexual relationships, and marriage and child-bearing aspirations, as well as sexual decision-making and sexual behaviour);

\section{7) Drivers of Teenage Pregnancy}

In general, mentors, community leaders, AGEP girls themselves and their parents, from all four study sites, spoke positively about AGEP, and the impact it has had on girls in the community who have been part of the programme.

The key benefits of the AGEP programme as described by respondents included:

$>$ Health knowledge gains

> Improved motivation and inspiration to attend and complete school

> Positive behaviour changes: including increased respect for elders, more responsible and considerate behaviour, more modest dressing, and avoiding risky behaviours such as drinking alcohol and frequenting bars and nightclubs;

$>$ Increased self-confidence, self-esteem, self-worth, self-belief and self-efficacy

$>$ Increased knowledge regarding safety and self-care, and increased awareness of individual rights to bodily integrity and agency to report cases of abuse and rape;

> Improved health seeking behaviour and medication adherence, particularly for those with Health Vouchers;

> Improved financial sense in terms of earning, budgeting, and saving money.

$>$ Positive impact on social networks and relationships

$>$ Increased sexual agency

> Being motivated by the programme to "dream big", complete their schooling, pursue a career, become financially independent, and delay marriage and childbearing until they had achieved these goals.

As seen from the comments made by community leaders and parents, community perceptions of AGEP were generally positive. However, there were some negative views of AGEP expressed by respondents. These included widely held views in the community that AGEP was Satanist, and perceptions that the programme promoted promiscuity by teaching young girls about sexual and reproductive health, and termination of pregnancy. Some respondents also felt that the programme had failed to meet expectations, especially with regards to the prizes given to group members. However, these negative views came from a minority of respondents. 
Although AGEP mentors felt that they had benefited from the programme, gaining valuable knowledge, life skills and experience, some of the mentors explained that they had found it challenging to provide information to the girls on topics which they disagreed with on a personal level. In other cases girls described messaging from their mentors that was not in line with the core values of information and choice that the program was trying to convey. One example of a challenge for the mentors was having to teach girls, especially those in the younger age groups, about termination of pregnancy. The AGEP health curriculum informed girls of the importance of accessing termination of pregnancy services at a formal health facility. However, from the narratives of some of the girls, it seemed that some of the mentors were displaying judgemental attitudes and instead moralistically condemning abortion. Another example is of girls expressing that their mentors did not think unmarried girls should use contraception or fearing that their mentors would be disappointed if they became pregnant. It would appear that despite values-clarification exercises conducted as part of the mentor training, some of the mentors may not have shared the programme's values.

From the narratives of girls in the control group, it appears that those control group girls who were engaged in some sort of programme such as a church youth groups, or NGO activities, gained some similar kinds of support and encouragement through these groups as AGEP girls did in Safe Spaces, such as encouragement and motivation to attend school and complete education, moral support and advice, and in some cases information about HIV and other health issues. Within the control groups, there appeared to be a wide variability in terms of girls' knowledge levels, access to social support levels of selfconfidence and agency, and money management behaviour. Some of the girls in the control group exhibited similar attitudes and experiences as the AGEP girls, others were disadvantaged and lacked the same levels of knowledge, skills and awareness. This is important to keep in mind as the quantitative data will be presenting program impact based on change in the AGEP girls relative to the control group girls.

A wide range of factors were listed by respondents in explanation of the high rates of teenage pregnancy in the communities. Reasons included transactional sex, peer pressure, hunger and poverty, materialism, lack of education and information, bad behaviour including drinking alcohol, poor parenting, abuse, boredom and dropping out of school.

There are several limitations to the research findings presented. There is likely to have been an element of social desirability bias present in the interviews. If the interviewees perceived the interviewers to be part of AGEP, they would have been less likely to express negative views about the programme. The social desirability factor may have been enhanced amongst all respondents by the fact that girls had been receiving prizes from the programme, and they may have anticipated that they may benefit from responding positively during the interview. In addition, respondents may have wanted to give positive answers about the programme, with the hope that it would continue for a longer period of time.

Another limitation apparent in the transcripts is that in the interviews, some of the interviewers' questions appeared to be leading respondents' answers, particularly when the interviewers were probing responses to the section on the drivers of teenage pregnancy. This is likely to have influenced respondents' answers. Additionally, in some cases it appeared that the respondents did not fully comprehend the interviewers' questions, which would have affected the quality of the data.

Overall these findings provide valuable insight into the views and experiences of girls who were involved in the AGEP programme, as well as the perceptions of programme mentors, the girls' parents, and community leaders. In addition, these findings highlight the areas in 
which the experiences of girls in the control groups, who had not been engaged in AGEP's programmes and activities, differed from or were similar to those of the AGEP girls. The findings also highlight issues and factors in the community that contribute to the problem of pregnancies amongst young girls in the study communities. 


\section{Background and Introduction}

\section{Situational Context}

The World Bank profile on Zambia estimates that $60 \%$ of the population live below the poverty line, with poverty prevalence in rural Zambia standing at $76 \%$. Adolescent girls in Zambia face a range of risks and vulnerabilities that compromise their healthy development from girls into young women. At the same time, girls in Zambia lack the social, health and economic assets to mitigate these risks. The issues that girls are confronted with-high rates of gender-based violence, unsafe sex that puts girls at risk for unwanted pregnancy and HIV infection, school dropout, lack of economic resources and incomegenerating options, lack of agency and participation-are linked together through their root causes.

Lack of social protection and social isolation are risks for adolescent girls in Zambia, limiting their agency and voice, and making it difficult to access societies' institutions-e.g., health facilities. Married girls also have limited social, health, and economic assets. Child brides often experience a sudden shrinking of their social networks as they move to their husbands' residence, leaving them with few, if any, friends and peers. While parents may attempt to marry their daughters at an early age for apparent economic stability, in reality early marriage leaves girls with limited control over resources, highly restricted mobility and little or no power in their new households. Thus married girls may face significant challenges in negotiating safe sexual relations. Education is a critical component of a healthy transition to adulthood. For example, being in school has been associated with delays in the age at first sex, marriage, and childbearing. Lack of social protection and voice leaves girls exposed to violence, both physical and sexual.

A significant health risk to girls in Zambia is HIV. The threat is particularly acute among young women and girls with limited social and economic assets who are unable to avoid, manage, or leave unsafe sexual relationships, whether inside or outside of marriage. In Zambia, HIV prevalence is more than 2:1 female to male, meaning that girls are the ones most at risk in that age group. Among 15-19-year-olds, 5.7 per cent of females are infected as compared to 3.6 per cent of males. Additional health risks-especially early pregnancy, unsafe abortion, and STIs-result from high levels of unprotected sex.

The situation described above is a challenging one for adolescent girls in Zambia. Across a range of issues-education, social support, safety, and sexual and reproductive healththey are at a disadvantage compared to their male peers. This added vulnerability for adolescent girls in Zambia is the basis for designing an intervention that a) focuses on adolescent girls ages 10-19 and b) selects girls for the programme with the intention of including those with the most vulnerabilities.

(Reference: Austrian et al., 2013) 


\section{The AGEP Programme}

In Zambia, the Population Council is implementing the Adolescent Girls Empowerment Program (AGEP). AGEP reaches over 10,000 vulnerable girls 10-19 years old in five urban and five rural sites spread across four provinces in Zambia. The programme works to build adolescent girls' social, health and economic assets, providing them with key skills and opportunities to help them transition from adolescence to adulthood in a healthy way. The theory of change behind AGEP posits that adolescent girls are empowered (the desired outcome) by acquiring social, health and economic assets, which they can then draw on to reduce vulnerabilities and expand opportunities, thereby increasing their likelihood of completing school and delaying sexual debut, and reducing the risk of early marriage, unintended pregnancy, and the acquisition of HIV (Hewett et al., 2014).

AGEP is comprised of three major components:

4) Safe Spaces groups in which girls meet once a week over the course of two years for training on sexual and reproductive health, life skills and financial education. Groups are facilitated by a mentor, a young female from the same community as the girls;

5) A health voucher that girls can use at contracted private and public facilities for general wellness and sexual and reproductive health services; and

6) A savings account that has been designed to be girl-friendly.

\section{Safe Spaces}

The core of AGEP is a Safe Spaces component. Implemented in partnership with YWCA Zambia, Safe Spaces are weekly girls' group meetings in which 20 to 30 girls get together with a mentor-a young woman from their community-for short training sessions on a variety of topics as well as a chance to discuss their experiences of the past week. These regular group sessions serve two critical functions: 1) they build a platform in which girls can be reached with interventions and educational topics, and 2) they build social assets, including friendships, trusting relationships, and self-esteem, which have a positive influence on their livelihood and health. The aim is that the group meetings become an integral part of what girls expect in their lives in these communities and can be sustained in the long term via cultural change.

During the introductory meeting, girls are assigned to one of three groupings: 1) 10-14year-olds; 2) 15-19-year-olds; or 3) married girls/mothers. Each group is assigned a mentor, and a regular meeting day, time and location is chosen. Most of the groups meet in places that are free of charge, although a few have to rent the space. If a girl misses more than two or three consecutive meetings, the mentor conducts a home visit to identify the reason for the girl's absence. In addition to the weekly group meetings, parents/guardians/ husbands meetings are held two to three times per year.

Mentors Each master site has 24 mentors. During the community sensitization process, a job posting is circulated in the community for the mentor post. Mentors must be between the ages of 20 and 40, female, able to speak English and the local language, and have completed secondary school. Applicants are interviewed and 30 mentors per site were selected for training. At each site, an initial training of trainers (TOT) is held and the 24 final mentors are selected. An additional six mentors are selected as alternates in case of mentor dropout. Refresher trainings were held after 2-3 months of group meetings, and again at the start of the second year of the programme. In addition, mentors met once a month with the site coordinator. At these meetings mentors would submit their attendance data, discuss successes and challenges, and receive short training sessions. Mentors were paid a monthly stipend and received rain-coats and gum boots for the rainy season. In addition, mentors in the rural sites received a bicycle. 
The Safe Spaces Curriculum AGEP has developed two curricula: 1) a health and life skills (HLS) curriculum and 2) a financial education curriculum. The HLS curriculum includes sessions on reproductive health, HIV, life skills, gender and gender-based violence, leadership and human rights. The financial education curriculum includes sessions on saving, budgeting, financial negotiation, and earning money. In addition, girls in the savings "arm" of the programme have a session on the Girls Dream savings bank account. All mentors use the same curriculum and are given the order in which the sessions should be delivered to ensure standardization across all groups.

In addition, half of the groups were randomized to receive a nutrition curriculum. The first three sessions, including topics on the food pyramid, eating a diverse diet and anaemia, were for all girls and the next three topics on nutrition during pregnancy, infant and child feeding and growth monitoring were included for the older girls only.

\section{Health Vouchers}

In partnership with the Ministry of Health $(\mathrm{MoH})$ and Ministry of Community Development Mother and Child Health (MCDMCH $)^{1}$, the Population Council developed a health voucher for AGEP respondents that was redeemable for health services at partner public and private health providers. The Council had a contract with each provider outlining the terms of the voucher, service provision, quality assurance, and payment. The services covered include basic wellness exams and age-appropriate sexual and reproductive health services. While services at public facilities are currently free in Zambia, the objective of the health vouchers was to provide an incentive to the health providers to improve the supply of adolescent-friendly health services, and it was hypothesized that giving vouchers to girls increases demand.

As per the study design, two-thirds of girls in AGEP received Health Vouchers. Vouchers were valid for one year. If a girl dropped out of the safe space programme, she was able to continue to use the voucher until its expiration date. Second vouchers were distributed at the start of the second year through the safe space mentors. To prevent people outside of the group from using the voucher, each girl receives a programme photo ID card with a serial number that could be used during the authentication process when accessing a service.

\section{Savings Accounts}

As one arm of the intervention, the Population Council worked in partnership with the National Savings and Credit Bank (NatSave) and Making Cents International to develop the "Girls Dream" Savings Account for AGEP girls. The NatSave account has a low minimum balance of KR 2.5 (\$0.50) to open, and any amount can be deposited or withdrawn with no fee. While girls were able to make deposits on their own, in order to conform to the Zambian legal minimum age of 18 for opening accounts, girls had to select a co-signatorya woman aged 18 or older-to assist with account opening and withdrawals.

Prior to account opening, mentors in the savings arm were trained by AGEP staff on the savings account, and an orientation session was held with the girls and their co-signatory to inform them of the account and begin the account opening process. In addition, a field trip to the bank branch was organized for girls and their co-signatory to complete the account opening process. This three-step process was uniform across all the study sites to ensure standardization.

\footnotetext{
${ }^{1}$ Now the Ministry of Community Development and Social Welfare (MCDSW)
} 


\section{Evaluating AGEP}

In conjunction with programme activities, Council researchers are conducting a rigorous four-year impact evaluation of the programme using a randomized controlled trial - the gold standard in impact evaluation. The study is following girls for the two-year intervention period and for two years after completion of the intervention. Baseline data was collected in 2013 and the two-year intervention started in each site immediately following.

A randomized control trial (RCT) using a cluster design is being used to evaluate the impact of AGEP. The research aims to identify the impact of the intervention on the following key indicators: HIV prevalence, HSV-2 prevalence, age at first sex, age at first birth, contraceptive use, experience of gender-based violence, and educational attainment. The programme is being implemented in three versions to assess the added effect of each programme component:

1) Safe Spaces only (SS Only)

2) Safe Spaces + Health Voucher (SS + HV)

3) Safe Spaces + Health Voucher + Savings Account (SS + HV + SA)

In addition to the quantitative data there are three rounds of qualitative data. The first was collected at baseline (2013-14) in four of the ten sites. This report presents findings from the second round of data collection.

(Reference: Austrian et al., 2013) 


\section{Evaluation Methodology}

This report presents findings from the second of three phases of data collection. The first phase was conducted at baseline after the first 3-4 months of the programme, the second phase comprised data collected after two years of implementation of the intervention, and the last phase will entail data collection two years after the intervention period.

\section{Research Team and Research Tools}

Training of the research team was conducted in September 2015; the team was comprised of six research assistants and two research coordinators. The research assistants, all female, were trained to conduct the interviews, and underwent a two-day training session on how to use the interview guides. Interview guides were translated by the research team into the most commonly spoken languages at each site: Bemba, Nyanja, Tonga and Kaonde. Before the interview guides were used at the four selected sites, they underwent field-testing at another AGEP site where interviews were not to be conducted in this round; feedback from the field testing was incorporated into the final guides.

The interview guides used in this round of data collection were adapted from the guides used during the first round of qualitative data collection. The guides were edited to incorporate themes/trends that had materialized over the course of the two years and warranted further exploration. Thirteen separate interview guides were developed, one for each respondent group: AGEP girls were divided into intervention arms and age brackets, control group girls were divided into age brackets, and mentors were divided into intervention arms, community leaders, and parents.

The guides included the following major topic sections, as appropriate for and relevant to the respondent grouping: views on AGEP; self-esteem and decision-making; financial selfefficacy; health self-efficacy; social networks; life goals, social support and agency; sexual relationships; and drivers of teenage pregnancy.

\section{Data Collection}

The qualitative data collected in this round comprised a total of 144 in-depth interviews (IDIs) conducted from September to November 2015. Ninety-six IDIs were conducted with adolescent girls (girls who had been included in the intervention and girls in the control group) and 48 IDIs with adult stakeholders (parents, community leaders and mentors). Interviews were conducted in the preferred language of the respondent. There was representation of parents and mentors from each of the three study arms.

All interviews were conducted at a place most convenient for the respondent to ensure that the respondent felt comfortable to discuss and disclose sensitive information covered in the interview guide. Most programme girls opted to be interviewed from their Safe Spaces venue. Control group girls typically opted to be interviewed seated outside their homes or near their places of work.

Interviews were recorded using a digital voice recorder. Digital recordings were submitted to the research coordinator upon completion of each site's interviews. Audio-recordings of interviews were transcribed by research assistants into English after the completion of data collection at each site, and prior to the commencement of data collection at the next site. The transcripts underwent a process of validation by research assistants who had not conducted the interviews listening to the original recordings while reading the English translation, and making changes to the translation where necessary. 


\section{Informed Consent Process}

All respondents under the age of 18 signed an assent form, in addition to their parents/guardians providing written consent. Respondents over the age of 18 were eligible to sign consent forms on their own. Mentors and site coordinators aided in the process of collecting consent forms from the parents before the research team reached the site. Where this was not possible, research assistants first sought consent from parents/guardians prior to conducting the interview.

\section{Research Sites}

Two urban sites (Chipata/Chazanga and Ndola) and two rural sites (Mumbwa and Solwezi) were selected for sampling to reflect the diversity of the ten sites across the programme. The geographic dispersion of the four selected sites also highlights differences in predominant languages in Zambia, namely Nyanja and Bemba in Chipata / Chazanga; Bemba in Ndola; Lenje, Nyanja, and Bemba in Mumbwa; and Kaonde in Solwezi. Urban communities (Lusaka and Ndola) earn their living working in blue-collar jobs and tend to earn slightly more than the rural communities; however, the cost of living in urban areas is relatively higher. On the other hand, rural communities (Mumbwa and Solwezi) mainly earn their income from cattle rearing and subsistence and in some instances crop farming.

\section{AGEP Site map}

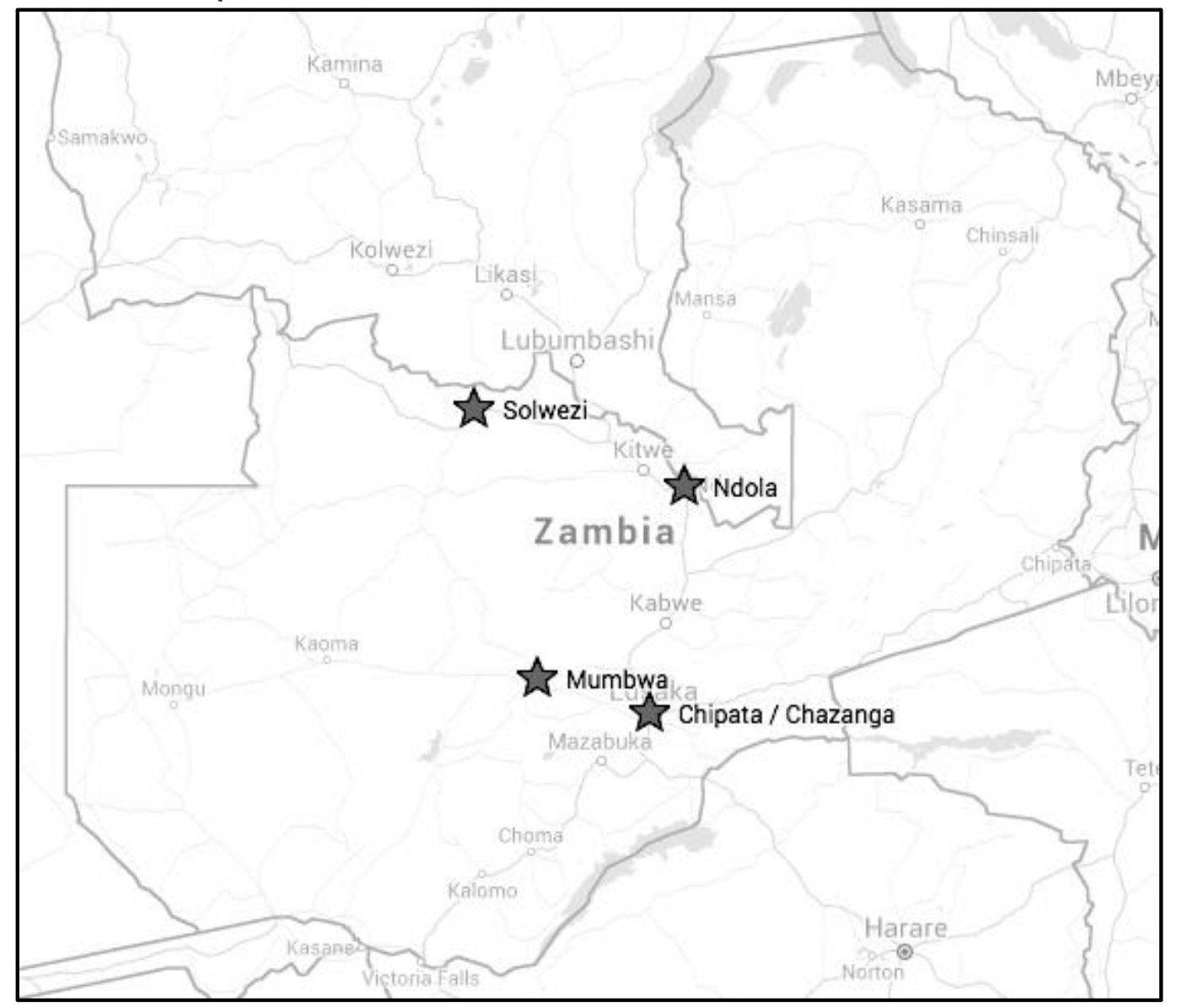

\section{Sample}

A total of 144 respondents were interviewed, with 36 interviews conducted at each of the four study sites. Two transcripts from the Ndola site were lost during the data processing; hence the final number of transcripts included in the qualitative data analysis was 142. 
Table 1: Sample

\begin{tabular}{|c|c|c|c|c|c|}
\hline Respondent group & All sites & $\begin{array}{l}\text { Solwezi } \\
\text { (rural) }\end{array}$ & $\begin{array}{l}\text { Mumbwa } \\
\text { (rural) }\end{array}$ & $\begin{array}{l}\text { Chipata/Chazanga } \\
\text { (urban) }\end{array}$ & $\begin{array}{l}\text { Ndola } \\
\text { (urban) }\end{array}$ \\
\hline AGEP girl (10-14*) & 36 & 9 & 9 & 9 & 9 \\
\hline - SS Only & 12 & 3 & 3 & 3 & 3 \\
\hline$-\quad S S+H V$ & 12 & 3 & 3 & 3 & $3 * *$ \\
\hline$-\quad S S+H V+S A$ & 12 & 3 & 3 & 3 & $3 * *$ \\
\hline AGEP girl (15-19*) & 36 & 9 & 9 & 9 & 9 \\
\hline - SS Only & 12 & 3 & 3 & 3 & 3 \\
\hline$-\quad \mathrm{SS}+\mathrm{HV}$ & 12 & 3 & 3 & 3 & 3 \\
\hline$-\quad S S+H V+S A$ & 12 & 3 & 3 & 3 & 3 \\
\hline Control girl (10-14) & 12 & 3 & 3 & 3 & 3 \\
\hline Control girl (15-19) & 12 & 3 & 3 & 3 & 3 \\
\hline Mentor & 20 & 5 & 5 & 5 & 5 \\
\hline - SS Only & 4 & 1 & 1 & 1 & 1 \\
\hline$-\quad S S+H V$ & 8 & 2 & 2 & 2 & 2 \\
\hline $\mathrm{SS}+\mathrm{HV}+\mathrm{SA}$ & 8 & 2 & 2 & 2 & 2 \\
\hline Parent & 20 & 5 & 5 & 5 & 5 \\
\hline - SS Only & 4 & 1 & 1 & 1 & 1 \\
\hline$-\quad \mathrm{SS}+\mathrm{HV}$ & 8 & 2 & 2 & 2 & 2 \\
\hline$-\quad S S+H V+S A$ & 8 & 2 & 2 & 2 & 2 \\
\hline Community Leader & 8 & 2 & 2 & 2 & 2 \\
\hline TOTAL & 144 & 36 & 36 & 36 & 36 \\
\hline
\end{tabular}

* Age at baseline

** Two of the interview transcripts from Ndola were lost during the data processing, and were not included in the analysis

\section{Recruitment}

Program respondents were recruited using two methods. Firstly, whether they participated in the previous round of data collection and secondly the level of safe space attendance. For each age group of the three programme arms, two girls who frequently attend Safe Spaces were chosen to interview as well as a girl with very low attendance rates. Control group girls were also selected based on their participation in the first round of qualitative data collection.

\section{Data Analysis}

Qualitative data were analysed using an integrated approach, employing a deductive organising framework for code types (start list), as determined by the content of the interview guides, combined with an inductive (ground-up) development of codes as they emerged from the data (Bradley et al., 2007). A codebook was iteratively developed reflecting the key research questions and the topics covered in the interview guides. The codebook was revised and modified throughout the coding process to ensure that it reflected the emerging themes. Qualitative data were coded and thematically analysed using the Atlas.ti software package by two data analysts concurrently. The data analysts double-coded $>10 \%$ of the transcripts to ensure consistency in coding application. Any discrepancies that were identified were then resolved through telephonic communication, until agreement and consensus was reached. Inter-coder reliability was established using the online tool CAT-Coding Analysis Toolkit (http://cat.texifter.com)-and verified throughout the coding process. Once all the transcripts had been coded, the data was divided into sections and allocated for the next phase of analysis between the two analysts. 
On-going communication and discussion between the two analysts occurred throughout the process. The final report was compiled by the lead analyst.

\section{Data Presentation}

The report is structured according to the key themes that emerged through the analysis of the data, and then arranged under seven overarching topic areas:

1) AGEP (including AGEP girls' experiences of Safe Spaces meetings, community expectations of the programme, positive and negative views of the programme and mentors' experiences);

2) Behaviour Change (relating to changes in behaviour in AGEP girls as a result of programme participation, and as compared to non-programme girls);

3) Health (including health seeking behaviour and health self-efficacy, health knowledge and experiences of AGEP girls who received health vouchers);

4) Education (including the educational benefits of AGEP, decision-making around education, school attendance behaviour and school aspirations);

5) Finance (including financial literacy, financial decision-making, earning, saving and spending behaviour, experiences of AGEP girls who opened bank account, and the effects of saving on relationships);

6) Social Networks and Relationships (including friendships, sexual relationships, and marriage and child-bearing aspirations, as well as sexual decision-making and sexual behaviour);

7) Drivers of Teenage Pregnancy

Throughout the findings section of the report, themes that commonly emerged in the data are emphasized, and similarities or differences across and between sites are drawn out. Due to the qualitative nature of the data, there was no quantification in terms of the number of respondents who expressed specific views of each topic. The reason for not providing numerical representation of responses is that at the heart of qualitative research methodology is the belief that qualitative data cannot be quantified (for example a statement such as " 13 out of 20 participants said X"). Qualitative enquiry posits that social phenomena cannot be explained numerically, instead seeking to describe and explain what and how respondents feel, think, and experience the phenomenon in question-aspects which cannot be captured numerically or statistically (Basit, 2003). Qualitative research aims to "understand the social world from the viewpoint of respondents, through detailed descriptions of their cognitive and symbolic actions, and through the richness of meaning associated with observable behaviour" (Myers, 2000).

While it may be interesting to know how many people feel positively or negatively about something, or how often a certain view occurs, this is not the intention of qualitative inquiry, and qualitative data, being textual, non-numerical and unstructured, do not lend itself to such presentation. In addition, the sampling methodologies employed in qualitative research do not aim to identify a statistically representative set of respondents, but are instead purposive, aiming to capture the richness and subjective experience of a phenomenon (Gale et al., 2013). Therefore attempting to express qualitative findings in numerical form, percentages, or relative frequencies would be misleading and counterproductive (Pope et al., 2000).

Another note on the organisation of the data in this report relates to the presentation of data from the control group girls as compared to the AGEP group girls. There is no fixed structure for this; in some sections control group data is presented alongside data from the AGEP girls, and in other sections it is separate. The reason for this is that in some 
topics, there was no significant difference between the two groups, and the themes were common. In these situations it made sense to present the data together. In the sections where control group data is presented separately, there was a substantial amount of data from the control group, and noticeable or interest contrasts to draw out between the two groups. 


\section{Findings}

The findings presented in this section come from the interviews conducted with AGEP girls, control group girls, parents, mentors and community leaders. Findings are arranged under seven main topic areas:
1) AGEP
2) Behaviour Change
3) Health
4) Education
5) Finance
6) Social Networks and Relationships
7) Drivers of Teenage Pregnancy

Within these main topic areas, the data are arranged into key themes that emerged during the analysis process. Direct quotations from the transcripts are provided in italics, followed by brackets detailing the respondent's characteristics and which site they came from. For girl respondents, additional details are provided describing which age group category they were in and which study arm they had been randomised to: SS Only (Safe Spaces only), SS + HV (Safe Spaces + Health Voucher), SS + HV + SA (Safe Spaces + Health Voucher + Savings Account), or Control (no intervention).

\section{AGEP}

Respondents shared their perspectives about the AGEP programme, including views on Safe Spaces meetings, reasons why girls were motivated or discouraged from attending; the experiences of being a mentor in the programme; parent and community leader expectations of AGEP; and concerns about or negative views of the programme.

\subsection{Safe Spaces}

Weekly Safe Spaces meetings were the core component of the AGEP programme. Meetings generally involved a group between 20 and 30 girls of similar ages meeting with a mentor to discuss a variety of topics and their experiences of the past week. These meetings were intended to 1) create a platform through which to reach girls with interventions and educational topics, and 2) to help the girls build social assets, including friendships, trusting relationships, and self-esteem, which are thought to have a positive influence on their livelihood and health.

\subsubsection{Motivating factors for attending Safe Spaces meetings}

Respondents detailed a range of factors that motivated AGEP girls to attend the Safe Spaces meetings, including the social support that they received, and various people who gave them encouragement to attend. 


\section{Social Support}

According to one of the community leaders, one factor that motivated girls to attend Safe Spaces meetings was the social support that they received at the meetings.

Whenever (the girls) had family problems they would come (to Safe Spaces) and share with us and we would counsel them. (Community leader, Ndola)

Some of the AGEP girls said that attending the meetings gave them something to do with their time and a good reason to get out of the house, where they would get bored and involved in unconstructive behaviour.

When you stay home doing nothing, you can end up being involved in a fight and this has given me the confidence to not stay home and go to school and also come for meetings here. (Girl, 18-21, SS Only, Chipata / Chazanga)

Some of the girls explained that attending the meetings kept them focused and well behaved, and kept them from relapsing back into bad behaviour.

The things that I was learning there kept me on a straight path. One would not want to go back to their old habits again. (Girl, 15-21, SS+HV+SA, Ndola)

Some of the AGEP girls demonstrated agency, and expressed their own determination to continue attending the Safe Spaces meetings despite discouragement and rumour mongering from others in the community.

Some were saying that AGEP is for Satanists and others were going mad but we never listened to them, we continued coming... no matter what they were saying, we continued to come. (Girl, 15-21, SS+HV+SA, Mumbwa)

There are some who would say that perhaps AGEP is satanic. I told them that if that's the case I will continue attending these meetings and get to the bottom of the truth myself. (Girl, 15-21, SS $+H V$, Ndola)

\section{Encouragement to Attend}

Girls described how they had been encouraged to attend Safe Spaces meetings by various people, including parents, guardians, siblings, AGEP mentors, other group members, and friends. Some parents encouraged their daughters to attend meetings for the educational benefits.

My mother... encouraged me that if I continued attending AGEP I would learn life changing things that would help me later in life, I would learn things that would help me make good decisions in life and help you live properly and take care of yourself. (Girl, 18-21, SS+HV+SA, Chipata / Chazanga)

Parents and mentors were described as the people who mostly encouraged girls to attend.

My mum is the one who used to encourage me, sometimes I would forget but my mother would not forget and always remind me to go... it was my mother and my mentor who always used to encourage me and said you will learn something that will be helpful for you both now and in the future. (Girl, 12-17, SS+HV+SA, Mumbwa)

Family and household members who had witnessed positive behaviour changes in the girls as a result of attending Safe Spaces would encourage the girls to continue attending the meetings.

My mother... and other house hold members... told me to continue attending Safe Spaces because they had seen a change in me... in my behaviour, before the programme I would be 
told to wash the dishes and I would refuse. I changed after participating in the programme. (Girl, 18-21, SS+HV, Chipata / Chazanga)

My mother... told me to keep coming for these meetings because AGEP had changed me as a person from the way I used to think and behave, she told me to keep learning and if ever my friends tried to talk me out of going for the meetings, I must still go... She told me that I should not be swayed by my friends because what lies ahead in our lives are different things. (Girl, 1014, SS Only, Ndola)

Some of the parents felt that attending the Safe Spaces meetings gave the girls something constructive to do with their time.

These meetings keep her busy she has no time to play around because she spends most of her time at school and she is home. Over the weekends, she goes for these same meetings. (Parent, Ndola)

The prizes that girls received for continued meeting attendance were an incentive for some girls to attend the meetings.

There were clocks, chitenges, phones, and AGEP t-shirts... also there was powder, lotion and sanitary pads. (Girl, 12-17, SS+HV, Chipata / Chazanga)

Some girls commented that they were encouraged by their friends and co group members to attend the Safe Spaces meetings only so that they could get the prizes.

My friends... they said lets be going to AGEP so that they give us the phones. (Girl, 18-21, SS+HV, Mumbwa)

\subsubsection{Demotivating Factors / Discouragement to Attend}

AGEP girls were also asked to outline the reasons why some of the group members stopped attending Safe Spaces meetings. Various factors discouraged girls from continued attendance. Notably, the majority of the comments regarding girls being discouraged from continued attendance of the Safe Spaces meetings came from the two urban study sites, Ndola and Chipata / Chazanga. These findings are in line with attendance records from Safe Spaces indicating that meeting attendance figures were higher at the rural sites.

Figures from the programme data indicate that a small proportion of girls who participated regularly in the Safe Spaces meetings (6\%) got pregnant over the two years (amongst all girls invited, $15 \%$ got pregnant in the same period, regardless of whether they joined or how much they participated). Some of the girls said that one reason AGEP girls stopped attending meetings was if they got pregnant during the programme, they were worried that they would feel ashamed and ridiculed at having got pregnant despite the programme's teachings.

Some do not come because they have babies, they are ashamed because the mentor used to teach against having babies when you are still young but they have children and others are pregnant. So they are afraid that they will be laughed at by others in the group. (Girl, 15-21, SS Only, Ndola)

Some fell pregnant and were embarrassed to attend AGEP because they had not adhered to the advice given to them by AGEP mentors. (Girl, 18-21, SS+HV+SA, Chipata / Chazanga)

It was apparent that some of the girls didn't like being scolded or nagged by the mentors for their bad behaviour, so chose not to attend the meetings.

Some of the girls did not like it when they were confronted and corrected on what they were doing wrong, so they stopped coming for that reason (Girl, 15-19, SS+HV+SA, Ndola) 
One comment on discontinued meeting attendance related to complaints about the length of the AGEP programme; reportedly towards the end some of the girls lost interest and stopped attending the Safe Spaces meetings.

I am not sure of the reasons why most of them stopped attending the meetings, I tried to encourage them to keep coming but I got tired of doing that as well. Most of them gave the reason that they were simply tired of the coming to this programme as it had gone on for such a long time. (Girl, 15-21, SS+HV, Ndola)

Some girls said that having seen no benefit from attending Safe Spaces meetings, they girls decided to stop attending.

My other friends... They would say that they are tired of coming to AGEP because they see nothing that can benefit them. (Girl, 15-21, SS+HV, Ndola)

\section{Location of Meetings}

Another complaint about the logistics of the Safe Spaces meetings concerned challenges relating to the physical location / venues for the meetings. Respondents at a few of the sites complained that there was no dedicated building for the meetings, which meant that sometimes there were issues with gaining access to the spaces.

The place where the meetings are taking place for the Safe Spaces should be okay... They should at least build a place for these Safe Spaces... sometimes when we come for the meetings we find that the classes are locked and we have to stay outside and wait outside. (Girl, 10-14, SS+HV+SA, Chipata / Chazanga)

A number of the girls remarked that the meeting venues were too far from their homes, which was de-motivating.

Safe space is far from home so I feel lazy... I do come once in a while, the problem it is far I feel lazy to walk all the way alone because I don't have friends who came for safe space from where I stay... my friends who come for Safe Spaces stay far from my home. (Girl, 18-21, $\mathrm{SS}+H \mathrm{H}$, Solwezi)

A lack of transport, hot weather, and having to walk in the hot sun were also cited as reasons that discouraged girls from attending the meetings.

There are times when I was absent... I used to feel lazy... it was hot... I didn't want to walk in the sun. (Girl, 12-17, SS+HV, Chipata / Chazanga)

\section{Belief that AGEP is Satanist}

It was evident from respondents' narratives that a widely held view in all of the study communities was that AGEP was Satanist. Notably, the bulk of the comments regarding Satanism came from Mumbwa, one of the rural study sites. However, the other site at which the Satanism belief was very apparent was Chipata/Chazanga, one of the urban sites.

People were telling us that it is satanic. They started forbidding me from attending the meetings... My elder brother, he was saying that it is for Satanists (Girl, 15-21, SS Only, Mumbwa)

Some of the AGEP girls kept their confidence in attending the meetings despite other trying to discourage them and telling them that it was Satanist. 
(People) were saying that AGEP was taking children to initiate them into Satanism... they used to say that it is for Satanists, we used to tell them that if we get killed then our time has just come. (Girl, 15-21, SS+HV+SA, Mumbwa)

In addition to the belief that AGEP was Satanist, some people in the community believed that there was witchcraft involved in AGEP activities.

Others say that the group belongs to Satanist, but I do not listen to them I tell them that if indeed they were Satanist we would have been initiated a long time ago and I They are just mare people (strangers from the community)... I don't pay attention to what they say because most of them are just jealous because their children are not part of AGEP. (Girl, 18-21, SS Only, Solwezi)

Apparently parents feared for their daughters' safety enrolling in AGEP.

They were saying that AGEP was taking children to initiate them into Satanism. (Girl, 12-14, $\mathrm{SS}+H \mathrm{H}+\mathrm{SA}$, Mumbwa)

During AGEP, girls aged 15 and over were tested for HIV and HSV-2 as part of the study. These blood-testing study procedures appeared to fuel rumours in the community regarding the drawing of blood from programme participants, which were linked to people's fears about Satanism.

My best friend said the project was Satanic and that these people just wanted to draw blood from our bodies so we should stop attending their meetings. (Girl, 12-14, SS+HV+SA, Chipata / Chazanga)

The monetary incentive / compensation provided to study participants was interpreted by some people in the community as AGEP purchasing participants' blood.

The time they came for round two to draw blood, some were chased because they were drawing blood so they were said to be Satanists, they would scold at some of us who got involved that the blood that we have donated would turn against us, they would laugh at us that we sold our blood for K20.00. There was so much talk. (Girl, 15-19, SS+HV, Mumbwa)

Some community members believed that the prizes girls were given in the programme proved that it was Satanist.

Some of them used to say there is Satanism involved... that they wanted to take us for Satanism because of the computers with the headsets they were giving us. (Girl, 15-19, SS+HV, Mumbwa)

The belief that AGEP was Satanist was allegedly the reason why some girls stopped attending the Safe Space meetings.

They stopped (attending) because they thought that there was witchcraft involved and all the gifts that they were giving us were of witchcraft. Others say that they are teaching us prostitution... (People) were saying that it's to do with witchcraft, others were saying that we were being lied to, others were saying that they were teaching us, prostitution that's what they would say.... On my part they would ask me if I still attended the meetings and I would say yes even if they would tell me that there is witchcraft involved but I would just leave them and continue going. (Girl, 12-17, SS+HV, Chipata / Chazanga)

Some of the girls were forbidden from attending Safe Spaces meetings by family members who believed AGEP was Satanist.

People were telling us that it is satanic. They started forbidding me from attending the meetings... My elder brother, he was saying that it is for Satanists. (Girl, 15-21, SS Only, Mumbwa) 
Some of the girls' parents initially expressed concern about AGEP being Satanist, but once they learned what the programme entailed, they were happy for their daughters to attend the meetings.

At first people were sceptical saying that this programme is Satanic, then later they discovered the benefits and they started coming back to say we need our children to join because they are learning a lot of important things. (Parent, Mumbwa)

My mother told me to be going to the meeting because they were teaching us a lot of things and said that if it was satanic would be better if we died together. (Girl, 12-14, SS+HV+SA, Chipata / Chazanga)

\section{Timing of the Meetings}

Some of the negative views on AGEP related to the logistics of the meetings. Some of the respondents, parents of AGEP girls at the rural Mumbwa site in particular, commented that the timings of Safe Spaces meetings were problematic, as they conflicted with Church services.

The only thing that I would love to change is the timing for Sunday meetings. The time the meetings are held is the same time that the service runs at church... Most times the girls rush out of church to attend these meetings. They would rather abscond from church in order to be at AGEP. So perhaps the timing for AGEP Sunday meetings could be revised in order to accommodate all Sunday functionalities such as church... Otherwise I'm very happy with the programme. (Parent, Mumbwa)

The conflict in timing between Safe Spaces meetings and church services was one reason for girls not attending the Safe Spaces meetings.

The meetings are usually on Sundays so you would find that the time we are supposed to be meeting is the same time that we are congregating. (Girl, 13, SS+HV+SA, Mumbwa)

Notably, the above complaint appeared to be particular to the Mumbwa site.

\section{Disappointment}

Not all of the parents had witnessed positive behaviour changes in their daughters since their involvement in AGEP. Some of them said that there had been no change.

I just wanted (AGEP) to teach her how she can take care of herself so that she can know how to take care of herself so I encouraged her to be going there and not to be like her friends who are just having children because there are times that a child can't listen from me as a parent but can listen from someone else... (But) I have not seen her change from her ways. (Parent, Ndola)

Many of the girls spoke of their expectations not being met with regards to receiving prizes: either they didn't receive the prizes they were expecting, or there were delays in receiving them. These unmet expectations regarding prizes were cited as a key factor discouraging girls from attending meetings.

Some (of the group members) would just say "I have stopped (attending meetings)"... because when they get to the set number of days for being given prizes and then they are not given, the mentor would say those things have not yet been received at the office, so they would be discouraged and stop attending the meetings. (Girl, 12-17, SS+HV+SA, Mumbwa) 
They would say the mentors just keep lying, that we will be given presents and yet they don't bring those things. (Girl, 12-17, SS Only, Ndola)

There was just one thing that I didn't like (about AGEP)... when we were being awarded I was just given a chitenge (wrapper). The prizes ran out on me... The other gifts ran out on me there was only a chitenge left to be given to me. (Girl, 12-17, SS+HV, Chipata / Chazanga)

There were complaints from some of the respondents that the prizes they were given by AGEP were of poor quality.

The gifts that we have been given... They should change some of the gifts, like the watches that they brought last time they were too small, they were supposed to give us big ones... and even the wrappers (chitenges) they were bad quality, they should have bought real wax. (Girl, 12-14, SS+HV+SA, Mumbwa)

The present that they give us is not valuable and it doesn't make sense... The bags that we are being given are not strong, we just use it for 5 days and it gets torn, moreover I didn't even get mine, I was told by my mentor that the bags were finished. (Girl, 18-21, SS+HV, Solwezi)

Some of them (AGEP girls) said they stopped (attending) because the T-shirts they were given used to change its colour from its original one to another. (Girl, 12-14, SS+HV+SA, Mumbwa)

One of the girls said that it would have caused less consternation and unhappiness if instead of material awards for attendance, the girls had been provided with meals, or taken on day outings.

The prizes, they should just remove the prizes and replace with food, when we come we eat that's all or removing the prizes and instead they should just be taking us to different places to play, places like dream valley, that would be better. The prizes brought about a lot of confusion. (Girl, 12-17, SS+HV, Chipata / Chazanga)

Some of the girls reportedly sold the prizes they were given by AGEP, in order to purchase other things that they needed.

Last time (my daughter) got a present in the form of a blanket, which she sold and bought things for school. Recently she got a prize in terms of a phone, which she intends to sell again (Parent, Chipata / Chazanga)

\section{Lack of Access to Meetings}

According to some of the mentors, a few of the married AGEP girls were prevented from attending the Safe Spaces meetings by their husbands.

(One girl) joined AGEP while she was married already but the husband never use to allow her to come for the meetings. What used to happen was if the husband is round she would not come but when he is not there she would come... she would attend meetings when her husband was away. When he was away she wouldn't miss meetings. (Mentor, Chipata / Chazanga)

One girl's husband allegedly thought that Safe Spaces was immature and childish, and forbade his wife from attending the meetings.

I had about two (married girls in my group), one of them was barred from attending the meetings by her husband, he told her that it was for children, I tried to follow up but it failed. (Mentor, Chipata / Chazanga)

Some of the girls who had young babies or children also found it challenging to continue attending the meetings. 
When we started AGEP, she already had a child who was two years old, after same months she became pregnant again, so when she became pregnant, she stopped felt lazy and stopped attending the meetings, so even with her I tried to make follow-ups but to no avail, that's how she stopped. (Mentor, Chipata / Chazanga)

\subsubsection{Others Girls Joining AGEP}

Some of the AGEP group members commented that other girls in the community who were not part of the programme were jealous and resentful that they were not part of the programme.

We used to argue with my friends... They were bitter because some of us used to be followed in our homes to be interviewed. So they used to ask why this was like this and why they were left out. (Girl, 15-21, SS+HV, Mumbwa)

A few of the girls who made remarks about their non-AGEP friends being jealous, said that these same friends would discourage them from attending the Safe Space meetings.

My friends whose names were not on the list or who just didn't attend AGEP discouraged me from attending, and advised to just stay home and play as AGEP was just a time wasting activity. (Girl, 18-21, SS+HV+SA, Chipata / Chazanga)

Some of the AGEP girls said that they would try to encourage other girls in their community to join the programme, so that they could also benefit.

This girl who is a neighbour, from a bar, I will tell her AGEP is good. They teach you how to cook, make door mats things like that. So I encouraged her that if you go for meetings you will find something good in there, preventing you from having sex with men, and she said ok and she tried (to join). (Girl, 15-21, SS+HV, Ndola)

As well as jealousy and resentment, some of the other girls in the community who were not involved in the programme displayed interest and curiosity in the programme, especially those that had witnessed the positive changes in their friends who were part of AGEP.

I had some friends that followed me for the meetings despite them not being on the list, they attended some of the meetings and were not chased. Because of that they got interested and motivated to come and learn because of the good things that were being taught. (Girl, 18-21, SS+HV+SA, Chipata / Chazanga)

Mentors commented that non-programme girls in the community would ask if they too could join the programme after seeing the benefits their friends had gained from AGEP.

Most of them would come to request if they could join AGEP when they saw how much their friends have changed, most of them would come, peep through the window and ask me if they could join, I would allow them to join just for then. (Mentor, Chipata / Chazanga)

\subsection{Control Group Girls: Non-AGEP Program Participation}

Girls in the control groups were asked if they were involved in any projects or activities, aside from school, that were run by NGOs or Churches in the communities. Many of the girls in the control group were involved with faith-based NGOs, bible study groups or church youth groups. Some of the benefits of such programme involvement described by the control group girls echoed the AGEP girls' descriptions of the benefits of Safe Spaces, for example social support and guidance, lessons on respecting elders, encouragement to attend school, and information on HIV. 
We educate ourselves on how we should behave as youths... We need to show love to one another and also be obedient to our parents... I have benefited because I am now knowledgeable... I have benefited a lot because I avoid associating myself with men. If I go out with a man who is infected, I may also get infected with HIV/AIDS.... In my way of life am able to determine on what is good and bad, if my parents tell me not to do certain things, I will need to obey them so that I stay blessed. (Girl, 12-17, Control group, Solwezi)

In the past I never used to obey my parents but after joining the YWCA programme I started obeying them and followed what they teach for example not engaging into prostitution... It has helped me proceed so that I can finish school in future... they encourage me and I stopped everything. (Girl, 14, Control group, Solwezi)

\subsection{Mentoring}

Mentors in the Safe Spaces programme were young women, aged between 20 and 40, recruited from the study communities. Each of the main study sites had 24 mentors, each responsible for a specific group of girls. During the evaluation interviews, Mentors were asked to describe their experiences mentoring in the AGEP programme. Mentors described some of the ways in which they felt that they had benefited from their involvement, the factors that motivated them to become mentors, and also detailed some of the challenges they had faced as mentors.

\subsubsection{Mentors benefited from AGEP}

The respondents suggested that it was not only the AGEP girls who benefited from AGEP, but the mentors themselves had gained from their involvement in the programme. Many of the mentors commented on their own knowledge gains from the programme.

For me there a lot of things that have changed in me, for me to reach were I have reached 29 years old it was a challenge because you couldn't find anyone to tell you the truth, so it was up to me to know what was right and wrong, so when I was taking the girls through the topics, I realised there were certain things that I used to do wrong, there were certain topics were you are encouraging the girls, at the same time you are encouraging yourself, so I really found this programme to be very useful. When I found out that it was coming to an end I was so saddened. (Mumbwa, Mentor)

Mentors pointed out that it was a mutually beneficial reciprocal learning process between them and the girls.

I have leant a lot from the programme that we are having with the girls, because it's not about the things that we have or the books, but there are some things which the girls know that we don't even know. It's for us to learn from each other, not just me giving them information, though they need information but I also need information from them, because they know some things that I have never even known... with the some books that we use, I have leant a lot, it's not just for the girls but I have also benefited. (Mentor, Ndola)

Mentors also felt that they were helping to make a positive difference in the lives of the young girls in their groups.

I was encouraged because a mentor is more like a teacher, and I was encouraged to teach them and to give them the information that they need, so that they can get it and practice. It helped them in their lives. (Mentor, Ndola)

Mentors were thankful for the employment and financial impendence that they had gained through being part of the programme. 
I love working, I am not a weak person who depends on people, I like working for my own things, as it is I am a widow, I have three children, my husband passed away in 2010, at that time my children were still very small young they have grown up just through my own hard work. I have never gone to a person's home to ask for help or even to go to my relatives to go and ask for help, no, I don't like doing that. I like doing things for myself not bothering people. That's how I am, I love working. (Mentor, Chipata / Chazanga)

Other benefits that mentors described as a result of mentoring included the acquisition of new skills and literacy.

At least I am able to do everything myself, because if it wasn't for AGEP... I would have been a prostitute this time just looking for money but at least am able to do one or two things, I am able to write, able to read, that's the important thing. (Mentor, Mumbwa)

Some of the mentors commented that their own education has been furthered by their being mentors, and they had renewed and improved aspirations of furthering their education and career.

Now I have even started to think of going back to school to re-write some subjects I didn't do well may be I can have an opportunity of getting a job in government. (Mentor, Chipata / Chazanga)

Many of the mentors also felt that they had gained self-confidence from being mentors to the AGEP girls.

When we are talking about reproductive health I don't feel shy to mention some feel shy to mention words like vagina or penis but for me I even say those things, I am proud of it, I love being a mentor because it has taught me a lot, I now have the courage to be around girls. (Mentor, Ndola)

Some of the mentors commented on positive changes in their own behaviour as a result of being a mentor.

I have changed in the way I find money and how I use it... I no longer spend my money carelessly... I no longer move about aimlessly an example is that I have stopped drinking beer... I just use to drink beer. (Mentor, Solwezi)

Mentors themselves had also learned a great deal about their own health, and how to be healthy, through teaching the curriculum to the girls.

I now know how to look after myself, how to keep of my body and how diseases come and how I can prevent myself from contracting HIV and other STIs. (Mentor, Ndola)

Some of the mentors themselves made comments regarding how much they had learned from teaching the girls about HIV; from their statements it would seem that their own knowledge levels were poor before their involvement with the programme.

I have a learnt a lot when it comes to health that I should protect myself, if I could have known earlier that time, that if I have sex with a man I can get pregnant I would have protected myself but I have learnt from it next time it won't happen because I know if I need to have sex with a man I can say let's protect ourselves won't be able to get HIV, I won't be able to get STIS because I will tell him that if he doesn't want to protect himself and myself then why should we go on to do things that I don't even like because I know that it will bring problems. (Mentor, Ndola)

One mentor described how she has learned about HIV and the importance of going for regular HIV testing. She said that previous to her involvement with AGEP she was reluctant to seek health care and scared of going to the clinic. 
Even me from the time I became I mentor I don't even fear to go for VCT but from the time I started teaching at AGEP I realize that VCT is for everyone unlike keeping diseases within ourselves, what if you die? That's when we started going there every after three months for tests so that we know how our lives are doing and we also check BP. I never had a card for the hospital from the time I was born, but this has made me to have a card now. (Mentor, Mumbwa)

Mentors also gained new knowledge relating to contraceptives and family planning.

I had no knowledge of family planning (before becoming a mentor) but now I know... we have also learnt a lot. (Mentor, Solwezi)

Some of the mentors lamented the fact that they hadn't learned about contraceptives and safe sex earlier in life, as it would have saved them from early and unplanned pregnancies.

I got pregnant when I was very young, so I was very feeling very depressed that at a tender age I have two children... if I could have known earlier that time, that if I have sex with a man I can get pregnant I would have protected myself but I have learnt from it next time it won't happen because I know if I need to have sex with a man I can say let's protect ourselves won't be able to get HIV, I won't be able to get STIs because I will tell him that if he doesn't want to protect himself and myself then why should we go on to do things that I don't even like because I know that it will bring problems, I will have another child, he will ran away from me, it will be my responsibility and you know being a single mother is very difficult, so that's what I liked (about $A G E P)$, I have learnt from it. (Mentor, Ndola)

As also seen amongst the girls (as elaborated on below) Mentors described increased awareness of the importance of seeking formal healthcare instead of self-medicating.

I now have the confidence to go to the clinic and have myself checked because I have realised that there are many diseases that we are not aware of. Sometimes we self-diagnose and prescribe medication wrongly yet we are not even doctors. Now I know that one has to go to the clinic/hospital, run tests to know specifically what the health issue is and have it addressed correctly. (Mentor, Chipata / Chazanga)

Mentors found that the health care attention and services they themselves received at the clinics have improved since their involvement in the programme.

I remember before I became a mentor you would find that you come very early in the morning and you leave this place (clinic) at 12 and all I would get is a panadol and maybe piriton but now because they know me as a mentor they would give me all the medication to any problem that I would tell them I have. (Mentor, Ndola)

Mentors felt that they were treated with new respect by health care providers.

At the clinic, we are given a lot of respect we deserve as mentors. Whenever we want to seek help at the clinics, we are attended to without any difficulties because we are part of AGEP and we don't even have to stand in long queues. (Mentor, Solwezi)

Through their training and involvement with AGEP, mentors said that they had also benefited from the financial literacy education they conducted with the girls. Mentors described their reckless spending behaviour before the programme.

I am one person who never used to make a budget when going to the market. I would buy anything that I found. But now, I have a limit on what to buy and if it is necessary and still have some change not before when I would spend it all and remain broke. (Mentor, Chipata / Chazanga)

Some of the mentors were inspired by the programme to start up businesses and find other income-generating activities, which served to increase their financial independence. 
Before I joined AGEP, I never had that interest to start a business but this time around am doing my own business and able to pay for my school. I don't wait for someone to pay for my fees or wait upon my parents. (Mentor, Chipata / Chazanga)

Most of the mentors engaged in other income-generating activities, as well as working with AGEP; including waitressing, entrepreneurship, craft work, farming, growing and selling vegetables.

I do some other short time piece works, I was working with the alliance ginneries thou it was just a seasonal job and am also doing a small business, I do SIM registration for Airtel and MTN (mobile phone service providers). (Mentor, Mumbwa)

There is a Women's organization that I joined... we just do Income Generating Activities... We make doormats, earrings, drama groups, a lot of things, we also do poultry and organic gardening. (Mentor, Chipata / Chazanga)

A number of the mentors explained that as a result of their involvement with AGEP they had learned how to budget for their needs.

I know that before I use my money I should have a budget, not where I should spend each and every coin that I have, whatever fashion I come across a should buy, so AGEP has taught me to budget and stick to it. (Mentor, Chipata / Chazanga)

When I have that K500, I look at what I not there at home, charcoal because we us charcoal, I need to buy cooking oil and sugar, these are the big things that I help with at home, so when I just buy that but first before I get the money I make a budget of the things that I need, if I know that my daughter or my son doesn't have slippers, I will put that on the budget, this month I will put for her and him the rest I will get what I want. So this month if it's the two kids that I have put on the budget, that is apart from the basic needs because I always put the basic needs but what my sister likes is me giving her the money because she is a business lady, so maybe if I give her a K200 then she says this K200 maybe I will buy tomatoes, I will earn interest then she will use that interest to buy whatever is needed at home rather than I buy whatever she needs is, maybe I can get paid today then there is mealie meal, there is cooking oil and other, I can't buy those things because they are already there so I give her the money when those things finish, she can buy whatever is not there, if I remain with a K100 maybe my daughter doesn't have slippers I go to PEP and buy then the other month maybe it will be me, I will get that K200 and save then the other month end it will be me, I will put myself on the budget the rest I put in the bank. (Mentor, Ndola)

When a person has money and want to spend they need to sit down and write a budget, they need to know how much they have, list down all the needs, then you can save the remaining money and if they feel there is no need to save there any then, it's better to do a business so that, that money that has been used to buy the need things can be recovered. (Mentor, Solwezi)

\subsubsection{Motivation to become a mentor}

Mentors listed various reasons why they chose to become involved with AGEP as a mentor. Reasons included a desire to learn, gain work experience, find employment, and make a positive contribution to their communities.

What encouraged me to be a mentor is: I also wanted to learn because even if this programme was meant for girls, we also learnt a lot of things to do with our lives, that's the biggest reason why I wanted to be a mentor, I wanted to help the community, the children in the community because a lot of children get spoiled. You find that the children won't listen to their parents but they might listen to an outsider... To teach them how they can take care of themselves so that they can finish their education and not get unwanted pregnancies. (Mentor, Chipata / Chazanga) 
For some, the motivation to become a mentor lay in the financial benefits of employment, and gaining work experience. One mentor explained that she was seeking employment in order to support herself, and stayed motivated to work for AGEP despite other people telling her that the programme was Satanist.

What encouraged me to be a mentor: I really wanted in my life to work and have an experience of working... This is because I just wanted to work... I went and informed my friends about it but others were refusing saying "you will be going to Satanists (laughs), you are going to people whom you don't even know; and the government doesn't know that there is such a programme", then I told them that I personally will work, because I want money so that I can be able to buy whatever I want, not every time asking money from people "I want soap, I want perfume, I want lotion", that's the kind of life I refused. (Mentor, Mumbwa)

\subsubsection{Challenges of mentoring}

Mentors listed a range of challenges that they had experienced during their time as mentors. One complaint was that mentors felt that they weren't paid well enough for their work.

What discouraged me the most was that the allowances we were getting from YWCA were not enough to be able to sustain us especially those of us that have families. The funds were not enough to have done anything else rather than attending to the more urgent needs. (Mentor, Ndola)

Some of the mentors felt that the younger girls were too young to be receiving the information included in the curriculum, especially regarding contraceptives and abortion.

For the group that I was heading, it was quite a challenge with the 10-14 year olds, with some of the topics like 'my body is changing'. Some (girls) were very young to start teaching them some topics... Even if we were teaching these topics, it was coming out as if we are encouraging them to do certain things (promoting promiscuity), so for me that's where the challenge... About abortion... when telling them about how they could have a safe abortion by going to the hospital and get an injection and accessing contraceptives, for the 10-14 olds was a challenge. (Mentor, Mumbwa)

Some of the mentors explained that they had struggled with badly behaved group members who disrupted Safe Spaces meetings.

Sometimes when you are giving the sessions, (the girls) would start fighting... saying things like, "Madam this one has done this... this one has that"... so for you to now to calm them down... to convince them, there is a lot of work. (Mentor, Chipata / Chazanga)

Some of the mentors commented that group members would arrive very late to Safe Spaces meetings, which was frustrating, and meant that it was challenging to cover the required parts of the curriculum. According to one mentor, this lateness was especially a problem amongst the older girls.

Those of us who used to teach the 15-19, the most discouraging thing was that they used to come late for meetings, because you know when a girl reaches the teenage stage... we agreed that we would be meeting here at 14:00, but you find that you as a mentor will be here by 14:00, you clean and arrange the desks and sit waiting for the children, instead of coming at 14:00, they used to come at 15:30-16:00, by then you would be tired of waiting and then you have to start and finish a topic, then again if the topic is long maybe it's taking 1.5hours they start telling you that time has gone just cut some things and teach us the important ones when they are the ones that come in late. So those of us that had the 15-19, we had a challenge of late coming, you would talk and talk, they would say no next week we will come on time but still come late. For them to bath, apply face powder, you will be here getting tired of waiting for them. (Mentor, Chipata / Chazanga) 
The mentors had to deal with complaints and confusion on behalf of the girls' parents, who didn't understand the system for being awarded prizes for good attendance, and would accuse the mentor of being unfair.

The girls would be given the prices once they accumulate the number of weeks required like five straight weeks without missing, then they would be given the prizes, so this brought about so much confusion, you would find that you explain to the parents quiet alright about the whole process, instead when they go home parents used to feel we were being unfair, they thought everyone was supposed to receive these prizes despite missing the meetings and all that... The other thing that brought confusion was that the girls were not given the prizes on time so they would complain. The girls never use to understand the whole process of attaining that position of receiving a gift... we would make follow ups and the parents would give excuses and we would explain to them the importance of attending the meetings and the consequences of missing meeting. (Mentor, Chipata / Chazanga)

During the programme, when the prizes weren't delivered on time, people started complaining to the mentors.

Only when their presents delay to come, that is when other girls open up to me to say their husband couldn't allow them to attend meeting because there were no benefits attached to the meetings. Sometimes even the men approach me to ask me about their wives presents. This is the same challenge that my fellow mentors working with the 10 to 14 old girls are facing, their parents also get concerned if their daughters don't get their presents on time. But if they get them on time they feel happy. (Mentor, Solwezi)

The attendance pattern from the part of the children was another discouraging thing, this was because initially they had been promised to be rewarded prizes after they had attended meetings over (five) 5 times. To begin with they would reward these girls as promised but eventually they became inconsistent and some cases stopped rewarding the girls, that is what cost the organisation progress. We would take it upon ourselves us mentors to follow up these girls and even go as far as talking to their parents so that the girls could resume attending of the meetings. (Mentor, Ndola)

Some of the mentors were discouraged by the sense that group members were attending the meetings only for the prizes.

What used to discourage me is the issue to do with the prizes, they used to give me some trouble and they caused a lot of children to stop coming because they used to say a child can only get a prize if they have been attending the meetings continuously for ten weeks but you would find that some of them would miss some meetings and then when they come they find that their friends are being given prizes you find that they go back and never come back and secondly instead of giving the children the prizes at the time that they promised they would give them, they would delay, it used to take a long time and they would even start asking to say madam, when will we get the prizes, madam, we have been attending the meetings for the past so many weeks, when will we get our things? That used to discourage us, it used to be a challenge for us mentors... Most of them stopped because same of the children were coming for the meetings to get the prizes not necessarily to learn. (Mentor, Chipata / Chazanga)

Some of the parents were also of the opinion that prizes for babies would encourage the girls to get pregnant.

Option two consisted of stuff for the babies and for that parents thought it wise to eliminate it because they felt it would encourage the girls to do things they are not supposed to, so they were to be given pants and pencils. (Mentor, Chipata / Chazanga)

One mentor commented that there was competition between various NGOs in the community, and AGEP was not able to offer some of the same incentives and benefits as the other programmes, which served as a de-motiving factor for mentors. 
Usually in communities, NGOs tend to be competitive with each other and what they have to offer. Most of the NGOs offer rewards to keep the members motivated... In the case that one of the girls who is a member of AGEP has an grievance such as the loss of a parent, it is also expected that the organisation or programme she is part of will step in and assist her financially, but you find that AGEP is not able to do that. In seeing this the members of the community will pit AGEP against other programmes that are able to assist girls in this way. This is what would demotivate us in many instances. (Mentor, Ndola)

The lack of dedicated and suitable venues for the Safe Spaces meetings was also cited as a challenge, which discouraged girls from attending meetings, and created extra stress and work for the mentors to encourage the girls to continue attending.

We had a challenge with where we were meeting, we were not safe. At first we were just meeting outside so there was no concentration, they (group members) were not participating, they were just looking around and doing other things. When you are in an enclosure they concentrate, but the problem that we were having is that they [Pop Council] were not giving us rental money on time, even last time again we had a challenge, we were even chased from the place where we used to meet... when we told the girls about the new meeting place, some were saying "even last time we were chased... we had no place to sit, where are we going to sit? There is no place for us to sit, the owners said we don't even want to see you in these premises"... the time we were chased I had to start doing the home visits again... so at least if they can improve and just have a specific place for meetings, things can be easy, it would be fine. (Mentor, Ndola)

Many of the mentors experienced challenges with group member attrition, one reason being the widespread belief in the community that AGEP was Satanist, as elaborated on further below.

The first thing is the parents, since inception of the programme it was difficult even the time we were distributing letters some parents used to refuse, for those that understood what we were explaining are the ones that came but some didn't and they never showed up, because they had already told their minds that we are Satanists. There was a lot of influence going on among the members of the community that led to most of the girls dropping out. Due to the rumour of us being Satanists. (Mentor, Chipata / Chazanga)

At first when we started it was more like a challenge, like when we were delivering the letters for those who were invited, we were going door to door and some of the parents were refusing that not my daughter you people are into Satanism, we would find that some had shifted, then we invited them most of them came... At first they came in numbers as days went by some started influencing their children to stop coming that we were Satanist, you know like that attendance report there is a log and the books that we gave them at first that they were using to get paid and they would refer to that log as satanic because of the tower, some parents would even burn the passports just like that, it eventually became interesting especially after the girls got used to the programme. (Mentor, Chipata / Chazanga)

\subsection{Expectations of AGEP}

Various community stakeholders were interviewed as part of the research process, including parents of the AGEP girls, and community leaders. In the follow-up interviews, parents and community leaders were asked about their initial expectations of the AGEP programme, and whether or not these expectations had been met. On the whole both parents and community leaders expressed the sentiment that they were happy with the programme, felt that it had had a positive impact on the girls and on the community in general, and were disappointed to witness the programme coming to an end.

To begin with I was impressed with the programme because it brought change within our children and kept them occupied with something productive... What I was really anticipating was for the programme to equip these young girls. As I had witnessed some at the hospital 
had been given some cards, some were fortunate enough to open up bank accounts, some had been fortunate in school opportunities. Even when I heard that they were phasing out the programme, I was the first one to lodge a complaint, because I felt it was too soon for them to phase out. I requested for an appeal to keep the programme running longer because I have seen a change in the behaviour of the children. And if they take away the programme, the children will go back to those old habits, so I am still appealing for the programme to continue running... (My expectations) have been met because there are not many children who have a bank account in this time and age or a health scheme... I was very much impressed with your programme. (Community leader, Ndola)

One view expressed by community leaders was that some of the old traditional rituals that used to educate girls have now died out, so AGEP is able to play the role of these rituals by imparting knowledge and information to the girls.

In the past we had visungu [local traditional ceremony were they keep a girl in the house immediately when she has her first periods to teach her how to take care of herself as a young lady]... we call it nkolola in Tonga. That nkolola used to protect the girls because they were taught a lot of things, maybe she can be there for one month teaching her how to protect herself, she would be taught a lot but this time the nkolola has finished so they just move anyhow, so organizations like AGEP if they were to continue I know young ladies will learn more even if we don't have nkolola but they will learn more because this time it's even difficult to call my auntie, to call my neighbour to tell them to teach my child because I am scared that they will bewitch my child [laughs], so with organizations like AGEP it's going to be very easy. (Community leader, Mumbwa)

One community leader had hoped that those people engaged as mentors by AGEP would be enabled to further their own education, however this expectation was not met.

I thought those people who are teaching these girls (mentors) would be taken to colleges to further their education so that in future they find employments in hospitals, mines, schools and other places.... As you know, it's not easy to be a mentor, I used to think that these mentors would be receiving prizes they deserve... Nothing has been met yet, there isn't any mentor who has been taken to college to further her education. (Community leader, Solwezi)

Some of the parents of AGEP girls explained that they had held expectations of the prizes that were promised to the girls by AGEP, and that some of these expectations weren't met, as the girls didn't receive all the prizes they anticipated.

What I was expecting are things that were promised for the girls like phones, clothes, we were expecting those things and we are still expecting even now... Some things were given to the girls but for some things we never saw them... There are some parents who approached the AGEP people and actually asked them why some things that were meant for the girls were not awarded to them as promised, some said the people that receive those items must have done something to them some say the things are not in yet. (Parent, Mumbwa)

\subsection{Concerns about AGEP}

Respondents' views on AGEP were generally positive, as detailed in the separate topic sections. There were however, a few negative views and concerns about the programme. The most commonly cited concern has already been outlined in the section on factors discouraging girls from attending meetings - namely the widely held belief in the community that AGEP was Satanist.

The other key theme that emerged in relation to the concerns about AGEP that respondents had related to the view that the Safe Spaces curriculum encouraged promiscuity amongst young girls. Some of the parents and guardians expressed the concern that the information about sexual and reproductive health that the girls were receiving at AGEP encouraged and 
promoted the engagement in sexual behaviour. One grandmother advised her granddaughter to discontinue her attendance, as from what she saw group members were all getting pregnant, and she had determined that what the girls were learning at Safe Spaces was the cause.

Maybe when people receive information some misunderstand it, some maybe would want to practice. They said that when we have sex we need to use a condom, so when I want to have sex with my boyfriend I will use a condom, you see, they want to practice... I have one girl, I received a complaint I think two days ago from the parent, the grandma complains a lot about her that this time she is doing things that are not impressing her, she is going out with boys and this time she didn't even sleep home for two days, so her parent called me... so I started asking myself if the sex talks that we have been having have been affecting her, Or what, so I asked the parents if that's the way she has been or maybe she just became that way recently then they said she has been naughty for a long time now but she never used to have boyfriends but maybe the other contributing factor is that she has grown up now. She is the only girl from whose parents I have received complaints but from the others I haven't heard of such situations. We were not just talking about sex, we also taught them about respect, we talked about how you can associate with partners, there are some other topics in there... but the thing is that in a group there are two or three that will misunderstand what is being taught, that is the thing. (Mentor, Ndola)

One of the parents, however, recognised that even if AGEP was discouraging sexual behaviour, the girls may not listen to the advice, and that AGEP cannot be blamed for their getting pregnant.

It raised concerns when most of the children who were going for AGEP fell pregnant, it seemed as though AGEP was not playing its role. l'll give an example of the preacher at church, he will do his part to preach but you may find that someone is only going to church because there is a certain guy she meets with there. While he may preach that you take a step back away from sin, they may not listen. So in the end, AGEP may have taught these children, but they have not been heeding to those teachings and warnings. (Ndola, parent)

One mentor said that if she could change something about Safe Spaces it would be changing the curriculum so that the younger girls are not taught about sexual and reproductive health. Some of the mentors found it challenging to teach the girls about sexual and reproductive health, and felt that the girls in the 10-14 age group were too young to be receiving information, especially regarding contraceptives and abortion.

One thing that I would love them to scrap are those topics that I talked about especially for the 10-14 years, topics about sexual reproductive, unless for the 15-19 years is okay because for some of them they have had sex already and some have children. (Mentor, Mumbwa)

The sentiment that some of the curriculum content was too 'mature' for some of the girls, and was polluting their minds, was echoed by other respondents, who linked this to Satanism.

Most have been saying AGEP is a Satanic programme, they find the content of the meetings too mature for our age hence it is useless to them. The discontinued attendances were also accompanied by support from their parents who also believe that AGEP is a Satanic programme. (Girl, 12-14, SS+HV+SA, Mumbwa)

One of the mentors commented that even though AGEP promotes abstinence and delaying sexual debut, the girls do not heed the advice, so the best thing to do is to tell them how to have safe sex.

When we talk about abstinence it's not working, just from having a talk with them on that they go and have sex, so the only thing to do is tell them abstain but if you can't, use a protective measure. (Mentor, Ndola) 


\section{Suggestions}

A few of the community leaders shared their suggestions and recommendations on how AGEP could improve. One respondent suggested that the girls would benefit from being taught more practical skills.

If they would include skill training such as tailoring, knitting and other types of skills, and then give them certificates at the end of their training, that they would use it to get a job even after the programme is finished. That would make the programme much more meaningful than it already is. (Community leader, Ndola)

One community leader commented that the situation in the communities would improve if AGEP could sponsor girls' education, paying school fees and providing school items.

Education wise, you need to sponsor these girls like world vision does. You need to select a few girls to help financially, buy them books and uniforms so that they can get an education and help out parents who are struggling to meet daily needs because of the exorbitant prices of faming inputs. That way, we will be so grateful because we believe that if you educate a girl child then the whole nation will benefit. (Community leader, Solwezi)

Important to note is that data from the quantitative survey shows that there was a very low refusal rate (3.2\%), and high response rates (90\%) after three years. In addition, 95\% of girls/guardians consented to the biomarker testing. This demonstrates that despite suspicions about the program amongst the community, many people in the community were still willing to get involved. 


\section{BEHAVIOUR CHANGE}

\subsection{Behaviour Change}

Much of the data relating to the benefits of AGEP was in relation to positive behaviour changes that mentors, parents and community leaders had witnessed in the AGEP girls.

\subsubsection{Better behaved}

The general view expressed by the adults interviewed was that AGEP girls were better behaved since their involvement with the programme. The view was that girls had become more responsible, better mannered and more respectful, and were more motivated at school and at home. Many of these comments came from the girls' parents who had noticed changes in their daughters' behaviour:

I can say $75 \%$, she has really changed... I have seen drastic change... She has become a good public speaker, she has good communication with friends, now has respect for parents at home and also she never used to do house chores but now she is able to do without even sending her... She is now able to study. (Parent, Chipata / Chazanga)

She learnt a lot of things and she also earned respect, she started respecting us... She became responsible, when you leave her home, she would do everything and when you get back, and you would still find her home. I cannot lie, she changed in a positive way. (Parent, Ndola)

One parent remarked that her daughter was now more mature, able to help her sell at her market stall, better at looking after young children, and had started saving money.

There is change (in her behaviour), though not everything can be completely met, but at least there is change and improvement... The first area I have seen change in is; when I go out and leave her to stand in for me (at market stall) and sell, she just sells well, and the way you leave things is how you will find them. Sometimes when I am wrong or miscalculate things, she controls me and shows me where I am wrong. Another thing is just how she lives with her friends, she has that care whereby even if you leave her with a child, she will take very good care of that child, she does not over react like other young girls neither does she talk back when you are speaking to her. The area where I have seen change sometimes when I give her money for food at school, she keeps. So you will just be surprised after some days she will tell you I have this kind of money and I want to buy what I want. So I could ask her where she is gets all these ideas and she tells me from AGEP. (Parent, Ndola)

Community leaders echoed the same sentiment relating to the positive changes in the girls' behaviour.

Those that belong to AGEP, some of them have really changed for the best, they are good, they are respectful to elders. Their behaviour, in short, has changed... Improvement in their academics, lifestyle, attitudes and actions. Even their reactions to what is a destruction with this modern world that we live in. (Community Leader, Chipata / Chazanga)

Mentors also remarked on the behaviour changes that they had observed in the AGEP girls:

In the past or rather before they joined AGEP, they had bad behaviour like having boyfriends, abusing alcohol and they were also ignorant but AGEP was introduced they have become better people. (Mentor, Solwezi)

One mentor provided an example of a girl in her group whose behaviour had dramatically changed for the better. 
I had (one girl) in my group, she was 13 years old, she is a girl that used to move a lot before joining AGEP, friends would go and pick her up every morning and they would go hang up with boys, and they would go drinking and all that... until she joined AGEP, when she came to $A G E P$... that's when she realised that what she was doing was not right. She said she realised that with what am doing I can get pregnant and maybe I can get STIs, then after learning she was such a well behaved girl and her parent really appreciated. (Mentor, Chipata / Chazanga)

It was also remarked on by some of the adult respondents that the girls were now better dressed, as they no longer wore inappropriate clothing or short skirts, and their attitudes were generally much improved.

At first it was very difficult because the girls didn't know me well, I didn't know them well, they came from different backgrounds with a lot of characters, different characters, some had bad behaviours... so as we started knowing each other, I started teaching them what was in the curriculum, at least they started changing bit by bit, about the dressing, about the attitude. (Mentor, Ndola)

The differences l've noticed in the girls that are in the programme is firstly, their way of dressing, they now dress modestly. The other thing is how they are able to time their activities when it comes to socialising and playing play with friends. Most of their time is spent either at school or at AGEP, and they would also spend time at home helping with the chores. They do not waste their time on foolish activities.... It is impressive because even the young girls are able to articulate themselves and what they have learned and one can only marvel at how much they know because of AGEP, it brings so much pride to the parents (Community leader, Ndola)

The girls themselves also commented on positive changes in their behaviour as a result of their involvement with the programme.

We have changed from our ways in the past since the coming of the programme... Some (girls) were mischievous and arrogant but are now well behaved... Some were disobedient to their parents, others would talk back and insult their parents, but now they have straightened their lives (Girl, 10-14, SS Only, Ndola)

Some of the parents and mentors indicated that AGEP participation had led to a marked improvement in the girls' confidence and interest in school.

Her manners have changed because some time back when I used to take her to school she would not even reach school, and I would force her, but still she would not want to go but now she has changed she goes to school on her own. (Parent, Ndola)

(AGEP) has made them choose the kind of friends they are having, because others had a bad group influence, who would just leave home in the morning and come back late or go and drink beer, but with what these girls have learnt they have known the importance of life. If they waste their life, they will not go back to being young. They know the importance of education and what they want to be when they complete school. (Mentor, Chipata / Chazanga)

\subsubsection{Respect for elders}

One theme that emerged from the data was that AGEP girls were now much more respectful of their parents and elders as a consequence of their involvement with the programme. Girls themselves spoke of how the importance of respecting and listening to elders.

I learnt that we should to love one another, and listen to parents' advice... We were taught that when your parents are talking, you need to sit down and listen to what they are saying, unlike standing up and talking back. (Girl, 18-21, SS+HV, Chipata / Chazanga) 
It is important to listen to parents and just other elderly person because when someone is advising you, it means they like you and want the best for you so you have to listen. (Girl, 1521, SS+HV, Ndola)

I never used to listen to elders when they are talking to me... I have changed... now that I am obedient... A while ago when they send me, I would take long to do what they are telling me maybe after three that is when I will stand up but now it is different, when my grandfather just tells me something, I will go and do it immediately. (Girl, 15-21, SS+HV+SA, Mumbwa)

\section{Improved Relationships between AGEP Girls and Parents}

One of the most commonly expressed themes in this area was that AGEP has improved relations between AGEP girls and their parents. Parents themselves commented on how AGEP had provided a platform and conduit for improved communication between parents and their daughters.

Young girls are very difficult to manage, there are areas where no matter how much we talk about them to them, they will not understand. It is more like (AGEP) were helping us talk and teach to our children (Ndola, parent)

On the whole, parents spoke positively of the impact that AGEP had on their daughters, and viewed the teachings of the programme as beneficial and important.

We all (parents) came to agree that this programme has been helpful and it can help us with teaching our children. They are better off having this programme empower them because they are the future as we have already spent our time here on earth... we should be very happy with this programme because it has come to teach our children cleverness and confidence (Ndola, parent)

In all cultures there are norms of communication, and culturally sanctioned and appropriate means of knowledge transmission between generations. Relating to this, some of the parents explained that there are certain topics that are considered inappropriate for a parent to discuss with their own child, for example sex. Some of the parents commented that the girls were able to learn about these topics through Safe Spaces, which was valuable.

I came to realise that they were gaining valuable knowledge which was being exhibited in their behaviour. It had a positive impact and has changed them... What I knew was that AGEP had come to teach our children therefore I was very excited that our children were learning things that we are not able to teach them; there are certain things that culturally, as parents we withhold from telling our children but AGEP goes into all the intricate details and openly discusses unmentionable topics with our children. Sometimes I would overhear what their discussions were about what they learned from AGEP when I'm in the bedroom and they are maybe outside with their friends. Even before their grandfather passed away, they would chat with him about these teachings without fear or embarrassment. This has really impressed me with the fact that they have learnt things that I may be unable to tell them. (Parent, Mumbwa)

Girls were taught at Safe Spaces to respect their elders, and be polite.

(AGEP girls) say they have now known how to live with elderly people and what they are expected to do, even when she is staying with people who are not her relatives she knows how to communicate with them, they even confess that before this programme they would refuse when parents send them but not anymore, they used to be arrogant and they realise when they are talking to elderly people. (Mentor, Mumbwa)

Some of the parents commented on the noticeable change, and increased respectful behaviour. 
I have seen it in my daughter... (her) general behaviour, the way she responds when we are talking to her, I can just say that she has discipline. She responds with respect. When an elderly person is talking to her and she humbles herself. (Parent, Chipata / Chazanga)

They (AGEP girls) no longer move carelessly, the girls are now responsible, they stay home. Like my girl, she used to move a lot and when I talk to her about it she would be upset. From the time she joined AGEP, she changed on her own and does things correctly... those girls that never used to respect their parents but now they do. (Community leader, Mumbwa)

Some of the girls said that when they attempted to share these lessons about respecting elders with friends who were not in Safe Spaces, they didn't listen.

I told them that we learnt how to be obedient and respect elders, irrespective of their relation to us. It is not very kind to insult our elders. But they do not listen to what I say (Girl, 12-14, SS+HV+SA, Mumbwa)

Before we were very naughty and arrogant, but these days we are better. Before we would not even help out elderly people but now after learning a lot from AGEP we would help out the elderly people if you see that they have so much luggage... We used to insult and laugh at elderly people (Girl, 15-19, SS+HV, Mumbwa)

(AGEP) made me change for the better... How to live with elderly people, respect them, when they are talking you shouldn't be talking as well but respect them (Girl, 15-19, SS Only, Chipata / Chazanga)

AGEP has taught me not to answer back at my parents when they correcting me because if I answer back this will just make them more angry (Girl, 15, SS+HV, Solwezi)

\subsubsection{Behaviour of AGEP girls compared to non-AGEP girls}

Many of the AGEP girls made comments regarding the difference between their behaviour and those girls who were not in AGEP.

They (non-AGEP girls) are different in that you can advise someone who is in AGEP and they will listen to you, but those who are not in AGEP don't listen when you advise them... They are different because you can tell some is in AGEP just by their actions and how they dress, the taught us but you can't advise someone who is not in AGEP about their dressing, you might end up fighting. (Girl, 18-21, SS+HV+SA, Ndola)

(Girls not in AGEP) differ in knowledge... Because we learn a lot of things at AGEP... (Their behaviour) is different from those who are not in AGEP... They are found in bad places at night and move a lot... Those that are in AGEP know a lot more things than those that are not in AGEP. (Girl, 14, SS+HV, Solwezi)

Non-AGEP girls were described as being rude and ill-mannered by some of the AGEP girls.

(Girls who are not in AGEP) have bad manners... they say anything and have bad language. (Girl, 15-21, SS+HV, Ndola)

One of the community leaders agreed with this sentiment regarding the marked difference in behaviour between AGEP and non-AGEP girls.

(Non-AGEP girls) have delinquent behaviour, even the way they carry themselves, the way they walk, you know that these children, we have lost them... when you look at these girls we have, there is that decency and in terms of the way they conduct themselves... That is what I can see from afar, I think there has been change in these people... AGEP people as compared to other groups of young people. (Community leader, Chipata / Chazanga) 


\subsection{Knowledge and Empowerment}

AGEP girls were provided with information to help make them safer, more aware of their rights, and empower them to make safe decisions.

\subsubsection{Self-care and safety}

In Safe Spaces, girls were warned about the dangers of getting involved with men, of sexual abuse, and the need to take precautions to avoid getting raped. One such piece of advice was that girls should avoid walking in isolated areas alone, avoid going out late at night and should avoid getting drunk so that men would not be able to take advantage of them. Many of these comments regarding safety came from girls at the urban study sites:

We were told not to move at night because we can be raped... You should avoid moving at night because they can be raped and left for dead... If a man entices you with money so that he can have sex with you, you should refuse. (Girl, 12-17, SS+HV, Chipata / Chazanga)

Not to be found with boys at parties, night clubs because they can get you drunk and rape you and you will end up with a child... I do go to parties but not all night out parties. (Girl, 12-17, SS+HV, Chipata / Chazanga)

I must not return home late at a time such 10pm, because I may meet people who would take me by force and rape me. (Girl, 15-19, SS+HV+SA, Ndola)

When you are going to meet your boyfriend, you don't go and meet him alone you need to go with a friend... (Our mentor) used to tell us to avoid paths that cuts through the bush. (Girl, 1217, SS Only, Chipata / Chazanga)

Though girls at the rural sites expressed similar concerns:

Boys like sweet talking and later drag you in the bush and rape you (Girl, 12-14, SS+HV, Mumbwa)

Girls were advised to dress modestly so that they keep themselves safe and avoid attracting the wrong kind of male attention.

They way girls dress causes them to be raped, they wear short skirts... ladies dress indecently, so some of them are raped because of this... we have been taught (by AGEP) about dressing, they tell us not to be wearing short things they cause rape. (Girl, 18-21, SS+HV+SA, Ndola)

When you put on something short e.g. a dress or skirt, a man can just catch and rape you... When you find your friend dressed indecently it's my duty to tell them and help them that, that's not the way they are supposed to dress. (Girl, 19, SS Only, Solwezi)

I learnt about how I can take care of myself as a girl, if am surrounded with males in my house, am not supposed to wear miniskirts. (Girl, 12-17, SS Only, Chipata / Chazanga)

Girls need to dress decent, because if the dressing is as if you are naked men will be seeing something in you that will attract them, and at the end they will propose to you for the purpose of having sex with you. Some are just being raped because of the way they dress. (Girl, 12-17, $\mathrm{SS}+H \mathrm{H}+\mathrm{SA}$, Mumbwa)

One girl commented that before she joined AGEP she used to enjoy drinking beer on a regular basis, but now sees how damaging alcohol use can be to the lives of young women. 
Before I would never encourage someone to stop drinking beer. I would say beer is life. I would never discourage them but now, I am able to encourage them and tell them that beer is not okay, it can spoil your body. (Girl, 15-21, SS+HV, Ndola)

\subsubsection{Physical and sexual abuse}

Overall, respondents described an environment where gender-based violence, physical/sexual abuse, and rape are common in their communities. Often these incidents resulted in underage pregnancies. Physical and emotional abuse by parents was also cited. However, one parent shared the view that due to the human rights discourse and legislation against abuse, parents can no longer beat their children, which has led to bad behaviour, early sex and pregnancy.

This is a government problem because when you beat up your child, you can be arrested but discipline need to beat so this is a weapon that the devil is using so that children may be disobedient to their parents but us they used to beat us so we grew up as disciplined children, somehow it's good but again I can say it's not because it has contributed to children not being disobedient to their parents... parents do not beat their children because of the same human rights... Human rights has to be removed because a parent has to reinforce discipline in the children and sometimes parents are blamed of which it's not their fault but because of this human rights thing. (Parent, Chipata / Chazanga)

According to the respondents, often cases of sexual abuse were perpetrated against girls by members of their own families. At times girls were sexually abused by their step-fathers, in situations where their mothers got remarried.

She was raped by her step father but she never said anything about it, she would say it at the side (not in the open), but was scared to tell her mother so in the end she just pointed at someone else as the father of the child but the one that made her pregnant was her stepfather. (Mentor, Ndola)

Rape usually happens in families where some step fathers sleep with girls, or maybe some girls that are forced to have sex because of walking long distances alone. (Mentor, Solwezi)

One of the mentors described a theoretical situation in which an attractive and shapely young girl would be at risk of sexual abuse at the hands her mother's new husband.

If I have a daughter... (and) I get married - my daughter is fatter than I am... men say when you see a girl's buttocks, you start having certain feelings. So my daughter is fat, she has hips, I even hear men say, this girl is beautiful so I know that my daughter is at risk. So when I get married, seeing as a I already have a daughter, when am not around, he (husband / stepfather) might start having other thoughts about the child then the child might be raped when I go back maybe the child won't say anything because she doesn't even have information maybe she is just not able to say something to me at the end of it she will be pregnant, when she realizes that she is pregnant, she will decide to have a boyfriend so that she can say it is his and yet it's her stepfather. (Mentor, Ndola)

There were also reports of incest being an issue in the respondents' narratives.

If you make them touch you and enter your bedroom, you end up starting a relationship... (One girl) used to play with her brothers when her mother is not there until the brother slept with her... and she ended up getting pregnant... The brothers have to respect their sisters and not being very open to one another. (Girl, 12-17, SS Only, Chipata / Chazanga) 


\subsubsection{Bodily integrity and rights awareness}

Some of the adult respondents explained that women and girls in these communities are not aware of their bodily integrity rights and are not empowered to speak out against rape, or to report incidents of abuse and rape.

Girls get pregnant everywhere not just here because we see in newspapers is because they lack knowledge. They do not know their rights, when someone touches their bodies; they do not what to say... The first (reason) is because they do not know their rights. Secondly, they have that fear, they do not know how to tell a person that they do not like what they are doing to them, and they are shy... They are threatened by those who make them pregnant... Girl children do not know their rights because they do not know how to say no when a man touches their back or their breasts. They do not know how to refuse but like the way they learnt from AGEP that are able to report such cases but now since most of them lack that knowledge, they suffer. When such men touch them, they end up sleeping with them but if they know their rights they will report and at the end of the day they get protected... What should be done is that you must continue teaching these girls from AGEP so that they can know their right and when they know their rights, they will be protected. (Community leader, Mumbwa)

The lack of reporting of incidents of rape and sexual abuse was cited as a common problem in the community.

When somebody has just been raped because she doesn't even know what to do when she is raped, maybe she was raped by an elderly man, she will keep quiet and say if I talk mum will say that it was my fault or no one will ever believe that this man raped me. At the end of it she will fall pregnant because she doesn't even know the process unless if they speak out then they can be helped but if you don't you can't be helped at the end of it you get pregnant, when you ask her who made her pregnant she keeps quiet. (Mentor, Ndola)

As for victims of rape they should be encouraged and advised that they can scream and shout for help when someone wants to rape them. Some don't scream they just stay quiet. But as for those that already have children, they must be warned to never to repeat that mistake, that child should be the first and last. (Girl, 15-19, SS+HV+SA, Ndola)

One view expressed by a community leader was that girls need to be empowered and taught how to refuse the sexual advances of men.

There are only two keys words; yes or no and if you keep quiet a man will take advantage of you. I do not know how you can eliminate this shyness in girls by teaching them so that they can know what they're supposed to say when a man wants to sleep with them. They should be able to refuse when they do not want what a man is telling them. (Community leader, Mumbwa)

Another suggestion made by one of the mentors related to the need to speak honestly and openly with young girls about sex, so that they would be able to recognise sexually inappropriate behaviour, make informed and empowered decisions, and have the selfconfidence to report incidents of sexual abuse.

Whether it's your daughter or niece, this time you don't have to hide things (information) from them, you need to tell them that these are the signs of someone who wants to rape you, when a man touches her on the breasts... you need to tell them that if a man touches you in a bad way you need to speak out, if you are not free with me, find someone that you can be free with to tell the information that you can't tell me so that they can go and report at the police station. They need information to know how they can handle these situations. That can help us. (Mentor, Ndola)

One of the topics covered in Safe Spaces related to empowering girls, informing them of their rights, and teaching them about the importance of reporting incidents of rape and abuse. Mentors at all the study sites explained how the girls had benefited from this: 
They have learnt how they can protect themselves from being harassed or being abused, they have gotten the concept of that. There are some that were being abused. Like the girl that I have in my group, who has been staying with her grandmother and her step grandfather, she used to have problems with them but now she knows how to handle that situation. (Mentor, Ndola)

One mentor warned the girls about abusive and controlling partners, using her own personal story as a lesson for them.

I used to tell them that if (a man) is beating you and is forcing you to be with him, refuse and let him go. I was even telling them that like me who never had a chance to learn what you are learning in AGEP, I had a boyfriend who was very jealous, he used to beat me (laughs)... he would even beat me, but without knowing that it was an offense I was just living blindly like that. And when I tell him that it's over he would refuse again saying you can't dump me he would beat me again for that not until I change my mind saying ok it's not over. So, I was telling the girls that if the boy is doing that you need to report him to the police you shouldn't just keep quite because such people can kill you. So, tell them that you don't want and if they force you report to the police. (Mumbwa, mentor)

Mentors explained that girls were taught to report cases of abuse, for example abuse from school teachers.

(They learned) how to report (abuse) cases, they did not know how to report a matter when they were abused even by a teacher at school. So we taught them and showed them where they can go and report such incidences. Be it the police or the Victim Support Unit. (Mentor, Chipata / Chazanga)

Another of the mentors commented that the AGEP girls have improved levels of selfesteem, and are better able to report abuse.

They have now changed, they can stand and voice out, they know that if someone does this and they can go and report... they have gained self-esteem... One of her neighbours started touching her breasts, okay she came to me as her mentor then she told me that this is what is happening and I said what did you do about it or what did I teach you about such a situation, you have to report this to your trusted adult, so for you to tell me means you have trusted me, so if he does that again, I will know what action to take but he never did it again, what did you do, she said I screamed and then my auntie heard and come out then she asked what was happening... At least now they can voice out if anything bad happens to them. (Mentor, Ndola)

One mentor described how she taught younger girls about Statutory Rape regarding sex with minors, and their legal rights.

We tell them that you are still young, like I said am dealing with ages between 10 to 14 years, so I would say you are still a child... It is better you refuse to have sex and go to school. We tell them when you finish school in future you will get good men... Others would say we have not started because we are still young but others within the group would say "madam I had started (having sex) but I have now stopped because I have known that it is a bad thing to have a boyfriend when you are still young and since you have said it's a crime", so I would tell them to say when you are young and you have sex with a man, that person can be taken to jail because it is an offense because you yourself you are a government property so, if you are doing such a thing you should stop. (Mentor, Mumbwa)

One of the community leaders remarked on how the AGEP girls are noticeably more empowered than before.

These girls have learnt to know their rights of which they did not know at first, they now know what is right and wrong and they know how to respond when a man touches them.

(Community leader, Mumbwa) 
Girls themselves also described how they had been empowered and had learned to stand up for themselves, and learn to say 'no' when propositioned by men.

We were advised to respect ourselves and fear hanging out with boys even when approached by a sugar daddy, we should stand our ground and learn to say 'no'. (Girl, 15-21, SS+HV, Ndola)

One of the mentors described her own experience of rape when she was younger, which led to her having a child. At the time she did not know how to disclose the rape to her parents, and spoke of the difficulty in reporting these incidents, despite them being common. She commented that the girls in AGEP have been empowered and informed that they must report rape immediately, and seek necessary health care, instead of keeping quiet.

I will give an example of myself... when I was in grade ten in Zambia compound, there was a man who use to get along with my elder brother and he would call me most of the time to clean the house for him but what happened one day is that there were no people at our place so he called me to do the cleaning for him, when I finished he locked the door and raped me, I had my first born not because I wanted... It is common only that we are usually not aware about it, when the girls are raped it is usually difficult to report like what happened to me I didn't know where to start from to tell my parents and in most cases people think one just agrees to have sex but it is common... With these teachings am sure it can be prevented because we tell the girls that when a man uses his power to rape them, they should immediately report to their parents or any trust adult or even me their mentor and not wait for days and the clothes during rape should not be removed. The girls should also go to the clinic where they should be tested for pregnancy or any disease. (Mentor, Solwezi)

\subsection{Self-Esteem / Self-confidence}

Adult respondents were asked to comment on whether they had noticed any changes in AGEP girls' confidence in themselves, or changes in the way that they feel about themselves. In general, respondents remarked on noticeably increased self-confidence and self-belief in the girls who were part of the programme.

\subsubsection{Improved self-esteem / self-confidence}

The programme mentors from across the study sites gave feedback on the changes in the AGEP girls' attitudes and levels of self-confidence and self-esteem, giving examples of some of the girls in their groups. They shared scenarios in which girls who had previously had low self-esteem and were unmotivated to finish school had developed a sense of selfworth and self-belief which prompted them to decide to finish their education.

(One girl) had a negative attitude towards life and she was convinced she would never amount to anything because she is old for her grade, she is a 19-year-old, in grade 6. This would discourage and worry her often and slowly she started to pull back from school and she started contemplating marriage. But through her participation in AGEP, her mind-set has been transformed and she has decided to continue with her education so that she can have a better future. She has stopped looking down on herself and even the other young ladies have a new confidence in themselves and even when things are hard they encourage themselves.

(Mentor, Ndola)

Despite most of them not being in formal education, they have become literate and sharp because of AGEP... they are not shy compared to other girls, their self-esteem is high, if they don't understand anything they are very free to ask unlike those that are not part of AGEP they may even find it hard to look at into the eyes of the stranger, because they lack self-esteem. (Mentor, Solwezi) 
As well as being more confident, girls were described as now being more articulate.

AGEP has contributed to the confidence that the girls have, the girls in the first place when they were bought on the programme, they never used to have confidence, you could ask a question, you would want to interact with the girls but they never had the confidence to articulate or just to explain issues even how to handle issues, but as the programme continued, when we were six months into the programme, their confidence started showing and you could see that the girls were free to even share information that in the beginning they could not even share. (Mentor, Mumbwa)

One mentor believed that the act of gathering together with other girls of a similar age in the Safe Spaces meetings gave the girls a sense of companionship and community, reducing their social isolation.

Safe space has been so useful to the girls... just the gathering itself, the interaction the girls used to have, it has made the girls to at least gain on their esteem. I would say that the girls used to have low self-esteem but due to the interactions they have made friends, they have come to realise that they are not isolated any more as they used to be so this time the girls seem to be having high self-esteem in themselves. (Mumbwa, mentor)

In support of the mentors' views, AGEP girls themselves shared their views on how their involvement with the programme had improved their self-esteem, and made them happier.

It has definitely changed my confidence... at the Safe Spaces we are instilled with so much self -esteem, even if someone annoyed you at home when you get to the Safe Spaces you feel better... when you get there your mentor will start to give you different lessons in the process she will make you laugh about something or put you on the right path. (Girl, 15-21, SS+HV+SA, Ndola)

Girls expressed a newfound sense of self-worth and self-belief.

Before I joined Safe Spaces I was not very confident and I never used to feel good about myself. (Mumbwa, Girl 12-14, SS+HV+SA)

I have changed, I love myself... I also have confidence; I know that I can also do something that would impress people... Before I joined AGEP people used to laugh at me, they would say (I was) ugly, and will never amount to anything in this world but after they taught me at AGEP that I am somebody, so I know that even if they tell me that I will never amount to anything, I know what I am and what I can be. (Girl, 18-21, SS+HV+SA, Ndola)

One girl said that she now knows how to stand up for what she believes in, and be more assertive.

(AGEP) made me to have confidence... we were taught how we can be strong and never to give up easily, and also to believe in myself... I used to be very shy and I had fear, I couldn't come out in open and express myself, thinking that they will look down on me and maybe think that what I am saying is not true. But the time I joined AGEP I came to understand that I have to defend what I know, whether they believe me or not I will say it... At AGEP we learn how to relate with everyone, not only friends but like I said even parents. (Girl, 12-17, SS+HV+SA, Mumbwa)

Girls were more independent and empowered to speak for themselves, rather than relying on elders.

When there is a problem I used to tell my mother but now I have stopped I just speak for myself. (Girl, 12-14, SS+HV, Mumbwa)

The new girls' improved self-confidence helped them in their school participation: 
Because of this self-esteem am able to raise my hand in class and give answers but way back I never used to do that thinking that if I give the wrong answer my friends will laugh at me. (Girl, 12-17, SS+HV+SA, Mumbwa)

One of the mentors suggested that girls who had dropped out of AGEP missed out and did not receive all the benefits, such as building self-confidence, that the girls who stayed in the programme received.

The girls that we started with and are still in the programme, they have developed that confidence, but for those that were not consistent have not developed that confidence because they missed a lot of valuable lessons. (Mentor, Ndola)

The theme of shifting cultural norms and expectations emerged in a comment made by a community leader from one of the urban study sites, in relation to how the girl's newfound self-confidence was sometimes seen as a challenge to traditional gender roles of women being subservient to men.

(AGEP girls) are more confident because they have got this information... the community will expect that a girl should not be confident... so when you come out with that confidence it is like you are challenging the community. But ultimately that is what we want, a confident girl who is going to say no to mans approach... for me I think, it is good. (Chipata / Chazanga Community Leader)

\section{Agency and Decision-making}

Hand in hand with improved self-esteem and self-confidence amongst the AGEP girls, the programme also endeavoured to empower girls to make their own decisions about their lives, their health, their futures, and their education.

(AGEP girls can make decisions) because these decisions come from what we are being taught and those that are not part of AGEP don't know anything. (Girl, 19, SS Only, Solwezi)

One of the mentors from an urban area described how according to existing Zambian cultural norms, young girls are not traditionally empowered and do not have the agency to make decisions about their own lives, but have to obey parents.

Most girls used to be intimidated, looking at the tradition and culture in Zambia, mostly girls can't make decisions on their own especially concerning education and ambitions, once parents tell you what they want you to study when you complete school that was it, you have to abide by it no argument, even when you don't have interest. But through this programme the girls have been given an opportunity to choose the career of their choice something they will be able to do willingly and enjoy. Some people would disagree with this but I do think the girls are able to make their own decisions... especially for those (AGEP girls) who have been taught, they are able to make their own decisions, but those who haven't, are (still) unable to. (Mentor, Ndola)

In describing whom they sought support from in terms of making decisions, both AGEP girls and those in the control group cited their parents, guardians, elder siblings, teachers and friends. Comments from both the AGEP girls and mentors themselves also suggested that AGEP mentors play a supportive role in girls' decision-making.

As a mentor I help them a lot to make decision most of the times about these issues because I most of the times interact with them. You know these girls even if they have their parents or their mothers they can't open up to them if they have problems they would rather open up to me. (Mentor, Solwezi)

Not all girls felt able to make their own decisions; some girls explained that they need help from their parents. 
You can't manage (to make decisions on your own), if your parents can't think for you, you cannot manage on your own. You simply cannot manage on your own because you need to inform your parents about what you want to do. In terms of saving money, you can ask them to save for you and give you part of the money. Otherwise one cannot manage on your own... I can think for myself but I need to involve my mother, I can't do things on my own. (Girl, 15-21, $\mathrm{SS}+\mathrm{HV}$, Ndola)

\subsubsection{Control group girls: Self-confidence, agency \& decision-making}

Girls in the control groups were also asked about their levels of self-esteem and selfconfidence. Notably, in the interviews with control group girls, many of the girls did not appear to understand what 'self-confidence' and 'self-esteem' were. However, some of the control group girls who did understand the terms said they felt that they had good selfconfidence.

When I am at school and I get pointed at so that I read. I do stand up with confidence and read because I know that I know how to read... I also have confidence when it comes to church issues, since I sing in the praise team; I sing confidently because I have a nice voice, such that I can sing in any group. (Girl, 12-17, Control group, Solwezi)

Some of the control group girls also displayed traits and aspirations that the AGEP girls had learned. Some of the control girls were also able to make their own decisions, wanted to complete school and have a career.

I am capable of making my own decisions when it comes to school issues because I know that it will help me have a brighter future... When I complete school I want to become a nurse and whenever I see a nurse, I get inspired to concentrate on my education. I want to have a better life like those who are working, that's why I make certain decisions. (Girl, 18-21, Control group, Solwezi)

In the place of mentors, some of the girls in the control group sought advice and support from their school teachers.

(Teachers) give advice about how to look after yourself and stay away from bad influence as well as how to not spend money carelessly. (Girl, 12-17, Control group, Mumbwa)

(Teachers can support) by helping me in some areas which are not ok. (Girl, 18-21, Control group, Chipata / Chazanga)

\subsubsection{Life goals and 'Dreaming Big'}

Under the life goals, social support and agency section of the interview guide, all the girls were asked a series of questions on their thoughts and aspirations on completing school, getting married and having children. The sections on life goals and aspirations have been divided into their respective topic areas of education (school completion aspirations), and relationships (marriage and child-bearing).

One of the main topic areas covered in the Safe Spaces curriculum regarded aspirations for the future, and planning in order to achieve these goals.

We also learnt about goals; you need to know your goals in life and plan how you are going to achieve them. For example if you are in school, your goal is to complete school that would be your destiny, you need to plan how you are going to attain this... We have also learnt a lot 
although most of the girls just come to waste time, they do not know their aspirations in life. I for one have learnt a lot of things that I did not know about, I have learnt how to manage my life in a way that will be beneficial to me in the future. (Girl, 15-21, SS Only, Ndola)

One of the mentors described how girls in the programme were encouraged to believe in themselves and their potential, to 'dream big', and have high aspirations for their futures.

The time we were teaching about financial education we were talking about 'dream big', they would start talking about what they want to be, some would say I want to be a pilot... others would say I want to be a doctor... others would say I want to be the headmaster. (Mentor, Mumbwa) 


\section{HEALTH}

Components relating to health were a major part of the AGEP programme. The Safe Spaces curriculum covered many aspects relating to health; the two main areas related to nutrition and sexual and reproductive health. In addition there was the Health Voucher arm of the intervention

\subsection{Health Knowledge}

In Safe Spaces, girls were provided with health information, encouraged to look after their own health, and make healthy decisions.

I think about not getting involved in destructive behaviour that could lead me to contracting STIs. (Girl, 15-19, SS+HV+SA, Ndola)

\subsubsection{Nutrition}

Learning about good nutrition, how to have a healthy balanced diet, and how to prepare and cook healthy meals was one aspect of Safe Spaces that the girls benefited from. Mentors explained that previously, girls had demonstrated poor knowledge about nutrition and healthy eating.

They learnt a lot also on nutrition because we had a manual on that, so they learnt on how they can have a balanced diet. With some you would find that they don't know the kind of food. So from this they learnt that it's important to have a balanced diet. They learnt things like cooking porridge mixed with pound groundnuts, which is very nutritious and balanced. (Mentor, Chipata / Chazanga)

As anaemia is a common health issue amongst young women, the girls were educated on how to improve their diets to avoid the risks associated with, or treat, anaemia, particularly during menstruation.

Nutrition, because these girls had stopped eating vegetables, I asked them to say do you know how anaemia comes, it's when you don't have enough blood, we girls have menstruations, our monthly periods, so if we don't retain the blood in our bodies, we will be having little blood, that is why anaemia is very common in adolescents, yes, I was taught them on nutrition. (Mentor, Ndola)

Girls gained knowledge regarding good nutrition for themselves, as well as good nutrition for their babies and children.

They taught us that when a baby is born, you are not supposed to give her food until she is 6 months. (Girl, 15- 21, SS only, Mumbwa)

\subsubsection{HIV knowledge}

HIV was also one of the major topics on the curriculum, and girls learned about how HIV and other STIs are transmitted. From girls' narratives and statements it seems that knowledge levels concerning HIV transmission were poor before the programme.

I learnt how one may get HIV, they taught us that HIV is contracted when you are having sex with someone who is HIV positive without using protection. (Girl, 15-21, SS Only, Mumbwa)

I have learnt not to be too clingy to guys because they can impregnate you and infect you with HIV... Another thing is HIV/AIDS, not using the same sharp objects because you may not know 
that one is HIV positive and use the same maybe razor blade... I have just learnt a lot of things about life, and also how to take care of myself. (Girl, 12-14, SS+HV, Ndola)

I was taught about using a condom every time we have sex and in a case where your friend has a fresh wound and you do too and you kiss then in that manner you can get sick. (Girl, 1214, SS+HV+SA, Chipata / Chazanga)

Some of the girls in the control group demonstrated that they also had some knowledge about the ways in which HIV can be transmitted. It would appear that some of them had gained this knowledge through being involved with other NGO programmes.

(The programme) has helped me not to contract HIV/AIDS and they have helped me to know that HIV/AIDS comes in so many ways like razor blades and when you go to school and ask for a razor blade when you go to school and ask for a razor blade and use it, you might get infected sharing a razor. HIV/AIDS does not only come through sleeping with boys but through other ways as well. (Girl, Control group, Chipata / Chazanga)

One mentor commented that although the girls were taught about the importance of not stigmatising people who have HIV, they were also taught that they should still be careful not to contract HIV. The issue of girls not being worried about getting HIV because they can take ARVs has been raised elsewhere, and has been cited as a consequence of efforts to de-stigmatise HIV. The fact that HIV-infected individuals live a healthy, normal life on ARVs has meant that some young people are no longer concerned about HIV infection.

When you see the mentality that like it's not a big deal to contract HIV you can actually be on medication, if other people are on medication even you can do so, they had that mentality that you can date any man even if he was sick it's fine you will take ARVs, we taught them to change their mind set. We taught them that ART was not a justification to live recklessly, knowing that they can take ARVs later (Mentor, Ndola)

\section{HIV Stigma}

In addition to the girls being informed about the ways in which HIV can be transmitted, they were also taught that they shouldn't stigmatise people who are HIV positive, or fear that they could be infected through normal physical contact.

We learnt how to take care of a person who is HIV positive, we shouldn't be showing them or running away from them simply because they are sick, we need to show them love because we can't be infected just by being with them. (Girl, 12-17, SS+HV, Mumbwa)

When one is sick of diseases like HIV/AIDS or anaemia, you must not stigmatize, you must eat with them unlike what others do, and they separate them from these people. So the most important thing is to interact with them because they may feel bad if they are being isolated. (Girl, 18-21, SS Only, Chipata / Chazanga)

From what the mentors said, it would appear that before the programme, girls had inaccurate information about how HIV was transmitted, which had resulted in their stigmatising and avoiding contact with HIV positive people unnecessarily.

(The girls learned) how to communicate with people who are HIV positive, some of the girls testified that they used to fear sharing a cup with a person who is positive but I now know how to go about it (Mentor, Mumbwa)

Narratives suggest that there was increased awareness and compassion for those who are discriminated against and stigmatised for being HIV positive, as a result of the programme teachings.

When you have HIV/AIDS you will be shy to look your friend straight in the eye. You will look them in the eye for a few seconds and then look down, others will start refusing to sit with you, 
other friends start running away from you, and they hate you and they start singing songs about you and laughing at you (Girl, 12-17, SS+HV, Chipata / Chazanga)

However, some of the AGEP girls demonstrated that they still didn't have accurate understanding of how HIV can be transmitted, and perhaps had misinterpreted what they had been taught by AGEP.

If you are staying with someone who is HIV positive you don't have to eat from the same plate. (Girl, 13, SS+HV+SA, Mumbwa)

We learnt that when your friend is HIV positive, you do not need to stay very close because you can contract the virus (Girl, 12-14, SS+HV+SA, Ndola)

\subsubsection{Sexual and reproductive health}

Another of the topics covered in the curriculum was sexual and reproductive health. Girls were taught about contraceptives, how to avoid early unplanned pregnancies, and how to have safe sex.

It has equipped me good knowledge. For example, what I need to say when my boyfriend asks me for sex as well as the contraceptive and protective measures I can take when I want to be sexually active (Girl, 15-21, SS+HV+SA, Ndola)

We learnt a lot of things from there, that's the reason before I started using injectables we were using condoms (Girl, 15-21, SS+HV+SA, Mumbwa)

Girls learned about their own body processes, including their menstrual cycles and phases of fertility.

On health issues they now know, they have learnt about the life cycle, they now understand their cycle because most of them become of age at 10, and they start their menses so when they do that would they know how to go about it, they know how to take care of themselves and they even know that if they hang out with boys and they would get pregnant. (Mentor, Chipata / Chazanga)

We learnt that when you are having your monthly period you shouldn't have sex with a man because you can get pregnant. (Girl, 12-17, SS+HV, Mumbwa)

\section{Termination of Pregnancy}

The termination of pregnancy is currently legal in Zambia. The Safe Spaces curriculum covered aspects relating to the risks of unsafe abortion procedures, informing girls about the benefits of seeking formal health care at established health facilities for the termination of pregnancy. In illustration of this, one the mentors described how girls were advised to access termination of pregnancy services only in a proper health facility.

We were telling them about how they could have a safe abortion by going to the hospital and get an injection and accessing contraceptives. (Mentor, Mumbwa)

However, the narratives from many of the AGEP girls described how they had interpreted the teachings at Safe Spaces to be discouraging termination of pregnancy in the case of unplanned pregnancies. It may have been the case that despite the wording in the curriculum, the mentors were interpreting and teaching this topic in line with their own personal views and moral beliefs that were generally against the termination of pregnancy. 
We were told not to abort, abortion is a bad thing and those who abort can even die and you would have gained nothing, it would have been better for you to have a child than to abort. In fact if they know that you aborted they can even arrest you. (Girl, 12-17, SS+HV, Mumbwa)

If you do not take care of yourself, the end result could be HIV, pregnancy and maybe you try to abort the baby and that would be the end of you. Mostly we girls are victims because when such things happen we are the most vulnerable. (Girl, 15-21, SS Only, Ndola)

One of the mentors described her view that abortion was wrong:

They are taught here at AGEP about the consequences of abortion, even when she gets pregnant she already has an idea that abortion is bad because she learnt but for the one who is just at home they will just go ahead and do it because they do not know anything about abortion. (Mentor, Chipata / Chazanga)

Some of the girls commented that prior to the warnings by mentors at Safe Spaces, they would have terminated their pregnancies.

Before I became pregnant, we were taught that even if you are to become pregnant you are not supposed to abort it and that's the reason why I never aborted after I became pregnant had I not learnt from AGEP to tell the truth I would have aborted the pregnancy. (Girl, 18-21, SS+HV, Mumbwa)

\subsection{Health Self-Efficacy}

One aspect of the interview related to health self-efficacy of the AGEP girls. One mentor described the way in which the AGEP girls have become more empowered, and in realising the importance of looking after their own health, persuade their boyfriends to go for HIV tests. She gave the example of one girl who decided to end her relationship because her boyfriend refused to go for a test.

Most of (the AGEP girls) ended their relationships and others who still have boyfriends would tell me to say I have a boyfriend yes but I know what to do with him, and some have even taken their boyfriends for VCT... (One) girl broke up with her boyfriend simply because he refused to go for VCT with her. (Mentor, Chipata / Chazanga)

Some of the AGEP girls explained that they are able to make better decisions about their own health than girls who are not involved with the programme, who are influenced by their friends to engage in risky behaviours.

(AGEP girls) can make the decisions compared to the ones who are not in safe space.... you find that they listen to theirs mentors and others don't but for those that are not with safe space just listen to what their prostitute friends tell them... that's what they listened to, So and so let's wear this, so and so let's go and do prostitution here and there and that's how you find people getting pregnant and contracting HIV. (Girl, 12-17, SS+HV, Chipata / Chazanga)

\subsubsection{Health-seeking behaviour}

During the interviews, AGEP girls in all the study arms were asked to comment on their use of health care services, and most specifically remark on any differences in their health seeking behaviours before and after joining the AGEP programme. Both AGEP girls and control group girls were asked if they had attended a clinic in the last six months, and if they had, what services they had sought, and their experiences of accessing these services. In these discussions about health seeking behaviour, the most commonly listed conditions for which girls sought health care included malaria, stomach-aches and diarrhoea, 
headaches, VCT and STI treatment, antenatal care, and chicken pox. However, many of the girls reported that they had not been to the clinic at all in the past six months.

\section{Reduced Fear in Seeking Health Services}

Many of the AGEP girls suggested that prior to being involved in the Safe Spaces programme, they had been reluctant to seek health care services, due to fear, embarrassment or dislike of clinics.

I used to feel shy going for the test at the clinic but now I'm no longer shy... It was very easy (to go to the clinic) because I was not shy. (Girl, 17, SS+HV, Solwezi)

I used to have phobia for the clinic thinking that when I go there they will give me a lot of medicines to take... I am no longer scared since they told us that when we go to the clinic they give us medicine which is meant to make us feel better and that if you are scared of taking medicine you can die. (Girl, 12-17, SS+HV+SA, Ndola)

Before I used to be scared but now am able to go to the clinic... Because they used to teach us that when you get sick you need to go to the clinic that's how I started going to the clinic till I got used and was no longer scared by the thought of going to the clinic. (Girl, 12-17, SS Only, Ndola)

Mentors echoed the sentiment above, explaining that when girls first joined the programme, they had been scared of going to clinics, and fearful of health care providers.

(The girls') confidence of going to the clinic has increased. They used to be scared before saying nurses would shout at people. I sometimes meet with the girls at the clinic and they tell me that they are not comfortable to seek medical attention (Mentor, Chipata / Chazanga)

In contrast to this, and demonstrating the effect of Safe Spaces in health seeking behaviour and confidence, some of the girls in the control group described their fear and reluctance in seeking health care services.

R: Going to the clinic, I don't have confidence unless to those who do mobile and they are doing just fine because even if you don't want, you are forced to do it.

I: Why don't you have confidence to go to the clinic?

$R$ : Because there a lot of things that happens there... like diseases and things that you wouldn't even want to see. (Girl, Control group, Chipata / Chazanga)

One key theme emerging from the data relating to health seeking was that the girls were taught in Safe Spaces that they should go to the clinic for regular well-being check-ups, including blood pressure, weight and HIV tests, not only when they are sick.

The things they have learnt (at Safe Spaces), that is what gives them confidence, when they sit they think to themselves, they taught us such things, so let me go to the clinic, to have myself examined or just check-ups so I know my status... because of what they learnt. (Mentor, Chipata / Chazanga)

We taught them that even if you are not sick you can still go to clinic just for check up, like temperature, BP and weight so that you know your health. (Mentor, Mumbwa)

Girls themselves echoed this, saying that they now know that they can go for regular checkups, rather than only seeking health care when ill.

AGEP has taught me that I can go to the clinic even when am not sick to seek for health services. (Girl, 15-21, SS+HV, Ndola) 
We learnt about the importance of going to the clinic. We used to go only when you are not feeling well but now we go for medical check-ups to see how your body is doing (Girl, 15-21, SS Only, Ndola)

(My confidence) has increased because they taught us the importance of going to the clinic when you are sick or just for general wellness. (Girl, 18-21, SS+HV+SA, Ndola)

As part of keeping themselves healthy, at Safe Spaces, girls were taught about the importance of going for regular HIV tests, especially if they were in sexual relationships.

I was teaching them that these boyfriends they have, you wouldn't know whether or not you are the only girlfriend or he has others, as a result, you find that he will infect you with different diseases. So if you... have a boyfriend, and you love each other... it is better... both of you go for VCT and (test for) all STDs. So that even when you are in that relationship, you are free. You need to go for family planning injections, so that you are safe. (Mentor, Chipata / Chazanga)

One of the mentors commented that due to traditional beliefs and cultural health practices, some women are reluctant to go to formal health facilities for services, especially for antenatal care. The mentor explained that AGEP girls are different.

Other girls did not even want to go to the clinic to access family planning, even anti-natal because of their traditional beliefs, but now the (AGEP) girls access the clinic each time they are not feeling well, they definitely go to the clinic. (Mentor, Mumbwa)

One mentor explained that girls were advised to seek emergency care in situations where they had miscarriages, instead of staying at home, where there was risk of complications.

We taught them that in case you had a miscarriage, not an intended abortion, you cannot stay home because they need to be cleaned to avoid being septic. So there is that fear and that is why they now have confidence. (Mentor, Chipata / Chazanga)

Mentors explained that girls had also been taught to seek health services if they had any STI symptoms, instead of ignoring them.

Before what they used to think is that when they have rash on their private parts it's normal, they would just scratch and when it disappears, they forget about it, they don't think of going to the clinic but after we taught them that when you find yourself with rash on your private parts you have to go to the clinic that's when most of the knew that when they have that problem they have to run to the clinic (Mentor, Chipata / Chazanga)

We taught them the signs of sexually transmitted diseases. So when they see those signs, they rush to the clinic to be checked. So from this they gain confidence and rush to the hospital to get treatment (Mentor, Chipata / Chazanga)

Some of the mentors described how girls in the community who don't have access to sanitary pads go the clinic to get cotton wool to use for menstrual management.

When they are menstruating they go to the clinics to ask for cotton wool to use, you know in the village it's not everyone who can afford sanitary pads and also they go to the clinic when they are not feeling well they get medication on whatever sickness they are experiencing. (Mentor, Solwezi)

Some of the AGEP girls reported that they had improved their adherence to prescribed medicine regimes.

(Before AGEP) I just hated medicine and when I was given at the clinic, I never used to take that medicine but they taught us at AGEP that when they give you medicine at the clinic you need to take it, because they know what is wrong with you and they want you to get better. (Girl, 16, SS+HV, Ndola) 
Instead of the parents medicating their child at home, parents and AGEP girls have learned that it is better to seek formal health care.

We would even educate their parents. In most cases when a child is unwell, they opt to buy painkillers or self-medicate. But through the knowledge they have gained, even when she is unwell she will able to take herself to the clinic and seek medical attention as opposed to selfmedication. (Mentor, Ndola)

\subsubsection{Health vouchers}

Those girls who had been randomised to the arm of the intervention that received health vouchers were asked to comment on their experiences of using the vouchers at clinics, and any differences they noticed between accessing services with and without the vouchers.

\section{Positive Aspects of Health Vouchers}

Many of the girls who received health vouchers described how not having to pay for services improved their health seeking behaviour, reducing the barriers to accessing necessary health services and increasing their own confidence and independence in doing so.

My confidence (in getting healthcare) has grown because I now have a health voucher therefore I don't pay anything unless there are no drugs then I have to buy my own. (Girl, 1217, SS+HV, Chipata / Chazanga)

Mentors supported this view, explaining that the health vouchers had made it much easier for the girls to access health services at the clinics, mostly as a result of not having to pay for health care.

The health voucher helped them a lot because (before) when they got to the clinic they had to buy a book... then when she goes to see the doctor and they write down the medicine that she needs. (With a voucher) there was nothing like go and buy this and this type of medicine and they give her a prescription, the medicine was readily available for them for free, so that really helped them a lot. Even when it came to the private clinics where they had to pay a huge amount of money to be attended to, maybe she needs to pay a lot of money to be treated for the problem she has, if she has a health voucher, she was treated free of charge then Population Council would pay, so that used to help them a lot. (Mentor, Chipata / Chazanga)

I can say that now it's easy because they have the health voucher... because it's free they do not have to buy a book so it's easy, they are given the books and everything than before were they would have to look for K1.00 to buy a book so that would be a problem and they would end up just prescribing medicine for themselves and getting from the chemists. (Mentor, Ndola)

AGEP girls spoke of the way in which they received special treatment when attending the clinic. They would be given preference over other patients when they presented their health vouchers.

I am very confident (to seek health services)... It was easy for me because I have a health voucher, so they attended to me and give me the medicine... (without the voucher) it would have been a bit slow and they would have asked me to buy some of the medicines... they attend better to us now that we have the voucher and we are given all the meds that we need unlike before when we didn't have the voucher, they would even shout at us. (Girl, 18-21, $S S+H V+S A$, Ndola)

When I went without a paper (health voucher) they never paid attention to me compared when I went with the paper. (Girl, 16, SS+HV+SA, Solwezi) 
One common theme related to the benefits of health vouchers was that the girls in this arm of the intervention didn't have to queue at the clinic when they had health vouchers, which improved their health seeking experience, and made them more willing to go to the clinic. Narratives of this nature were apparent across the study sites.

When we were given cards (vouchers), we never had to queue up, we just used to go straight to be attended to and we were very happy. (Girl, 18-21, SS+HV, Chipata / Chazanga)

They gave us vouchers to use when we go to the clinic and I used the same voucher and I was given medicine... I wouldn't have gone there (without the voucher) because I was not going to afford being on the queue but when I went with the voucher, I didn't have to stand in a queue... (Before) I went there without a voucher I just went with a book and when you present your book, you wait to be called... That was before we were given (vouchers)... It (voucher) has really helped me because I don't even have to make a queue when I go to the clinic.... when you go with a voucher, there is no need for you to make a queue especially when you are very sick. (Girl, 16, SS+HV, Ndola)

The other thing that made it easy was because of the vouchers that we were given so upon seeing those vouchers, they had to attend to me so quickly. (Girl, 17, SS+HV, Solwezi)

Long queues at the clinic were cited as a barrier to accessing health care, affecting willingness to seek health services. The girls explained that the vouchers, in enabling them to skip the queues, meant that they could be in and out of the clinic quickly, instead of spending all day there, as was the case before.

(Before AGEP) I never had confidence (to go to the clinic) because I used to take time to get out from there, I would go there in the morning and come back in the evening, so, that never used to give me confidence of going to the clinic... (My confidence) has increased because nowadays when I go to the clinic, the moment I arrive they would stop working on other patients and attend to me first as long as they have known am coming from AGEP then just within few minutes I would be out of that place that's when they would continue seeing other patients (Girl, 12-17, SS+HV+SA, Mumbwa)

When I am not feeling well, I just think of going to one of the clinics that we were told... When you go there, you just show them your health voucher and they attend to you no matter how crowded it is, you jump the queue and you are attended to very quickly and you leave. (Girl, 1521, SS+HV+SA, Mumbwa)

When I didn't have a health voucher we used to have difficulties when we go to the clinic, you would find that you go there and you find a very long queue and they would shout at us and we would come back without being given any medication... Now when we go they take good care of us and put us on treatment and make sure they check everything to make sure all is well and give us treatment (Girl, 12-17, SS+HV, Chipata / Chazanga)

Some of the girls commented that having a health voucher had given them more independence when it came to accessing health care, and that they were now confident to go to the clinic on their own, without a parent or guardian.

Because of the same AGEP card that I was given... (Before) my mother was going to take me there (to the clinic)... now that I have (a voucher), my mother told me that I should be going there alone... When I'm sick, I am able to just go alone because I know that I have a voucher (Girl, 14, SS+HV+SA, Solwezi)

Comments from the mentors echoed the sentiment that the health vouchers resulted in the girls being given special attention and treatment at the clinics.

Their (AGEP girls) confidence has increased because they never use to go to the clinics where they have been registered, especially because going to the clinic these days requires money. This time around they are feeling nice because they use the health vouchers and get the medicine unlike in the past when they had fear... it has been easy because even when they 
find a lot of people at the clinic they welcome them and attend to them when they present either the health vouchers. (Mentor, Solwezi)

Before (the AGEP girls) had the health voucher they were just treated like other patients but when they had the health voucher they treat them in a special way, because they knew that they are on the programme and the clinic was aware. (Mentor, Ndola)

One mentor explained that the simple fact of having a health voucher made some of the girls more confident about accessing health care.

(The voucher) helped them because it makes them feel important, there are some that don't even have that but some just feel good because they have the voucher they say me I go to the clinic with my own book, the doctor sees me. (Mentor, Ndola)

\section{Negative Aspects of Vouchers}

When asked how the health vouchers could be improved, one of the mentors said that the vouchers don't currently cater for all types of health care, which is restrictive.

The health voucher does not cater for problems like the eyes, bones even if the girl had a lump somewhere, the voucher does not cater for that, the girl cannot be admitted at the clinic, so if they can just include all those things then it can be easier, because the way I know it, it caters for things like headache, flu, stomach, check your weight and all that. In the event that you have to be referred to a bigger hospital, the voucher will not be accepted there, thereby causing a challenge to access treatment. (Mentor, Ndola)

\subsubsection{Barriers to accessing health services}

One barrier to girls accessing health services cited by respondents was that for some of them, particularly those in the rural areas, the nearest health facility was very far away from their homes, and transport was an issue. Two respondents from the Mumbwa site mentioned this as a problem.

It is very far from here so distance is the barrier it is affecting them very much. (Mentor, Mumbwa)

The problem is with transport, the clinics are very far away. (Girl, 18-21, SS+HV+SA, Mumbwa)

One girl spoke of how she was unable to find the time to seek health care because of her responsibilities at home.

(My family) refused me to go (to the clinic) because there was too much work to be done at home... I had flu and a cough... every time I want to go to the clinic, they refuse me at home and say there will be no one to do chores. The family is only agreeable to me going to the hospital when they see for themselves just how seriously ill I am. (Girl, 15-21, SS+HV+SA, Mumbwa)

In support of the narratives above from the AGEP girls who received health vouchers that they didn't have to queue for health services, some of the girls in the control group complained about queues at health facilities being one factor in their reluctance to seek health services.

I cannot even remember the last time I went to the hospital... Hospitals irritate me, the queues and everything, I hate them. (Girl, 15-21, Control group, Ndola)

One community leader described conservative community attitudes as a barrier to girls accessing contraceptives and family planning services. 
(Lack of access to contraceptives) is huge, that one is huge... you know the society, has made it so difficult for a young person to just make a decision to go (to access care)... even if in the clinic there is just somebody who is willing to provide condoms to a young person, contraceptives to a young person, they would still not feel comfortable to go there... because they still feel society has not yet come to a point where we accept that. There is still a problem you know (Community leader, Chipata / Chazanga)

One of the mentors at an urban site had a contrasting opinion to the view above, saying that contraceptives are widely and easily available to girls in their community, and lack of access is not an issue, and is no excuse for girls not using them.

There is plenty of those things (contraceptives) at the clinic... that wouldn't be an excuse because even if there is nothing at the clinic, there are found at the drug store and not expensive. One cannot fail to buy. (Mentor, Chipata / Chazanga) 


\section{EDUCATION}

Respondents were asked to describe the various ways in which AGEP had an impact on the education of young girls. Aspects covered under this topic included the educational benefits of AGEP, decision-making about education, girls' motivation to attend and complete school, and barriers to school attendance.

\subsection{Decision-making about Education}

In terms of making decisions about their education, some of the mentors explained that AGEP girls were generally aware of the importance of getting an education, and wanted to go to school.

When (AGEP girls) just wake up they know that they have to go to school even their parents are preventing them from going to school as you know there are parents who do not allow their children to go to school. If as a parent I don't allow my child to go to school but she has that will of knowing that she can make the decision of going to school, she will go because she knows it is the right thing. (Mentor, Solwezi)

Despite a desire to attend school, some of the girls, especially those in the younger age groups, explained that they do not have the agency or independence to make their own decisions about education; instead it is up to their parents to decide, as they are the ones paying school fees.

My parents are the ones who are making decisions for me because they are the ones paying for me in school... I don't think a child can make her own decision about anything to do with school... like myself, if there is need for me to go back to school, I would always ask from my mum that I want to go back to school and if she refuses then I have no option but to be at home and help with the house chores. (Girl, 12-17, SS+HV, Mumbwa)

\subsubsection{School attendance}

\section{Motivation to Attend School}

On the whole, AGEP girls' narratives suggested that they were very motivated to attend, and to complete school.

(AGEP) has helped me because they taught us that school is important, school can be your mother and father [meaning source of livelihood]... it helped me but the fact that they beat me at school and they beat me at home; it's not a good thing... that discourages me from going to school, like the school where I am, they shout at us a lot. (Girl, 12-17, SS+HV, Chipata / Chazanga)

Some of the girls remarked that they are more motivated to go to school since their involvement in the programme, and that their school attendance has improved.

I never use to adhere to what my mother would tell me... When she would question me as to why I never used to go to school, I gave no reason. But after I became part of AGEP I have started going to school. (Girl, 10-14, SS Only, Ndola)

Some of the girls explained that they felt that it is important to stay focused in order to finish school, and not get distracted by boys and friends.

Boys can make you lose your way. If you are not careful, he can ask you to quit school. But if you stay focused, you don't have to do what he asks you to do and you can continue going to 
school... if you are in bad company, those friends can advise you to stop school just as they have, but you need to know that having an education will give you a better future. (Girl, 10-14, sS Only, Ndola)

Some of the parents interviewed also had positive things to say about AGEP's effect on their daughters' studying habits and goals of school completion.

She concentrates more now on her school than before. (Parent, Ndola)

Now she knows that if I engage myself with such (bad) friends they will make me lose my concentration at school, she knows the kind of friends she is supposed to hang out with. (Parent, Chipata / Chazanga)

\subsubsection{School completion goals}

Under the life goals section of the interviews, girls were asked about their aspirations regarding finishing school. Generally those girls who were still at school expressed a desire to complete their education. Those girls who were not currently attending school talked about their interest to return to school and complete their education if given the opportunity to do so. Overall, the girls believed that their chances of completing their education was dependent on a combination of factors including personal motivation and will to do so; enabling financial circumstances; and support from parents/guardians, teachers, mentors, and friends and other support networks within the community.

Across the four AGEP sites all the currently 'in-school girls', whether in AGEP or in the control groups, expressed a desire to complete their high-schooling (attain Grade 12), and even pursue tertiary education, before going on to find employment.

I want to complete my grade 12, then go to college, and then start working. (Girl, 17, SS+HV, Solwezi)

\section{Motivations for completing school}

Reasons for wanting to complete school as described by girls in both the intervention arms and the control arms varied from wanting to support parents in future, attaining career goals and aspirations, earning an income and having personal ambition. One girl in the control group commented on how attaining an education opens doors for your future.

When you finish your schooling everything becomes easy. (Girl, 15, Control group, Solwezi)

Demonstrating the sense of familial responsibility amongst these young women, a number of the AGEP girls interviewed expressed a desire to complete school so that they could one day support their parents, guardians or other relatives. This view was especially apparent amongst girls in the two urban sites.

I want to complete school so that I can take care of my mother and my father... I want to work an office job so that I can take care of my mother. (Girl, 12-14, SS+HV+SA, Chipata / Chazanga).

I want complete high school then from there I want to go to college, and after college I want to start helping out my family. (Girl, 18-21, SS+HV+SA, Chipata / Chazanga)

Personally I would like to concentrate and complete my school so that someday I may look after my relatives. (Girl, 15-21, SS+HV, Ndola) 
Many girls, both those in the control group and intervention arms, and particularly those in the two rural sites, described how they were driven to do well at school by the career goals they had set for themselves. Some aspired to be nurses, others teachers and one girl said that she wanted to be a lawyer.

When I complete school I want to become a nurse. Whenever I see a nurse, I get inspired to concentrate on my education. I want to have a better life like those who are working. (Girl, 1821, Control group, Solwezi)

I want to complete my education, go to college and become a nurse. (Girl, 12-17, SS+HV+SA, Mumbwa)

I want to finish my grade 12 and then go to college and become a lawyer. (Girl, 12-17, SS+HV, Mumbwa)

I want to finish school and start working as a teacher. (Girl, 18-21, SS+HV+SA, Mumbwa)

The prospect of finishing school to some girls meant the possibility of finding a decent job, which ultimately meant the ability to earn a good income, be independent, and improve their lives.

I would like to finish school well so that in future I can be independent and start making my own money. (Girl, 15-21, SS Only, Mumbwa)

I know that if I don't finish school, I will suffer in future but if I continue with school and finish I will have a good life. (Girl, 12-17, Control group, Chipata / Chazanga)

A few girls of the girls were motivated to complete school by a sense of self-worth and belief in themselves.

I would love to complete... I go to school and never miss classes, I'm able to tell that what I am learning is beneficial, and because of this I can be able to pass my exams. This is how I know that I am doing well in my education and that someday I will be able to complete. (Girl, 15-21, SS+HV, Ndola)

Some girls showed that despite setbacks and demotivating factors such as being old for their grades, they were still motivated to finish school and achieve in life.

I want to finish school even if others are saying that I am too old to be in Grade 5, I want to finish school and go further. (Girl, 12-14, SS+HV+SA, Mumbwa)

\section{Barriers to Completing Education}

Data shows that in Zambia, people living in urban communities are more likely to attain higher levels of education e.g. Grade 12 school certificate, as compared to those in rural communities, many of whom drop out in junior secondary. The proportion of children of secondary school-going age (14-18) out of school in rural areas in 2014 was 30\%, compared to $24 \%$ in urban areas. Additionally, there is a marked gender disparity in educational attainment. In 2014, nearly $36 \%$ of female youth of secondary school age in Zambia were out of school compared to $19 \%$ of male youth of the same age (FHI360, 2014).

Respondents were asked to comment on the reasons why girls are often unable to complete their education. One commonly cited barrier to completing school that was identified by girls in both the control and intervention arms, in both urban and rural areas, relates to financial constraints. 
I think it's lack of money, since my mother does not work and it's only my father who works, he likes complaining that he has a lot of children to support. Sometimes he sends money for my school fees but sometimes he doesn't. I think it's just lack of financial support that can prevent me from completing my education. (Girl, 12-17, Control group, Solwezi)

A few girls also shared their fears of not being able to complete their schooling if their parents were to die, and they would be left without any support.

I can fail to complete my education if my parents were to die and I lack financial support (Girl, 18-21, SS+HV, Solwezi).

A number of the girls in both the AGEP groups and the control groups described how due to a lack of resources their parents or guardians were unable to pay school fees, or in some cases they had been orphaned. Some of the girls had been temporarily suspended from school due to unpaid school fees, or others had interrupted their schooling due to lack of money.

I had one girl... when she passed her grade nine exams to go into grade ten, her parents didn't give her the money and the people she is living with are just her guardians, they told her that we don't have money now but you will start school in the second term, so term one finished without her going to school, I used to ask her every time if she has started and she would say no I haven't, they are telling me that they don't have money so am still waiting. (Mentor, Chipata / Chazanga)

Next year if money will be found, since my dad doesn't have money, my young brother is in boarding school in Kafue, he told me that when he completes (he is writing grade 12 this year) that's when maybe I will go to school... I have not stopped it's just finances. (Girl, 18-21, Control group, Chipata / Chazanga)

Girls gave various reasons for dropping out of school. The most common reason was lack of finances, as cited above. The two quotes below come from girls at the urban study sites.

(I left school) in Grade 7... My parents don't have money to send me to school... It was never my decision... No one decided, but my parents do not have money to send me to school. (Girl, 15-21, SS Only, Chipata / Chazanga)

I dropped out in grade ten because there was no money for school fees. (Girl, 18-21, SS+HV+SA, Ndola)

Death of a parent, particularly the father, was another reason for girls having to drop out of school.

(I left school) in Grade one... There was no one to pay for my school fees, my dad died when I was still a kid. (Girl, 18-21, SS+HV, Chipata / Chazanga)

Another commonly cited reason for having to leave school before completion was pregnancy, amongst both AGEP and control girls.

(I left school) because I met this guy who impregnated me and that was how I stopped school. I stopped because I got pregnant. (Girl, 15-21, SS Only, Mumbwa)

I dropped out in grade 9... I got pregnant... The people who were paying for me refused to continue paying for me. (Girl, 15-21, Control group, Ndola)

One girl's narrative suggested that peer pressure played a part in her leaving school early. She explained that she dropped out of school because her friends did.

(I left school) in grade six... When I started school we were the four of us and my friends stopped and that's how I also stopped going there that I can't be going to school alone without my friends. (Girl, 15, SS+HV, Solwezi) 
One parent described how peer pressure and friends getting married was the reason that her daughter left school.

She used to go (to school) but when she saw that the friend got married, she also stopped going to school. (Parent, Solwezi)

Not being able to go to school negatively affected girls' self-esteem and happiness, as explained by this girl in one of the control groups.

The time I wanted to go to school the finances were not enough so that really affected me, I would see my friends go to school and I would just be home and I would be thinking like am behind and my friends are way ahead of me... I used to feel important with that vision of completing my education, but after the disturbance of my school I feel low. (Girl, 18-21, Control group, Chipata / Chazanga)

The three main reasons why girls had dropped out of school were finances, pregnancy, or lack of interest. Girls who dropped out of school due finances shared their interest and willingness to go back to school if money was made available.

I have been talking with my sister in law and am hoping that she takes me (pays for me to go) to school so that I can become a lawyer. (Girl, 18-21, SS+HV, Chipata / Chazanga)

Girls who had dropped out of school due to pregnancy had either decided to do it on their own accord, or the guardians had refused to continue to pay for their school fees once they were pregnant.

The people who were paying for me refused to continue paying for me. (Girl, 15-21, Control group, Ndola, 08)

Some girls who had dropped out of school for other reasons such as lack of interest said that they were now motivated by AGEP to go back to school.

It (motivation to go to school) has changed because I now know how to read and a lot of other things that have made me think about going back to school. (Girl, 15-21, SS Only, Mumbwa).

\section{Support Needed to Complete Education}

In order to achieve their goal of school completion, the girls indicated that they would need to get support from parents or guardians, siblings, friends, teachers and mentors.

Parents Overall the girls said that they relied on support from parents to pay their school fees and purchase books, stationery, uniform and shoes, without which they would not be able to complete their schooling.

They should help me by paying money for my school fees. (Girl, 18, SS+HV+SA, Solwezi)

Girls also felt that they needed advice and guidance from their parents in staying away from bad behaviours and focusing on school.

They should advise me to concentrate at school and not to involve myself in bad things. (Girl, 12-17, SS+HV+SA, Mumbwa)

Friends The majority of the girls interviewed suggested that their friends and peers could give them useful encouragement and inspiration to complete school. 
My friends can encourage me to continue with my education and finish in case I want to drop out, they can tell me to be strong and look at those that are driving it's because of school. (Girl, 12-17, SS Only, Chipata / Chazanga).

(Friends) can encourage me to pay attention at school and tell me the positive things about school. (Girl, 12-14, SS Only, Mumbwa)

Because we all go to school, we encourage each other about school work and how important it is to complete school. (Girl, 15-19, SS+HV+SA, Ndola)

A few girls commented that they could be inspired and motivated to study hard and achieve school completion by their friends who were in grades above them at school.

Friends can encourage me by inspiring me since they are ahead of me in terms of grades one of them is in grade 10 while the other one is in grade11 (Girl, 12-17, Control group, Solwezi)

However, friends and peers could also be a bad influence, as hanging around in bad company could result in a girl 'losing her way'. Therefore the girls said that it was important for one to be able to choose her friends wisely and make a personal decision to complete school.

If you are in bad company, those friends can advise you to stop school just as they have, but you need to know that having an education will give you a better future. (Girl, 10-14, SS Only, Ndola)

I always think about finishing school, not following my friends who do not go to school or my sister who is uneducated. I want to complete my studies. (Girl, 15-21, SS+HV, Ndola)

Although one of the girls who was no longer in school mentioned that some of her peers who had completed school made her feel intimidated, and negatively impacted her selfesteem.

I don't even want to be found with them, it's like because they have completed (school), they are special... I don't feel comfortable to be found with them sometimes. (Girl, 18-21, Control group, Chipata / Chazanga)

Partners/Husbands One married girl in a rural study site explained that her husband wanted her to go back to school and complete her education, and was willing to support her financially by paying her school fees. In this regard husbands can also play a role in school completion. On the other hand, in reference to short-term boyfriends, the girls indicated that boyfriends rarely encourage them to complete school but instead distract them from their school work. The challenge for the girl in the relationship is to stay focused on completing school.

Boys can make you lose your way. If you are not careful, he can ask you to quit school. But if you stay focused, you don't have to do what he asks you to do and you can continue going to school. (Girl, 10-14, SS Only, Ndola)

Mentors Programme girls spoke fondly of the additional support they had received from their mentors at AGEP. Mentors encouraged the girls, supported them to achieve their goals, and also gave them good advice.

The mentor has always encouraged us to work very hard and complete school and not sleep with boys, not to follow those who are just going after boys and terminating their pregnancies and not studying hard. (Girl, 12-14, SS+HV+SA, Mumbwa)

Mentors were telling us to concentrate very much on school. (Girl, 15-19, SS+HV, Mumbwa) 
(Mentors) usually tell us not to be so close with boys, but instead to study. (Girl, 12-17, SS Only, Chipata / Chazanga)

Teachers Comments from the girls suggested that school teachers also played a significant role in theirs hopes to complete education. They felt that by listening to their teachers and following their instructions they would have a better chance in completing their education. The role of teachers was especially prominent amongst the girls in the control groups, who unlike the AGEP girls, didn't have mentors to give advice, support and be role models. Narratives attesting to this were most prominent amongst girls from the rural study sites, Solwezi and Mumbwa:

I just concentrate on what my teachers are teaching me at school. (Girl, 12-17, Control group, Solwezi)

They give advice about how to look after yourself and stay away from bad influence as well as how to not spend money carelessly. (Girl, 12-17, Control group, Mumbwa)

The teachers always encourage me to finish school and be like them because they were also once like us. (Girl, 15, Control group, Solwezi).

(Teachers) can encourage us to work hard in school and desist us from playing around... Some girls like playing around with boys... if one gets pregnant then that can be the end of their education/ schooling. (Girl, 12-17, Control group, Solwezi)

Some of the AGEP girls also emphasized the importance of listening to and heeding their schoolteachers' advice.

I would want help form my teachers they can tell me how to live right and advise me on how to make my dreams come true. (Girl, 18-21, SS+HV+SA, Chipata / Chazanga).

Aside from support in school, the girls also spoke about other advice teachers could help them with, such as discouraging destructive behaviours, that would also assist them in their goal to complete their education. Notably, remarks from girls at the rural site Solwezi stood out most prominently:

Teachers just need to continue educating us on the need to take care of ourselves so that we don't get pregnant or get infected. (Girl, 18-21, SS Only, Solwezi).

(Teachers) can help me by telling me not to involve myself in prostitution. (Girl, 13, SS Only, Solwezi)

Programme girls in Solwezi said that besides listening to their teachers' advice they also needed their encouragement as well.

They can help me by encouraging me to concentrate at school. (Girl, 14, SS+HV+SA, Solwezi)

They should encourage me to concentrate on school so that I finish. (Girl, 14, SS+HV, Solwezi)

Girls also described how they needed their teachers to help them pass their exams in order to complete their education.

To be taught well so that I can pass my exams... and to be encouraged to continue with school and not give up. (Girl, 18-21, SS+HV, Chipata / Chazanga)

A few AGEP girls mentioned that they viewed their teachers as role models and provided them with an example of something to aim towards. 
They can encourage me to work hard since he/she is a teacher also. (Girl, 12-17, SS Only, Chipata / Chazanga)

Other sources of support A few girls mentioned that help and support from their parents was not sufficient. They believed that they would benefit from additional help from both government and non-governmental organisations such as the Population Council and FAWEZA, amongst others.

Things have been rough for me, but I would like others to help me. My parents are getting old and money is a problem. If I pass well, maybe even the government can come in. (Girl, 15-21, SS Only, Ndola).

An organization known as SOS... They encourage me to pay attention at school, and also just take note of how we live. (Girl, 15-21, SS Only, Chipata / Chazanga)

One girl mentioned that the sponsorship she was receiving at her school would ensure that she could complete her education.

The school that I go to, we are fully sponsored by whites and they will continue sponsoring us through even at college. (Girl, 12-17, Control group, Ndola)

One of the girls in the control group mentioned how she is inspired to work hard by looking at others in the community around her. Self-motivation can also be one way a girl can support herself in attaining her goals.

When I go to town I admire how people have made it big in life and that has inspired me to concentrate at school and change my confidence levels. (Girl, 18-21, Control group, Solwezi)

Support from other elders in the community such as neighbours could also help a girl completing her education. One girl explained that her neighbour was able to help her financially when her parents didn't have money to pay for her school fees.

At one time my parents didn't have money to pay for my school fees so our neighbour sacrificed to pay for me and that's how I started going to school. (Girl, 16, SS+HV, Ndola)

\subsection{Effects of AGEP on Education}

One of the key themes emerging in relation to the benefits of AGEP related to the learning and knowledge gains.

In the past I never knew a lot of things, but now with the knowledge I get from AGEP I have now learnt a lot am even able to teach others. (Girl, 16, SS+HV, Solwezi)

Many of the AGEP girls made remarks relating to how they were far more knowledgeable than their peers who hadn't attended Safe Spaces. Some of the adult respondents suggested that AGEP girls were now able to share what they had learnt with other girls who were not part of the programme.

She can even try to help others who are not in AGEP even though they might be hostile at first but in the long run they will learn from the child who has been tried by AGEP... those that are in AGEP can help out others with the knowledge they have attained (Community leader, Ndola) 


\section{Importance of Education}

One key theme that ran through the qualitative data related to the way in which AGEP encouraged school attendance, taught girls the importance of gaining a good education, and completing school.

We were taught a lot of things in Safe Spaces, we need to work hard and concentrate on school so that we can achieve our goals for sure. (Girl, 12-17, SS + HV, Chipata / Chazanga)

AGEP emphasised the importance of getting an education so that you can be independent, look after yourself, educate your children and provide for your family.

Those in AGEP are able to understand... we have taught them the reasons importance of going back to school and the importance of going to school, I have been giving them my example, if it wasn't for my parents taking me to school this time I wouldn't have been a mentor or I wouldn't have been supporting myself, like I do everything for myself, I take my son to school despite the dad not being there but at least am able to do everything myself. (Mentor, Mumbwa)

One mentor explained that she had told girls the importance of literacy, even for those not in formal education.

I tell them that nowadays if you are not educated then you are nothing, even those who are not in formal school I encourage them to at least know how to read and write if they would like to be better citizens of the community. (Mentor, Solwezi)

Some of the girls described the way in which all the things they had learned through AGEP had made them happier, with a more positive outlook on life.

I have learnt a lot about things I did not know, how we are supposed to live and conduct myself... When you go for AGEP, your mood automatically changes because you are with people that motivate you and help you to stay positive in life. Even if you went sad, you will be happy and you stop worrying... AGEP is just the best because we learn so much about a lot of things, it has improved our lives. (Girl, 15-21, SS+HV+SA, Mumbwa)

\section{Effect of AGEP on School Completion Goals}

AGEP girls shared their personal experiences of how their participation in the programme had significantly contributed to their interest in and attention at school, improved their study habits and class attendance.

I used to be absent from school but since I started coming to AGEP, I have stopped. (Girl, 1217, SS Only, Chipata / Chazanga)

When she (mother) would question me as to why I never used to go to school, I gave no reason. But after I became part of AGEP I have started going to school. (Girl, 10-14, SS Only, Ndola)

Part of this new motivation to attend school was that some of the curriculum in Safe Spaces overlapped with the school curriculum, and girls felt that they better understood some of the subjects, which made them more motivated to attend school.

I am now able to understand what we learn at school and that is motivating me not to miss school. (Girl, 15, SS+HV+SA, Solwezi)

According to some of the AGEP girls, their participation in the programme broadened their horizons, boosting their self-esteem and improving the way girls think about their future in light of school completion. 
I learnt that when you dream in the future you can become what you want to be a doctor, nurse or police officer. (Girl, 12-14, SS+HV+SA, Mumbwa)

Some of the topics taught during Safe Spaces such as 'setting goals' were also seen as contributing to girls' vision towards school completion.

We were taught a lot of things in Safe Spaces, we need to work hard and concentrate on school so that we can achieve our goals for sure. (Girl, 12-17, SS+HV, Chipata / Chazanga)

Lessons learned from AGEP also contributed to the girl's decision-making processes on how to prioritise their time, improve study habits, and highlight the importance of school completion.

They teach us to be reading and reading a lot since we are 7 th graders and not just to play after school. (Girl, 12-14, SS+HV, Mumbwa)

We never used to pay attention to school or study but we were encouraged on the importance of school. (Girl, 15-19, SS+HV, Mumbwa)

Mentors interviewed said they had personally seen how participation in AGEP had influenced girls' class attendance and motivation to complete school. In the case where girls got pregnant, they were encouraged to continue with their education. One mentor shared her experience of how one of her pregnant girls had sought help from her to get back into school.

AGEP encourages the girls to go to school, so I have seen that, I can give an example of this girl, she got pregnant and after delivering she came back and she was like no I appreciate what you taught us, I have realised that school is important even if I stayed home I can never take care of this child, she was like no, I want you to help me get a space in school because my mother has accepted to remain with my child as I go to school, so she managed to get a place in Lusaka. (Mentor, Ndola)

Two of the mentors from the rural site Mumbwa also explained the way in which AGEP girls were encouraged to abstain from sex so that they could focus on their studies.

There are some girls who would stop coming for these classes when they became pregnant or aborted. But at AGEP we would have topics, like you need to continue with school it doesn't end, school helps you to develop your career, so that you become what you want either doctor, nurse, teacher... from these topics most of them came to realise that it's better to abstain so that you are able to complete your school, because once you are educated you will be able to take care of your parents or other people in the community in future, so from that they were able to develop interest to say I can never stop going to AGEP because it will help me in the future. (Mentor, Mumbwa)

One of the head teachers... she announced that AGEP has really contributed to the school attendance because for the girls that are on AGEP it was rare that they could find that a girl would miss for more than five times in a term. Because for the girls in Safe Spaces... the girls really thought that it was really important out of the sessions that they have learnt at AGEP that going to school is the only key that is going to help them succeed in life, it has made them to work hard at school and it has also made them to realise that it's only a class room school environment that can make them to achieve their goals. (Mentor, Mumbwa)

One mentor described how one girl who had joined AGEP when she 19 years old and was only in grade 6 at school had felt very discouraged and had contemplated giving up on school. Through the life skills sessions she had been encouraged and built up confidence to complete her education despite her circumstances. 
Through her participation in AGEP, her mind-set has been transformed and she has decided to continue with her education so that she can have a better future. (Mentor, Ndola)

\section{FINANCE}

Financial literacy was one of the major topic areas covered under the Safe Spaces curriculum. Aspects covered included earning, saving, banking, budgeting and spending money. One of the mentors commented that generally people in the community have poor knowledge about how to manage their personal finances wisely.

People in my community seemed as though they do not make any money, when it actuality most of them look poor because of mismanagement. (Mentor, Ndola)

\subsubsection{Saving}

One aspect that the respondents were asked about related to the AGEP girls and money; the way they earned, spent, and saved money, and how these financial matters affected other areas of their lives, including relationships with others and self-esteem.

\section{Changes in Saving Behaviour}

Some of the mentors commented that prior to their involvement with AGEP, the girls lacked financial literacy and didn't know how to save.

(Before AGEP, girls) never used to save... most people in the community have money but lack knowledge on how well to spend it just as most of the girls before AGEP would have money but didn't know how to budget and prioritise. But now through the AGEP programme some know and they are saving, especially those that are orphaned, through saving they are able to buy for themselves anything they might need for school such as work and textbooks. Before this however, if they didn't have money for school requirements they would choose to stay home and depend solely on their providers and if they also don't have money, then they would stay away from school. But now through saving they are able to buy any school necessities (Mentor, Ndola)

Most of them told me madam, (before AGEP) once we had money all we could think about is spending but after we learnt about choosing a saving goal, some even started up some small businesses... Before they would spend everything but now they are able to say if my mother gives me money for transport I saved it all and walked home with my friends. All this is to help them save for the day their parents will not have money (Mentor, Ndola)

In general girls themselves commented on how they never used to save money before joining AGEP, but afterwards had learnt the importance of saving.

(Before joining Safe Spaces) I didn't know about saving money all I knew was when I have money I need to use all of it... We were taught that we need to save because there are things that come as emergency and when you save you can be helped with the same money. (Girl, 20, SS+HV+SA, Chipata / Chazanga)

\section{Saving for Emergency}

One theme that emerged in many of the narratives was that girls had learned in Safe Spaces that one incentive for saving money is that savings could be used in case of 
emergencies, for example caring for sick family members or friends, or contributing funds towards a funeral.

I decide to save money because I know that it is important, for example my parents may not be home and my little sibling gets sick I can use the money that I have saved to take her to the clinic which is far from home. (Girl, 18-21, SS+HV, Solwezi)

When there is an emergency like a funeral then you contribute or maybe there is someone who is sick, you use that money and contribute if you have. (Girl, 12, SS Only, Ndola)

Before whenever I would have money I would spend all of it but now they taught as that we should be saving money for eventualities, maybe someone at home gets sick, we can use that money to help them sick medical attention, so I started saving money. (Girl, 12-17, SS Only, Ndola)

If you are given money, you can keep it until it is not because sometimes you would find that maybe your young one is sick and your parents do not have money, you can use the money that you saved... Other times when my grandfather gets sick, we use the same money to take him to the clinic. (Girl, 15-21, SS+HV, Ndola)

Another motivation for girls to save money was thinking about the possibility of there being a time in the future when their parents didn't have any money and there wasn't enough food at home.

When someone sends me to wash their dishes, they give me money and I keep it. It is important to keep money because sometimes there may be nothing to use at home and you can use the money that you saved. (Girl, 12-14, SS+HV, Ndola)

When (parents) don't have at home you help out for example if they don't have cooking oil, you can buy using the same money because you will all eat. (Girl, 17, SS+HV, Solwezi)

This improved earning and saving behaviour was directly attributed to AGEP.

One AGEP girl told me that she went to do some piece works for doing laundry, and when she went home there was no relish at home... So she got that money that she had saved, and gave it to her mother to buy relish. The mother asked where she got it from and she explained about the savings that she had learnt at AGEP, and how she came to be found with that money. (Mentor, Ndola)

One recurrent theme that emerged in relation to savings was that the girls were now able to contribute at home, reducing the financial burden on their parents. One of the mentors explained this:

Saving has helped them in their education, the use the money they save to buy books for them when the parents have a shortfall. They sometimes buy things like stockings soap to use when going to school and sometimes when they make enough money they help their parents with paying school fees even for one term. This has lessened their burden. (Mentor, Solwezi)

One commonly emerging theme was that AGEP girls had learned how to save money from working in order to buy things that they wanted, whereas before they would have just spent the money on useless small things and snacks.

\section{Control Group Girls' Saving Behaviours}

Some of the girls in the control groups also spoke of their money saving behaviours.

If there is anything I want to buy, I will need to make a decision to start saving so that I can manage or afford to buy what I want. (Girl, 12-17, Control group, Solwezi) 
Some of the girls in the control group also expressed sentiments similar to those of AGEP girls with regards to saving up money in case of an emergency that might arise, such as illhealth.

There are times when problems or emergencies (unexpected occurrences) befall us, that is the right time to use some of the money... For instance, I may have a problem were a friend might fall ill. It may happen that there is no medicine; at that particular moment I can use my money to buy medicine for her. (Girl, 18-21, Control group, Solwezi)

\subsubsection{Earning an income}

Mentors gave the girls in their Safe Spaces groups advice on earning an income of their own, and various suggestions for ways in which to earn.

There are stories [in the curriculum] like Monica's story, where she started a small business and she started saving. I told them that you need to follow the season, for example this season people are want cassava and ground nuts, so just get cassava and ground nuts and start selling. That's good money. It's hot right now so you can even sell ice blocks, that money is your money. When you are saving money problems become less. For example if you have an emergency, maybe someone at home gets sick, or you don't have mealie meal. I would even joke with them telling them that begging for mealie meal is embracing and they would laugh, I would tell them that you can buy a small plastic of mealie meal if your parents don't have money at that point in time, you can sell ice blocks you can get money from there and buy mealie meal and vegetables. (Mentor, Ndola)

I used to tell them, that living like that is not a good thing. I used to tell them that they should learn how to do small business, when it is season for groundnuts they should be selling fried ones same with maize. (Mentor, Mumbwa)

AGEP girls learned how to be creative and inventive with income-earning opportunities in order to support themselves and have money to save, rather than resorting to transactional sex or sex work.

One should not be ashamed of how you raise money. You can wash people's clothes so that you earn some money and not stealing or prostituting yourself. (Girl, 18-21, SS+HV, Chipata / Chazanga)

Many of the girls said that they plaited people's hair for money.

I earn my money by plaiting peoples hair, on a good day maybe I plait about 3 to 4 people and once this money is earned I keep it in the house and use it later for the purpose I intended it for, e.g. if I need books or shoes, I later buy the item that I need. (Girl, 18-21, SS+HV+SA, Chipata / Chazanga)

Others did various chores such as washing laundry for neighbours.

At times my neighbour would ask me to wash for them at a fee and after I wash for them I would be paid K10 which I would keep safely in case I needed to buy shoes for instance that cost K25. At another time I may work for the same amount for someone else and also save that money, and as for the $\mathrm{K} 5$, when mum gives me $\mathrm{K} 1$ from time to time I will be able to save until it is $K 5$ and eventually I will have the K25 I needed to buy what I wanted to buy. (Girl, 1519, SS+HV+SA, Ndola)

Some of the girls from the two rural study sites did farming work, growing vegetables for themselves or others.

In this time of rainy season I do some piece works where I go to cultivate for other people and they give me money... I buy clothes, lotion, soap and shoes... I buy something that I will be able 
to look at even in future and say this is what I bought from the money I worked for. (Girl, 15 , SS $+H V$, Solwezi)

I do business... we do farming and later on sell the maize. (Girl, 15-21, SS Only, Mumbwa)

Many of the girls in the rural areas, specifically at the Mumbwa site, also got involved with selling foodstuffs, either wild foods that they had foraged, or food that they prepared and cooked themselves, or food stuffs that they bought and re-sold.

I would order sour milk and sell at the market. If I buy 2.5 litres of milk at $\mathrm{K} 15$, I would sell it at $\mathrm{K} 40$, then I would keep $\mathrm{K} 15$ from the $\mathrm{K} 40$ profit and save the rest of the money. If the sour milk finishes where we used to buy from, I would pluck mangoes from our trees and sell them. (Girl, 12-14, SS+HV+SA, Mumbwa)

I do business... Selling mangoes and busala (indigenous roots that are edible) also selling bananas and make a garden for vegetables like rape... For mangoes I just get from a tree and busala I get from the forest and sell to gain some capital. (Girl, 12-14, SS Only, Mumbwa)

I do piece jobs or pick busala (a wild fruit like a plum) to sell. (Girl, 15-19, SS+HV, Mumbwa)

One girl in Mumbwa also made and sold charcoal, instead of farming, which she said she was not able to do.

I make charcoal and sell, I cannot manage to do farm work properly so I concentrate on making charcoal. (Girl, 15-21, SS Only, Mumbwa)

\section{Control Group Girls’ Income Generation}

Girls in the control arms at the rural sites also described the activities they engaged in to generate income, many of which were similar to girls in the intervention arms, such as doing laundry for neighbours, or selling foraged wild foods.

I usually earn money through doing piece works e.g. (washing and drawing water) and I spend my money by buying clothes, books and pens. (Girl, 13, Control group, Solwezi)

I earn money by selling mangoes... And by doing some piece work... Going in the bush to pluck some sticks to use when making a door. (Girl, 12-14, Control group, Mumbwa)

\section{Financial Independence through Income-Earning}

One key theme emerging in relation to earning and saving was associated with gaining independence and securing one's future.

If you make your own money, you cannot find yourself in (bad situations), if you make your own money you are your own boss and you can do whatever you want to do with your money, no implications in the end. (Mentor, Ndola)

Many of the AGEP girls spoke of how they have gained financial independence through engaging in their own income-generating opportunities, and as a consequence are no longer dependent on their parents.

When there are piece works of cultivating or watering the gardens I do them and make some money... I use this money to buy the things that I want for example if there was something my parents intended to buy for me and they could not, I use my money and buy that particular thing. (Girl, 14, SS+HV, Solwezi) 


\subsubsection{Financial Decision-Making}

In terms of financial self-efficacy, some of the girls said that they were able to make decisions about how to spend their money themselves. However there was also the recognition by some girls that even with their newfound financial independence, they were aware that at times they might benefit from the guidance of others if they are making poor financial decisions.

When I am saving money I always have something in mind that I want to buy... I make those decisions myself... (Others can help) especially if they notice that I am not using the money that I have very well. (Girl, 16, SS+HV, Ndola)

\section{Envy, Peer Pressure \& Money}

The topic of envy and jealousy being destructive character traits was a theme that emerged often in the data.

Envy is the most difficulty issue because it is an inborn personality, for examples you may give me a big piece of meat and have some to yourself but if I have this quality of being envious I will always want to have your share... parents will be able to know that this child is envious by little things she does, for example you buy them same types of clothes or others you give them same size of meat she will still cry for the other persons meat, them from there you can start teaching her bit by bit about being envious can bring about problems in her life. (Community leader, Solwezi)

A strong theme running throughout the data was envying friends for things that they have. Girls spoke of this envy in relation to various areas. One area was connected to the benefits of saving; one respondent described how this envy could lead someone into theft in order to get what their friends had, whereas saving was a much better way of attaining what you want.

I make my own decisions (about money), in case my friend buys something then you start thinking my friend has bought this thing, what will I do, you will start to envy your friend and that can be good or bad, because again if you steal it's a problem, being envious is bad because it can cause you to become naughty, so you just start saving, that helps a lot, in the end you find that you will be able to buy the thing that you want. (Me and my friend) will start saving then we are able to buy the things that we want. (Girl, 12-17, SS+HV, Chipata / Chazanga)

Some of the girls described situations in which their friends try to encourage them to spend their savings; it required self-control and agency to stand up to this peer pressure.

When (friends) say to me let us spend the money, I refuse saying I am saving it for future use. (Girl, 18-21, SS+HV, Chipata / Chazanga)

Some of the girls explained that they sometimes lend money to friends, and never get paid back.

When (friends) don't have lunch money and they are hungry I lend them some money and they tell me that they will pay me back on a certain day but when the day comes and I remind them they say that they forgot and as I said before my friends don't pay me back... I am unfortunate with people paying me back. (Girl, 12-17, SS+HV, Chipata / Chazanga)

\section{Prioritising spending}

Items that AGEP girls spent money on fell into five broad categories: 1) personal items such as clothes, shoes and toiletries; 2) school items such as books, school bags, stationery, 
school fees; 3) household items for family consumption, mostly food staples such as maize, cooking oil, and relish; 4) health-care costs: girls spoke of spending money on paying for health care for sick family members; and 5) starting up small income-generating activities.

One aspect covered under the Safe Spaces financial education was budgeting.

Sometimes when I get paid K500, I will tell my mum then we make a budget, we will buy mealie-meal, cooking oil, charcoal and the money that remains I buy clothes. (Girl, 18-21, SS+HV, Chipata / Chazanga)

One girl explained how she budgets and makes plans for how to spend the profit that she earns.

I sell ice blocks... My thinking is that I could use my profit for hospital bills in case my mother fell sick again, I save the profit and use the remaining amount to buy ingredients to make some more ice blocks... I can buy something I like from the market, I can pay bills at the hospital in case my mother falls sick, I can also give some of the money to my mother to buy food at home. (Girl, 12-14, SS+HV+SA, Chipata / Chazanga)

AGEP girls learned about making wise decisions about spending money at Safe Spaces. These lessons included how to save, budget, and not spend money on unnecessary things.

When I am given money, let's say for food at school, I keep it in case there maybe something else that I could like in future. Sometimes I would not even eat but keep my money....

Sometimes I tell (my friends) I have this much money and they help me decide on how to use it and tell me if I am right or wrong about my choices of spending money... I think about what budget I have and I plan how I will spend my money on the things that I budgeted for. (Girl, 1821, SS+HV+SA, Chipata / Chazanga)

I make sure I make a plan and not spend money on unnecessary things I make sure I spend it on things that matter. (Girl, 14, SS+HV, Solwezi)

Because of the knowledge that we have acquired from AGEP... we did not know about how to save money, whenever we would have money would just end up misusing it but now we know and we save money such that we even buy things which are important and we really want. (Girl, 18-21, SS Only, Solwezi)

I buy a school bag, uniform, school shoes and if there is no food at home then I can also budget for that. (Girl, 18, SS+HV+SA, Solwezi)

If my pair of shoes wears out, then I need to replace it, then I would get a little from the money am saving to replace the pair of shoes... if I want to go for tuitions I get my money and go and pay for tuitions. (Girl, 15-21, SS Only, Chipata / Chazanga)

The lessons girls received around prioritising and budgeting their savings also related to learning to recognise the difference between "needs" (items of necessity) and "wants" (items that are not necessary), but are desired. Mentors explained the concept of needs versus wants covered in the curriculum:

As the girls are growing, they are growing into adults adolescents, you would find that there are so many needs that would come up and they are unable to differentiate what a want is and what a need is, sometimes they have even mistaken a want to be a need of which they can live without it but you would find that it is something that they will have on their mind to say it's very important that I have 2 pairs of shoes, better clothes, they don't realise that having more than 2 or three pairs of clothes is just a want, a need would be just having a pair of clothes or two at least to change, so you would find that the girls would continue to say let me have something with somebody who will give me then at least I will be able to compete with friends in the community and also be told that I also dress well, I look good. (Mentor, Mumbwa) 
Some of them used to say when it comes to the topic of needs and wants, they know that even if you don't have something for example if they see their friend with new clothes and they have liked those clothes, even if they don't manage to get one for themselves, life will still go on, she won't force herself to do things so she can buy it. Such things they would say we also leant this from here because a long time ago what they used to do, looking at the way the live in the community, when they see their friend with the latest shoe, they would say I will also get it no matter what but now after they were taught they know that even if they don't have that thing life will still go on. (Mentor, Chipata / Chazanga)

Girls explained their interpretation of the lessons on needs versus wants that were taught at Safe Spaces.

You may have money and you make a budget for that money but sometimes you will find that you see something that you like and is not in the budget. So you have to be disciplined when it comes to money even though you have a $\mathrm{K50}$ you have to know how to use it... Knowing your needs and wants... For example you cannot go and buy clothes... you may have not have mealie-meal in the house so you cannot go and buy clothes... (We learnt) not being influenced by friends, not wanting things that you can't have, you just have to be yourself and understand where you are coming from. (Girl, 18-21, SS+HV+SA, Chipata / Chazanga)

We learnt about the difference between needs and wants. We learnt that needs are things that you can't do without and wants are things that you can live without... there are things that you can't panic for and things that you have to work hard to have them first. (Girl, 12-17, SS+HV, Mumbwa)

Needs and wants... even if you haven't eaten you can survive but needs you cannot survive if you are not eating... needs like clothes and shoes... Wants like jiggies (sweets) and lollipop. (Girl, 12-14, SS+HV, Mumbwa)

\section{Control group girls' financial decision-making}

Generally girls in the control groups, similarly to AGEP girls, prioritised school items over personal items, sometimes under the advice of guardians.

When I have money, maybe I don't have books, I can buy books and shoes and I bag, if I don't have. After buying all the things I need for school that's is when I can buy the other things that I want... my grandmother can say those things that you want to buy you shouldn't buy them now, I don't have money to pay your school fees or buy you books so use that money to buy those things then I will give you... Maybe when they (guardians) also don't have money pay my school fees or buy my books, they can tell me to say use your money to buy school supplies since we don't have money right now, the money that will remain after that you can buy whatever you want. (Girl, 12-17, Control group, Ndola)

Girls in the control group similarly spent their savings on school items.

I used to save in the house, I would put in a piggy bag... I decided to save K200 for clothes... I managed to buy clothes for myself... I managed to buy books, school shoes and a school bag. (Girl, 18-21, Control group, Chipata / Chazanga)

One recurrent narrative amongst the girls in the control group was using savings to buy past exam papers.

The money I kept I wanted to buy slippers and also to buy a book for school... I kept in it my purse and put it in my grandmother's bedroom... It has really helped me because there times when they do not have money at home and I usually help out... It has really helped me so much even though I have not budgeted for it I can still use it to buy past papers at school. (Girl, 16, Control group, Chipata / Chazanga) 
With regards to decision making and spending, some of the girls in the control group said that they were able to make decisions about spending on their own, especially if it was money that they had saved themselves.

I don't have to always tell her (mother) what I don't have. I get from the saved money and buy what I need. (Girl, 12-17, Control group, Chipata / Chazanga)

Other girls in the control group, across a range of ages, described how they still need help and advice when it comes to financial decision-making, as they feel that they still make poor decisions about spending. The two quotes below come from girls at rural study sites:

I am still young and sometimes when I am given money I end up spending it on useless things. (Girl, 12-17, Control group, Mumbwa)

My mother keeps my money for me... I am afraid to keep money for myself because I might end up squandering it. After seeing that money I may end up buying biscuits hence misusing the money. I am better off giving it to my mother to keep it for me. (Girl, 18-21, Control group, Solwezi)

Girls in the control group got advice on financial management from elders in their families.

(My auntie) tells me that whenever I have money I am not supposed to misuse money anyhow and make haste decisions instead I should take time and think it through. (Girl, 18-21, Control group, Solwezi)

\subsubsection{Banking}

Respondents were asked to comment on their views and opinions of the savings account arm of the intervention, in which girls were given the opportunity to open accounts with the local bank NatSave. One of the community leaders described how challenging it can be for people without large sums of money to open a bank account.

(It has) helped the girls... opening an account - it's too difficult to open an account when you don't have any support. Most banks would not accept a K20.00 or K2.00 cash deposit.

(Community leader, Ndola)

One of the mentors detailed a range of benefits of saving money in the bank, instead of keeping savings at home.

For those saving in the bank if there is an emergency, for example am going to a party with my friends or they have a variety show at school, so when I go there and see my friends eating and buying things I will also want to buy those things so if I am saving the money at home, I can say let me go and get that money so that I can use it but when the money I at the bank, how can the girl move to go into town, she will need money to go that side. so there is a difference between the one saving at home and the one saving at the bank... the bank is safe, no one can steal that money, it's for her only but for those who can at home, maybe they have dag a hole and buried the money there or they have a piggy bank, when other people see where she keeps that money, they will get that money, or maybe I keep the money in my shirt or trousers then my niece sees where I put it, I move out then she goes in and gets the money, who will I blame because you haven't seen anyone, then what happens, that amount which I had will decline. (Mentor, Ndola)

One of the mentors recounted her own personal story illustrating that having money saved in the bank, as opposed to somewhere at home, makes it less accessible and safeguards against spending it all for family needs.

(Before AGEP) whenever I had money, the money is in the house, my sister would say that I have money in the house so if there is an emergency, like I can remember I had saved about 
K1500 then my sister got sick, I used all the money to spend on because she stopped selling so I used that money to feed ourselves at home, to help with the medicines and all that. If the money was in the bank, I wouldn't have used all the money, at least I would have left some and I would have used some. But now I keep the money at the bank. (Mentor, Ndola)

In general, the girls who had been randomised into the savings account arm of the intervention reacted positively to having the opportunity to open a bank account.

I never used to manage to save... (after AGEP) I started thinking to myself about the way I was spending money on a lot of useless things and that needed to change. I started saving by keeping change in a tin and whenever that money would be enough to buy something important like shoes or a piece of clothing, I would go out and buy it... before I was very careless with how I was keeping or saving my money, but now am able to save using the bank... I never used to save money but then I was advised at home about how others my age save money and also what I started learning at AGEP altogether helped me to save and because of that I am able to buy what I want. (Girl, 15-21, SS+HV, Ndola)

Having money saved in the bank, as opposed to somewhere easily accessible, also means that it is less likely to be spent on a whim.

The bank is the safest place to keep money. Sometimes you may like something, maybe a dress so you can use the money that you have saved to buy that dress. It is very important to keep money from the bank because you will not be tempted to touch the money even when you see something nice. (Girl, 15-21, SS Only, Ndola)

Relating to the sentiment expressed above, some girls who weren't part of the savings account arm of the study said that they didn't trust themselves with having the self-control not to spend their money on unnecessary things, so they would give their money to a family elder to keep for them.

I give an elderly person to keep for me because I fear that I can use it for some other things that cannot benefit me... I save so that I can buy things that I lack because my grandmother is now old and she cannot manage to give me everything that I need. (Girl, 17, SS+HV, Solwezi)

Theft of savings that were not kept in the bank was mentioned by some of the girls as a problem.

I use my money wisely. If I have a lot of money I just use a bit for lunch at school and keep the remaining in my bag... When I keep my money in my bag sometimes I find that someone has stolen it, at school people steal whether it's a pen or what. (Girl, 12-17, SS+HV, Chipata / Chazanga)

A number of the girls in the Savings Account arm of the study had not yet made use of their bank accounts. Reasons for not using bank accounts included lack of understanding as to how to use the account, lack of funds to put in the account, and large distances to the bank branch.

l: Have you opened an account with NatSave?

R: Yes

I: Describe your use of that account.

R: I don't know how to use it.

I: Does it mean that you have not taken any money.

$R:$ Yes

I: What prevented you from using the account?

$R$ : Because there is no money. (Girl, 13, SS+HV+SA, Solwezi)

Distances to the bank branch and lack of transport were barriers to girls using their savings accounts.

I: Have you opened an account? 
R: Yes I have an account.

I: How have you used this account?

R: I can't lie, I haven't even been there ever since I had it opened, and I haven't been there to save some money.

I: Why haven't you used this account?

R: Uhh I will start using it...(laughing) I feel lazy to go all the way considering it's very far... (The account is with) NATSAVE in town. So I feel lazy to go all the way and take my money because sometimes the money is really little and I would have to spend transport money to get there.

(Girl, 18-21, SS+HV+SA, Chipata / Chazanga)

In addition to lack of transport being a barrier to using their savings accounts, some girls lacked the agency and independence to go alone, and their parents were unable to take them.

\author{
I: Do you save money in your account? \\ R: No \\ I: Why don't you save your money in an account? \\ R: I don't have anyone to take me to the bank. \\ I: What about your mother? \\ R: My mother is never at home. (Girl, 12-14, SS+HV+SA, Chipata / Chazanga)
}

\title{
8.1.5. Savings groups
}

In Safe Spaces, girls were encouraged to form savings groups with their friends - called a 'chilimba' locally. The way in which a chilimba usually works is that the girls pool their money together, and the collective amount is given to one person in the group each week until everyone in the group has had an equal turn.

Saving has changed them others a lot. They have started doing chilimba... what they are doing is every week one person should get the money, everyday each person has to give a $\mathrm{K} 1$ by the end of the week everyone would have given a $K 5$ so it will be $K 5$ by the number of people then given to one person. So, that money helps them to buy what they want or even help parents at home then others would now get that money and save it the bank. (Mentor, Chipata / Chazanga)

Many of the girls talked about forming savings groups / chilimbas with their friends after being taught about them at Safe Spaces.

I: Were you doing chilimba with your friends before AGEP?

R: No, I wasn't

I: What made you to start doing chilimba?

$R$ : Because of this programme and what we were taught. That's why I now know how to keep the money. (Girl, 15-19, SS Only, Chipata / Chazanga)

However according to the mentors, some of the girls were already part of chilimbas before getting involved with AGEP.

I have one in my class who confesses that even before she joined AGEP she would save money they use to save money as a group through what is called 'chilimba', she would save a K2 every time she has money, so with the rest they only came to realise that you can save any amount when they joined. (Mentor, Chipata / Chazanga)

Some girls in the control groups explained that they also form chilimbas with their friends.

Way back when I use to go to school, we never use to carry packed lunch, he would give us money, so what use to happen is I would do a chilimba (a way of saving money in a group) with my friends, sometimes we would do like K5.00 every day, that's how I would save money, I never used it on lunch. (Girl, 18-21, Control group, Chipata / Chazanga) 


\subsubsection{Effect of saving on interpersonal relationships}

Respondents were asked to comment on how their saving behaviour has had an impact on their interpersonal relationships, with husbands, friends and parents. According to respondents' narratives, money saving behaviour by AGEP girls has had a positive impact on marriages, for those who were married. The positive changes remarked upon were understood to be a result of the girls now being able to contribute to the household needs, instead of relying on their husbands as the sole providers.

Their husbands are appreciating... because they realise that before the girls would just rely on their husbands to give them everything but this time the girls are also helping out, they have realised that their marriages are also working out well now because each of them is contributing towards the family needs. (Mentor, Mumbwa)

Similarly, girls commented that savings had also improved relationships with parents, as girls were now able to contribute to household running costs.

We (parents and myself) get along very well because my father who takes care of us has now stopped working so when I sell ice blocks and maybe I find a K5, that's what we use to buy food at home because maybe at that time my mother hasn't been paid. (Girl, 12-14, SS+HV+SA, Chipata / Chazanga)

\subsubsection{Effect of saving on education}

From the narratives of the respondents it appears that savings has had a huge impact on the girls' education in general. Some of the mentors explained that as a result of saving money, some of the AGEP girls were able to pay for their own school fees when their parents or guardians were unable to do so.

In my group, I had a girl... she lives with her grandparents, her mother is late, both her grandmother and grandfather are alive but they are very old, they can't manage to help her to find money for her to go to school but she helps herself... she goes to work at a company where they make earrings and other things, she is able to make earrings, neck chains, when she sells those things she uses the money for school, right now as I am speaking, she is in grade ten... she paid for herself, she managed to pay for herself after she passed her grade nine exams. (Mentor, Chipata / Chazanga)

One girl was motivated to start saving. After passing her grade nine exam her parents failed to buy her school uniforms and asked to stay at home for a year until they find money, fortunately she has saved something which she made through the piece works she was doing and she gave her mother the money she had saved to buy her school uniforms, as we are speaking she is doing her grade ten. (Mentor, Solwezi)

Sometimes parents were able to cover the costs of school fees, but not the additional extras required for school attendance, such as books, stationery, uniforms and school shoes.

Saving helped me very much... there was a time Mum had only money to just pay for school fees and she never had money to buy me books and other things that are needed at school, so, I told her that I had something that I had saved I can buy books for myself, that's how I got the money and bought what I needed at school. (Girl, 12-17, SS+HV+SA, Mumbwa)

As described above, a large proportion of the girls across all the study sites spent their personal savings on school items such as books, school uniforms and shoes, and stationery. 
If I don't have a pen I will use the money I have saved to buy one. (Girl, 18-21, SS+HV, Solwezi)

When I sell those vegetables, I can use the same money to buy school things and complete my school. (Girl, 13, SS Only, Solwezi)

It's important to save money because of school, in case you find that I don't have a pen, school shoes or other things that I need to use at school, I will get some money from that money that I was saving, I can buy books and do other relevant things. (Girl, 12-17, SS+HV, Chipata / Chazanga)

During term 1, I wanted to buy reading material, so I was saving money, and the reading material was going for K1.00 per booklet, I managed to buy all I wanted and it cost me K8.00. (Girl, 12-14, SS+HV, Chipata / Chazanga)

Many of the AGEP girls prioritise their spending to buy school items and pay for school fees with the money they earn and save.

For the girls that are saving, you would find that they are using that money for their needs... and on their needs it's the school needs, that's where they are concentrating more, you would find that they are buying books and at least they are able to part away with some monies and their parents top up and pay their school fees, others are able actually to pay full school fees for themselves because in the rural areas here where we are it's not that much, a girl is able to save K150 because they are paying K200. (Mentor, Mumbwa)

When I earn from casual works, I take it to the bank and save it for rainy days when I need to pay my school fees. I save little by little and eventually it can accumulate up to K2000 and therefore it becomes less problematic for me to pay my school fees. (Girl, 15-21, SS+HV, Ndola)

Some of the girls explained that being able to pay their own school fees out of their personal savings had helped to ensure their continued school attendance, and assisted them in their goal of school completion.

When money is needed at school and my parents do not have the means to pay the money, I am able to pay for myself because I was able to save. This means that I will not be absent from school due to financial constraints. (Girl, 15-21, SS+HV+SA, Ndola) 


\section{SOCIAL NETWORKS AND RELATIONSHIPS}

Social isolation contributes to young women's risk and vulnerability. The Safe Spaces programme aimed to enable girls to build social assets, including friendships, trusting relationships, and self-esteem, with the hope of having a positive influence on their general livelihoods and health. The data presented in this section pertains to girls' friendships, sexual relationships and sexual decision-making, as well as the girls' aspirations regarding marriage and child-bearing.

\subsection{Friendships}

One of the topic areas covered in AGEP related to friendship groups and peer influence. Girls were advised not to associate themselves with people who engaged in destructive and anti-social behaviours such as disrespecting elders, and drinking alcohol.

For instance if I associate with you and notice that your ways are bad I will slowly stop interacting with you for the sake of not going astray and for the sake of peace... in this community, there are adolescents are youths who engage in bad deeds like abusing alcohol, insulting and disrespectful to elders, so we encourage these girls who are part of AGEP not to associate themselves with such persons. They are discouraged to be friend those people who are not obedient to their fathers and also those people that insult and beat their mothers when they are drunk because such people are cursed and they will never be blessed in their lives. (Community leader, Solwezi)

During the interviews, girls were asked to describe their friendships, the different kinds of friends they had, and whether or not they had friends they could trust and confide in. AGEP girls were also asked to remark on the changes in their social networks since they had been involved with the programme. Themes that emerged related to the changes in the friends that they had since being involved with Safe Spaces, and the differences between those friends who were also part of AGEP and those who weren't.

\section{Better Friends}

Many of the AGEP girls commented that since being part of Safe Spaces, they no longer associated with naughty girls, and badly behaved peer groups, and had themselves improved their behaviour and sought out better friends. The three quotes below come from girls in the two urban study sites:

Personally I feel the programme has had a huge impact on my life and I have changed from the way I was. Since the coming of the programme, I have changed how I socialise with friends, I do not play with my friends anyhow, sometimes one would find themselves in bad company and get destructive advice from them, when you find yourself with such company, choose to ignore that person. (Girl, 15-21, SS+HV, Ndola)

I changed in many ways, changed from the bad things I used to do, I used to be found in groups with bad influence and gained bad advice but now I have stopped. (Girl, 18-21, SS+HV+SA, Chipata / Chazanga)

All the friends I used to have before I joined AGEP have changed I do not even talk to most of them... They are found in every new pub that they hear of and people are always talking about them that is why I stopped being found with them. (Girl, 18-21, SS+HV, Chipata / Chazanga)

These behaviour and friendship group changes were ascribed by the girls to AGEP. 
All the bad habits that I had, I have abandoned them... of misbehaving and being found in cliques that had bad behaviour. I have now stopped all that because of AGEP. (Girl, 15-19, $\mathrm{SS}+H \mathrm{H}+\mathrm{SA}$, Ndola)

Several of the AGEP girls explained that the friends they had before they joined the programme were untrustworthy and gossipy.

(The friends from before AGEP) are different... Those ones I had (before AGEP) when I tell them something, they would go and tell someone else... There times when we are chatting and you just hear some negative statements from one of your friends then you begin to have doubts about that friend. (Girl, 16, SS+HV, Ndola)

Those friends I had two years ago I never used to share my secrets with... I never had a close friend I would trust because I knew they wouldn't help me... those in AGEP we share what we learn in AGEP but those who are not in AGEP they always try to discourage me from attending... they are different because those in AGEP are seen that they are learning but those who are not in AGEP can only be seen that there is nothing they are learning. (Girl, 18-21, $\mathrm{SS}+\mathrm{HV}$, Mumbwa)

My friends from before had bad vices such as picking fights and quarrelling... The friends I have now are trustworthy because they can keep secrets and I the same for them... (My friends now) are different... The friends I had before were not trustworthy as they would lie often, but ones I have I have now, don't lie. It is best to tell secrets to someone who isn't a liar. (Girl, 10-14, SS Only, Ndola)

These old untrustworthy, gossipy and badly behaved friends differed from new friends, who tended to be trustworthy, caring and compassionate.

(Friends) I had before joining AGEP didn't know how to keep secrets, immediately you tell them something, they would go round telling people, so now I have stopped telling them my secrets... Even when am not feeling well I tell them then they go to tell my parents that am not well... I trust my current friends because they can keep secrets and when I'm not well they come to see me (Girl, 12-17, SS+HV+SA, Ndola)

\section{Difference between AGEP Friends and Non-AGEP Friends}

The girls were asked to comment on the differences they noticed between friends who were also part of AGEP, and those friends who were not part of the programme. Some of the girls commented that there were marked differences between the two groups, others said there was no difference. Besides being better behaved than those who are not part of the programme, one noticeable difference between AGEP girls and non-AGEP girls related to AGEP girls' interest and motivation to focus on their education, and live a healthy life.

My old friends would not talk to me about school, but the friends I have in AGEP do... they are different... They like to pick fights. (Girl, 10-14, SS Only, Ndola)

Those (friends) who don't come to AGEP safe space think we just come here to play; they just do bad things like play with boys... Those who don't go to AGEP don't even think about school... They don't think about life, maybe you can contract disease that you don't know and die. (Girl, 12-17, SS+HV+SA, Ndola)

When we come here (to Safe Spaces), we learn a lot and we know what is wrong and right but when we tell those friends who remain home, they refuse and say all what we tell them are lies. (Girl, 18-21, SS Only, Chipata / Chazanga)

In contrast to the narratives above, some of the girls explained that they still had the same group of friends as they did before they joined AGEP, and that their old friends were the ones that they trusted and confided in. 
My friends are still the same since I joined AGEP... Because I trust them... they are still the same because we are able to keep each other's secrets. (Girl, 12-17, SS Only, Chipata / Chazanga)

\subsubsection{Control group girls and friends}

Some of the girls in the control groups said that they chose not to have any friends, so that they would not be persuaded by peer influence, and could instead concentrate on school.

I don't have friends... I once had friends but not anymore because they used to tell lies, were jealousy, they were also not serious with school. Most of my friends got married and I didn't want to be among such friends because I would have started thinking as if they had done the right thing. And I really wanted to focus on school work. It is for this reason that I avoid having friends who have bad habits or are married at a tender age. If I associate myself with such people, I may envy to be like them. (Girl, 18-21, Control group, Solwezi)

Some girls said that this meant that you had to be careful in selecting your friends. Ideally you could find friends who would encourage you to engage in good behaviours.

If someone is pressuring you to do something that is bad, you will do it because you are not strong in the lord... You need to change the kind of friends that you have and have friends that will make you do good things. (Girl, 16, Control group, Chipata / Chazanga)

In addition to avoiding peer pressure, another reason given for not having close friends was that girls could be bitchy and two-faced to each other.

I don't have any close friends... Because a lot of girls like back biting so much. (Girl, Control group, Chipata / Chazanga)

Some of the girls in the control group who participated in other types of programmes said that they also learned the value of choosing one's friends wisely and not associating oneself with badly behaved peers.

I stopped finding myself with naughty people, we were told that when you see that your friends have bad behaviour you should stop playing with them and find better friends to play with.

(Girl, 12-17, Control group, Ndola)

\subsection{Sexual Relationships \& Sexual Behaviour}

"In Zambia, only 26 per cent of first sexual experiences are within marriage, and among 15-19-year-old never-married girls, a third in urban settings and $40 \%$ in rural settings had had sex. Overall, 14.3 per cent of 20-24-year-old women reported first sex before age 15 and 61 per cent before age 18" (Austrian et al., 2013).

Part of the Safe Spaces programme focused on sexual and reproductive health. In the qualitative interviews, the older AGEP girls were asked to comment on how their involvement in the programme had affected their sexual behaviour and sexual decisionmaking.

\subsubsection{Delaying sexual debut}

Girls who attended Safe Spaces meetings explained that they had been discouraged from getting involved with boys and starting sexual relationships, to avoid early pregnancy and getting infected with STIs and HIV. 
The things I am learning are encouraging me because I am able to reflect and realise that truly what they are teaching me is sensible and factual, such as discouraging promiscuity because I am young and should not be involved in such vices. (Girl, 15-19, SS+HV+SA, Ndola)

Some of the girls' parents also commented on how girls were encouraged by AGEP to delay sexual debut and abstain from sex.

The lessons have helped her to stay away from men, and abstain from sexual activities in order for her to avoid contracting sexually transmitted diseases and mostly I ask her what she has learnt and she tells me and we are thankful for these lessons, because times are bad nowadays you may find a girl who is only in grade 6 is married or even pregnant, these girls are not scared of men. But with the introduction of AGEP it has helped a lot of girls to stay away from such behaviours. (Parent, Solwezi)

Some of the girls who had not yet had sex said that they were motivated to wait until they had finished school until they engaged in sexual intercourse.

I want to take care of myself. So the man who wants to have sex with me will do that after I finish school. (Girl, 18-21, SS+HV+SA, Chipata / Chazanga)

Some girls commented that their decisions to delay sexual debut was due to fear of STIs and pregnancy that had been instilled by the lessons learned at Safe Spaces.

When we started AGEP we were taught (about the dangers of sex) and so I am very scared and do not even want to hear things about having sex. (Girl, 15-21, SS Only, Ndola)

I am scared of contracting diseases or I might become pregnant... (We learned at AGEP) by sleeping with boys, you can contract a lot of diseases. (Girl, 18-21, SS+HV+SA, Mumbwa)

Some of the girls commented that it was important to delay sexual debut, and also not to have multiple sex partners, in order to stay healthy.

One should not have multiple partners as you would not know who would infect you with diseases... I am waiting for marriage (to have sex), so we can have it (sex) together. I am scared of getting infected with different kind of diseases. Some men just want to use and leave you. (Girl, 18-21, SS+HV, Chipata / Chazanga)

One of the mentors suggested that instead of lecturing the older girls about abstinence, especially for those who had already started having sex, they should instead be teaching them about how to have safe sex.

The girls that are still sexually active are using condoms and we have encouraged them to continue because like those that are in the 15-19, others have grown to an age where you can't tell them that you shouldn't do this (have sex) but we have encouraged them that since you like doing that you have to use condoms. (Mentor, Mumbwa)

\subsubsection{Gendered power and sexual decision-making}

One mentor explained that due to what they have been taught at Safe Spaces, the married AGEP girls are able to stand up to their husbands, and not tolerate maltreatment or abuse.

I am mentoring the 15 to 19 years old (17-21 group)... most of them are married, these girls know that if their husbands mistreats them, they are confident enough to stand up for themselves and make the right decisions. Because of what I teach them here at AGEP they know how to make their own decisions very well... (AGEP girls) know how to make decisions about their health, they protect themselves from men who want to have relationships with them. They have the courage to tell men off and say no. (Mentor, Solwezi) 
However, in terms of gendered power and sexual decision-making, those girls who were in sexual relationships or had engaged in sex described unequal gendered power relations, with the male partners generally making the decision to have sex.

My boyfriend said he felt like doing it... I didn't say anything. (Girl, 15-21, SS Only, Chipata / Chazanga)

Many of the girls who had engaged in sex described the way in which their first sexual experiences were non-consensual.

It was his decision (to have sex), it's him who wanted it... I didn't want to. (Girl, 18-21, SS Only, Solwezi)

A number of the married AGEP girls, in both urban and rural study sites, explained that they have little agency when it comes to the decision to have sex, or timing of sex. Some of these married girls said they had little choice but to agree to sex when their husbands demanded it.

\author{
l: Have you ever felt pressure to have sex? \\ $R:$ Yes \\ I: Where or who is this pressure coming from? \\ $R$ : My husband \\ I: Can you describe what you do (or have done) to respond to this pressure? \\ $R$ : Nothing, I give in since he is my husband. (Girl, 18-21, SS+HV+SA, Ndola) \\ I: Have you ever felt pressure to have sex? \\ $R$ : Yes... (from) my husband. \\ I: Can you describe what you do to respond to this pressure? \\ R: Nothing, I just allow him to do it. (Girl, 18-21, SS+HV, Mumbwa)
}

Similarly to the AGEP girls, married girls in the control group described their lack of agency and decision-making power when it came to sex. However, one girl in the control group in rural Mumbwa explained that she sometimes refuses to have sex with her husband when he demands it, even though he threatens her.

I: Who in your household decides on how many times to have sex be it in a week or whenever you want to have sex is it you or him who decides when to have sex?

$R:$ It's him

I: Do you feel pressure to have sex from your husband?

$R:$ Yes

I: Can you describe what you do to respond to this pressure?

$R:$ I just refuse.

I: Doesn't he get upset when you refuse?

$R$ : He gets upset and tells me that you will see since you have refused.

I: What does he mean when he says you will see?

R: I don't know that's what he just says. (Girl, 15-19, Control group, Mumbwa)

In general, the girls' narratives illustrate unequal gendered power and agency in the sexual domain, and the sexual norms encompassing the primacy of male sexual desire and pleasure, and the expectation of female sexual acquiescence.

When your husband wants to have sex, there is nothing you can do, you just have to do it. (Girl, 19, SS Only, Solwezi)

The quotation below from one respondent illustrates the cultural norm dictating that it is deemed inappropriate for women to request sex from a man.

It's a man who makes that kind of decision (when to have sex)... because he wants to have sex 
so he is supposed to make a decision... I can't (make that decision)... how can you start as a lady telling him that you want to sleep with him? (Girl, 18, SS+HV+SA, Solwezi)

Only one respondent spoke about her own sexual pleasure and libido, explaining that her rational sexual decision-making is impaired when she is sexually aroused.

Love for sex... once a guy touches your breast or kisses you, you will easily get turned on and if he has no self-control he will take advantage of the opportunity and sleep with you because you are weak. (Girl, 15-21, SS+HV+SA, Ndola)

\subsubsection{Reasons for having sex}

Those girls who had already engaged in sex were asked to explain the circumstances and decision making processes that had resulted in them having sex. A few girls, especially those from the urban site Chipata / Chazanga, explained that getting drunk was the reason behind having sex.

I went with him at the bar, I got drunk, and then he took me to his house that was how he slept with me... we met at the bar and that was how he decided to take me to his house. (Girl, 1821, SS+HV, Chipata / Chazanga)

I was drunk... I just found myself naked on his bed. (Girl, 10-14, SS+HV+SA, Chipata / Chazanga)

Some of the girls spoke about how the desire for money was a key factor influencing their decision to have sex. The quote below comes from one of the girls in the control group at the urban Chipata / Chazanga site, and illustrates that she made a conscious decision to engage in transactional sex.

(I had sex) because of money, I wanted to buy something and I didn't have money. And in that situation a man can tell you to sleep with him especially when you are assured that he will give you something... (I decided) myself. (Girl, 18-21, Control group, Chipata / Chazanga)

Contrary to commonly made assumptions about young girls as powerless victims of male sexuality, some of the girls remarked that they had engaged in sex because they wanted to, and had not been forced by anyone.

I just wanted to have sex... I made the decision myself. (Girl, 17, SS Only, Solwezi)

Another girl in the control group from the rural Solwezi site explained that sometimes a couple decide together to have consensual sex.

(Pressure to have sex comes) from themselves... Just from themselves when they propose love to each other and they agree to each other that they want to have sex then no one has pressured them to have sex they have forced each other. (Girl, 18-21, Control group, Solwezi)

\section{Peer Pressure to Have Sex}

One of the contributing factors to early sexual debut amongst young girls is peer group pressure and being influenced by others.

I know of a girl... she had some friends who were very bad such that she even left home and started staying with them. Unfortunately she had no say over things that were going own in her life. Men would abuse her such that she even got pregnant and she gave birth last week... She 
is 14 years old and the person responsible has since left for Kasempa, this was all because of group influence. (Mentor, Solwezi)

One mentor described the way in which girls are influenced by their friends, and end up copying their friends' behaviour, sometimes without knowledge of the consequences. She gave the example of herself, where she ended up getting pregnant as a result of not having any information about contraceptives, and not being empowered to make decisions.

They were in a group where they all had boyfriends and they would be together everywhere but this girl was the only one who didn't have a boyfriend, but because she followed her friends blindly when she didn't have information, she didn't know how to protect herself. Her friends knew how to protect themselves, maybe they don't even have sex, they just move around. You who is seeing from afar, you think they engage in sexual activities, because sometimes when you go for outings as a group, you see people kissing and laughing. You start thinking, how come they are kissing, obviously they do everything, so you also want to do the same thing... The most important thing this time is sensitization and giving these girls the information, even if you see your friend doing something, you don't have to follow what your friend is doing, stand on your own, you know what you want, just stand. Like I said, when I got pregnant the first time, I was just following what my friends were doing, because I thought we were just playing, getting myself in to something that I didn't even know. But if I had information I wouldn't have done it. Information can help the girls in the community to stand on their own. (Mentor, Ndola)

Some of the girls explained the way in which they manage to stand up to the pressure from their peers to have sex.

My friends are always forcing me (to go ahead and have sex) and telling me at that age what are you waiting for? Just go ahead and do it and you will know how to protect yourself... I tell them that I can't do it because it's not the right time. If your time was right then I will wait for my time to come too. (Girl, 18-21, SS+HV+SA, Chipata / Chazanga)

\subsubsection{Effect of safe spaces on sexual behaviour}

In Safe Spaces, girls were encouraged to delay sexual debut, and were provided with information in order to empower them to make their own decisions regarding when they felt ready to have sex, instead of being pressured by a partner to have sex before they felt ready.

(I learnt) how to take care of myself... By saying no when someone approaches you for sex... When a boy or man is after you, you can rebuke him with just one stern answer, if he persists you should stand up for yourself and tell him off. (Girl, 10-14, SS Only, Ndola)

One of the mentors explained how girls were also discouraged from having casual sex partners, and to wait until marriage.

Before, they would accept to have sex with a boyfriend they have not even known that long. But we have learnt that giving in to sex is not how you show love, but when someone loves you he will be willing to wait for you to complete your education and be stable enough to no longer live in your parents' home and eventually marry you. (Mentor, Ndola)

\subsubsection{Contraceptive use and decision making}

One area covered in the Safe Spaces curriculum related to sexual and reproductive health, and provided girls with information about safer sex, family planning and contraceptives. 


\section{Lack of Information about Contraceptives and Condoms}

Some of the mentors described the poor knowledge levels amongst the girls regarding contraceptives and safe sex.

I was giving them a talk on contraceptives some of them came up and said madam we hear condoms are painful. (Mentor, Ndola)

Some of the AGEP girls, most notably from the rural site Mumbwa, who had already had children themselves said that before AGEP they didn't have any information about how to prevent pregnancy.

(Before AGEP) we did not have that knowledge of preventing pregnancy. (Girl, 15-21, SS Only, Mumbwa)

One girl remarked that she found out about contraceptives too late.

When I became pregnant, I never knew that there is the use of condoms, but after having a child that's when they (AGEP) had started teaching about the use of condoms and other family planning methods. (Girl, 18-21, SS+HV, Mumbwa)

\section{Contraceptive Myths}

A number of the girls demonstrated poor knowledge about condoms and contraceptives. Data from AGEP suggests that among older girls (15-19 years old) in the community knowledge levels around contraceptives were fairly high, but this was not the case amongst younger girls. One mentor at the urban site Chipata / Chazanga disagreed that there was a lack of information regarding contraceptives amongst girls in the community.

Most of the girls are educated on these issues, there are so many groups that are going round sensitizing people on that so that's not a reason. (Mentor, Chipata / Chazanga)

One girl in the control group at Ndola believed that mixing Coca-Cola and Paracetamol would be effective as a contraceptive.

I: Can you tell me if you know of any contraceptives other than condoms?

R: Mixing Coca Cola and Panado. (Girl, 15-21, Control group, Ndola)

Another girl from the same site said that she had been told by a mentor that they shouldn't use contraceptives if they wanted to have children later as their fertility would be adversely affected.

Our mentor told us that we shouldn't use contraceptives before we have children because you will have problems conceiving... they say if you don't have a child it's not good to use (contraceptives) because it can cause problems in conceiving. (Girl, 18-21, SS+HV+SA, Ndola)

\section{Access to Contraceptives}

Even when girls were informed about contraceptives, there were other barriers to their uptake and use. One barrier cited by the mentors related to disclosure and confidentiality, and parents enquiring about their sexual relationships.

There was one a problem because (the girls) would say "madam, how can I start using contraceptives, what will I tell my mother for me to start using contraceptives because she will ask me if I have a boyfriend" - so this was a difficult topic but I just continued to teach them and tell them that even if your mother asks you not, you know deep down your heart that you have a boyfriend, so it's up to you to choose whether to use contraceptives or not. (Mentor, Chipata / Chazanga) 
However, some mentors explained that girls did seem to be more informed and empowered to use contraceptives.

Two older girls from my group came to tell me that we heard about what you have been teaching us, that we need to protect ourselves from diseases so that we can finish our school and do what we want in future because our boyfriends used to refuse to use condoms but now they have agreed because we have explained to them... to stop sleeping with men and get the teachings that they are being taught. (Mentor, Solwezi)

Illustrating a degree of agency and independence in decision-making, some of the AGEP girls in the older age groups commented that they had decided themselves to start using contraceptives.

I went for an injection for 5 years... I just told myself that it was not good to have children without being married so I decided to go and get an injection myself. (Girl, 18-21, SS+HV, Chipata / Chazanga)

Some girls explained that they had successfully managed to negotiate condom use with their male sex partners.

It was me who told him to wear a condom. (Girl, 18-21, SS+HV+SA, Chipata / Chazanga)

There was a guy who forced me to sleep with him and he told me that there were no condoms, so I refused... (Since AGEP) I am now scared to have sex without a condom or contraceptives in fear of getting pregnant... (so) I refuse and say that I cannot succumb to such (condomless sex). (Girl, 15-21, SS Only, Mumbwa)

One of the AGEP girls explained that her husband made the decision that she was not allowed to not use any contraceptives.

We are not using any (contraceptive) method at the moment... It was my husband's decision. (Girl, 18-21, SS+HV+SA, Ndola)

One girl in the control group explained that her boyfriend told her that using condoms would prevent her from enjoying sex.

He told me I was not going to feel anything (if we used a condom). (Girl, 15-21, Control group, Ndola)

Illustrating the way in which young girls often focus on the prevention of pregnancy rather than the prevention of STIs and HIV, one mentor commented that girls generally choose to use forms of contraception such as injections or pills, which although preventing pregnancy, don't protect them from contracting STIs and HIV. The mentor suggested it would be far better for the girls to use condoms instead/as well, for dual protection.

The situation is very bad... because the girls will prevent pregnancy and not diseases... it would be better for them to use condoms. (Mentor, Solwezi)

Condoms were also perceived as reducing intimacy during sex. Some of the girls described their belief that using a condom would signal to your boyfriend that you don't love him.

Even if they have information on the use of a condom, they feel that they would not show love to a boy if they use a condom. (Mentor, Mumbwa)

It was not only the AGEP girls who demonstrated knowledge about contraceptives; some of the control group girls showed that they were also informed about contraceptive methods. 
I: What methods of contraceptives are you on?

R: Injection for three months.

I: Can you tell me what makes this your preferred method?

R: I just wanted the injectable... I think all methods are not good it's a risk they all have side effects, the only safe way is a condom but the reason why I use injections is because sometimes men are crafty they can break a condom intentionally, then you get pregnant. (1519, Control group, Mumbwa)

\subsubsection{AGEP discouraging transactional sex}

Several mentors at the urban study sites described the situation before AGEP was implemented where many girls were engaging in transactional sexual relationships.

When (girls) save money for themselves, what is a boyfriend for? Because we have learnt about delaying sex, you would find that these girls get into these relationships with different reasons for some it's love and some money, so after teaching them about strategies of earning money... Most of the time before AGEP (the girls) would earn their money through boyfriends. (Mentor, Ndola)

The mentors explained that by providing the girls with financial education, and teaching them to be financially independent, the girls had learnt about the dangers of transactional sex and were now more motivated to find other safer sources of income.

(AGEP girls) have changed because back then they were desperate to have a boyfriend so that they can be getting money from them, but nowadays they even say that even if they don't have boyfriends they can manage on their own to earn. Now they are concentrating on raising their own money. (Mentor, Chipata / Chazanga)

Highlighting the way in which being financially independent has positive impacts on the girls' health and safety, one mentor provided an example of a girl who was infected with HIV through a transactional sexual relationship, suggesting that if she had been earning her own income, she wouldn't have ended up in this situation.

In financial education, your money verses someone else's money your money will not enslave you but you will be a slave if you have someone else's money, they will give me expensive gifts, jewellery what, but in the end he will ask for something and that something is sex... with sex if am young I don't even know that there are even contraceptives, there are condoms and the like, I will fall pregnant and contract STIs and HIV... for example like that girl I told you about who was dating a truck driver, if that girl honestly had her own money, she would have been managing to buy a bag, even if I don't get a bag like this one, even if it's a smaller one, it's my own money, she wouldn't have found herself in such useless things, now as it is that girls life has been destroyed because she has this disease (HIV), we don't know about the other ones, even if she is not pregnant, if she continues the same way of life style she will fall pregnant, have more diseases and even infect more men who don't know her status. (Mentor, Ndola)

\subsection{Marriage}

In line with the study design, girls who were already married were excluded from the study sample. Therefore at baseline the entire sample of AGEP girls was unmarried. After a period of two years of project implementation, $15 \%$ of control girls were married, and $7.3 \%$ of girls who attended at least half the AGEP sessions were married. During the qualitative interviews, girls were asked questions about decision-making related to marriage. 


\subsubsection{Reasons for getting married}

Those girls who were married were asked to describe the decision making processes and situations that had led them to get married. Reasons for getting married included financial motivations, pregnancy, dropping out of school, boredom, cultural norms, bad behaviour, and pressure. Some respondents felt that young women may choose to get married in order to escape from hardships or maltreatment at home. Some of the girls who were married explained that the decision had been motivated by a lack of resources in the family.

There was no money for school and my parents were out of employment, they couldn't manage to support me, so I decided to get married. (Girl, 18-21, SS+HV+SA, Ndola)

One of the mentors explained that one of the girls in her rural community had got married due to a financial shortfall and being unable to cover costs at school, leading her to get involved in a relationship, which led to marriage.

There was a certain girl who was in school and they were required to pay $\mathrm{K} 50$ for computers, now because of poverty she couldn't afford and there was a certain boy that promised to help her pay $\mathrm{K} 50$ but on condition that the girl moves in with him and that is how the girl left home and as we are speaking she is married and staying with him. (Mentor, Solwezi)

Another mentor from the same rural community shared how one of the girls in her group was forced into marriage due to a lack of funds to pay for her unborn child, despite the mentor's efforts to try to persuade the girl's parents not to marry her off for financial reasons.

The father told me that if I can manage to buy clothes for their child's baby whom she was carrying then they were not going to allow her to get married, but if not there was no other option. (Mentor, Solwezi)

A girl from the same rural community said that she wouldn't have chosen to get married but due to pressure to buy the things she needed, and getting no support from her father she ended up in a transactional sex situation that led to her getting pregnant and eventually married.

What made me to get married is when I try to ask for money from my father to buy myself something he would tell me that am old enough to look for my own money. (Girl, 18, SS $+H V+S A$, Solwezi)

One community leader from an urban site was of the opinion that most girls decide to get married thinking that marriage would alleviate their poverty.

They lack knowledge and like I said earlier on that we live in the world of poverty and their thoughts are if I get married, I can have a good future without knowing that they are creating a problematic life for themselves, so we are praying that AGEP continues to impart this knowledge of waiting to complete ones education before they can think of getting married. (Community leader, Ndola)

Girls either chose to get married or the decision was made on their behalf, by parents or their future husbands.

He first got me pregnant and there was someone else he wanted to marry and that same lady disappointed him that's when he thought of coming to marry me since I have a child with him already. (Girl, 18, SS+HV+SA, Solwezi)

A number of the married girls in both the control and intervention arms explained that the reason behind them getting married was that they had got pregnant. 
(After falling pregnant) they took me to his parents by force and I started living there. (Girl, 1521, Control group, Mumbwa,)

One of the mentors also narrated how one of the girls in her group got married because she was pregnant.

There is a girl she was in grade 9 she got pregnant when she was in grade 9 , so when I went to check on her, I was told by the mother that the husband went and got her she is now married. (Mentor, Ndola)

A girl from one of the rural sites who had been married for 9 months explained that it was her decision to get married when she discovered she was pregnant. Another girl from the same community shared that even though she got pregnant it wasn't her decision to get married but the father of her child requested that they get married.

I never wanted to get married but it was just a mistake that I made by becoming pregnant... my husband requested that I should be with him after I became pregnant, but my parents wanted me to continue with school. (Girl, 18-21, SS+HV, Mumbwa)

Similarly, in the other rural site, Solwezi, a 19-year-old girl who had been married for 4 years said that it wasn't her decision to marry but the man who had impregnated her asked for her hand in marriage via her grandmother, and her grandmother accepted. In the same community, one of the mentors shared that one of the girls in her group had been married off by her mother simply because in the mother's opinion the daughter was not intelligent enough for school.

I had a girl in this AGEP group who was in grade (?) who was married of by the mother because she was not intelligent at school. I followed her to her mother who told me she wanted her daughter to be married because she was not intelligent. (Mentor, Solwezi)

Illustrating that low self-esteem could also be a factor leading girls to get married at a young age, one AGEP girl in Solwezi shared how one of her friends had also gotten married because she felt that she herself wasn't intelligent enough for school.

One of my friends never used to do well in school and the only solution she had to was just to get married because she thought she will never do better. (Girl, 17, SS+HV, Solwezi)

Other girls suggested that some of their peers were married off early due to being naughty.

Sometimes you will find that the girls do not listen and so they force her into marriage. (Girl, 12-17, Control group, Chipata / Chazanga)

Boredom was also listed as another reason why girls decide to get married at a young age. One mentor believed that girls in her group got married because they sat at home with nothing to do.

(Girls) say instead of me being at my parents' house doing nothing when am not going to school, it's better I also get married and have my own house. That's what one of the girls was saying. (Mentor, Mumbwa)

In one case a girl from the control group decided to get married because she wasn't doing anything constructive with her time, she was not working and was not going to school..

It was my decision because the man to marry me had already come along... I wasn't doing anything productive at the time. (Girl, 15-21, Control group, Ndola)

One community leader at a rural study site explained that sometimes consequences of cultural practices could play a role in girls getting married. In the part of Solwezi where he 
lived, a ceremony is conducted yearly where the community comes together to celebrate their history, dance and drink. As a result of substance abuse and sexual activity, some girls end up becoming pregnant and forced to marry the person responsible.

In some traditional gatherings (ceremonies)... (the young girls) got involved with some men unfortunately they even got pregnant some were forced into marriages. (Community leader, Solwezi)

Some of the girls who were already married when they joined AGEP, and had been married off at a young age, felt that they wanted to return to school and better their lives after having learned about the importance of education through Safe Spaces.

I count it all joy and a success story, for example there are girls who were married before AGEP started but after joining AGEP and getting enlightened, some have come to me to say they are no longer interested in their marriages but now they want to go back to school. So I don't think I can say that is a bad thing because they just want to better their lives... I feel there has been positive change in their lives because most of them share their secrets with me and I have noticed that those that were in unhealthy relationships are no longer in them (Mentor, Solwezi)

After coming to AGEP they realised that marriage was not the final thing and they realised that getting married at a tender age was not something that was pleasant and as a result the girls were making critical decisions, others have even gone back to school, others while still maintaining their marriages have also gone back to school and they have also made sure that they have their own income unlike depending on their small husbands ("small husband" refers to a boy under 21 years old). (Mentor, Mumbwa)

\section{Pressure to Get Married}

Although the majority of unmarried girls said that they didn't feel pressure to get married, a few girls who did experience pressure. One girl in Ndola narrated that at times she felt pressure to get married, but was able to withstand the pressure and stay focused on her goals.

I do experience that (pressure)... I just refuse because I don't want... I just ignore (the pressure) because I know what I want to do. (Girl, 16, SS+HV, Ndola)

A number of the respondents felt that girls in their communities were often forced into early marriages by their parents, guardian and elders.

For some they just want themselves while others it's their parents who force them to get married. (Girl, 18-21, SS Only, Solwezi)

I have a cousin who was forced to get married because she got pregnant while doing here grade 6, her parents told her that she was going to get married whether she liked it or not. (Girl, 18-21, SS+HV, Solwezi)

A few of the girls said that they also felt pressure to get married from their friends and peers.

They (friends) encourage me to get married but I refuse that I want to finish my school. (Girl, 13, SS Only, Solwezi)

One girl mentioned that her friends are against her wish to marry later on in life and discourage her from postponing marriage.

There are people (friends) who ask me are you sure you want to wait up to 27. You will grow old in school or at work. (Girl, 18-21, SS+HV+SA, Chipata / Chazanga) 
Although pressure to get married may come in various forms and from various sources, a few girls asserted their ability to overcome the pressure.

What I am doing is just standing on firm ground no matter what they think I will stand my ground (Girl, 18-21, SS+HV+SA, Chipata / Chazanga)

There is no one that can pressure or push me to get married. (Girl, 15-21, SS+HV, Ndola)

They can't force me to get married at this age. (Girl, 15, SS+HV, Solwezi)

At this time even if I was forced to get married I wouldn't because what happens in these marriages especially when you are not educated is bad, I see from my sisters, they go through a lot because they got married minus going to school. (Girl, 15-21, SS Only, Ndola)

\subsubsection{Marriage aspirations}

Although the majority of girls interviewed had never been married, the desire to get married at some point in the future was widespread. The ideal age that girls envisioned getting married varied between 20 and 40 years of age. The main reasons girls gave for wanting to delay marriage related to factors including education and employment, maturity, personal life goals, health and social norms.

I'm taking care of myself I don't want to ruin my life, even the time I will be getting married, I want to be a proper lady. As you know if you start to play with men early, they can easily ruin your life... You can get pregnant and they dump you. You would end up suffering and start to look terrible and lose a sense of value because of all the hardships you are going through raising the child by yourself... even when one used think of having a child outside wedlock you will begin to change all on your own as you begin to see how life truly is. You have to listen to your parents and not focus on having a boyfriend, that is no way for one to behave (Girl, 1521, SS+HV, Ndola)

In general, both the AGEP and control group girls in the younger age groups (10-14) were not interested in getting married in the immediate future as they felt that they were still too young.

I am going to school and also I'm still too young to start thinking about marriage. (Girl, 15-19, $S S+H V+S A$, Ndola)

I have never thought of that because I am still in school. (Girl, 12-17, SS+HV, Mumbwa)

I am still going to school, I am still young. (Girl, 12-14, Control group, Mumbwa)

One girl mentioned that it would be illegal for her to get married currently.

I am still young... you can be jailed if you got married at an early age. (Girl, 13, SS+HV+SA, Mumbwa)

Another girl in the youngest age bracket also expressed her fear of getting married early and the suffering it could cause a young girl.

When you get married while you are still young, you just suffer. (Girl, 14, SS+HV+SA, Solwezi)

The desire to complete education and start working before marriage resonated amongst the non-married girls from across the study sites.

Why I want to wait is because I want to finish school, done with college and after I start work that's when I want to get married. (Girl, 18-21, SS+HV+SA, Chipata / Chazanga) 
I want to finish school so that I can go to college and get a job. (Girl, 12-14, SS+HV, Ndola)

I want to complete my education and when I start working, then I can decide to get married. (Girl, 15-19, SS+HV+SA, Ndola)

When I start working that's when I can get married. (Girl, 12-14, SS+HV, Mumbwa)

School will make me wait to get married; I want to finish school first and start working. (Girl, 16, SS+HV, Solwezi)

I want to get is to just get educated if I am not educated, then men would take advantage of me and end up treating me badly.... the help I will get will be, to be encouraged to concentrate on school in order for me to complete school and be an independent person and if a man tries to take advantage of me I will just leave that man because I will have all that I need (Girl, 12 17, Control group, Solwezi)

The same sentiment was expressed by girls in the control group.

I just have it in my heart and mind that I will only get married after completing my education at college level and start working (Girl, 12-17, Control group, Solwezi)

For a few girls, education meant a better future for their family, and therefore marriage would have to wait.

I will get married when I am 25 years old after completing my college education because I want to have a better future with my family. (Girl, 18-21, SS+HV, Solwezi)

Many of the mentors interviewed narrated what their girls had shared in their Safe Spaces groups. The main reason girls gave for delaying marriage was the desire to complete their education.

Like most of my girls would say that they really want to complete school, they would say they want to get married after school, they even know how to take care of themselves so that they do not fall pregnant. (Mentor, Chipata / Chazanga).

A few girls from Chipata / Chazanga were of the opinion that it was important for them to delay marriage because their parents (mother) need their help and support.

I would want to solve all the problems that I would have and help my mother. (Girl, 12-17, SS Only, Chipata / Chazanga)

I think about what can happen if I get married early and think of who is going to help my mother because most of her relatives stay far. (Girl, 18-21, SS+HV, Chipata / Chazanga)

One of the control group girls mentioned that her reason for delaying marriage was the fear of abandonment and disappointment. She therefore wanted to ensure she was able to fend for herself and achieve her goals before she can begin to think about getting married.

I have not started thinking of that. I want to do my own things first because these men of nowadays might leave you if you are not doing anything but if you are doing something, you can stand on your own even if you are divorced. (Girl, Control group, Chipata / Chazanga)

For some, the fear of HIV/STIs that they had learnt about in Safe Spaces had made them realize that marriage was not something they should take lightly.

Most of the things that we learn really build me up make me realise that I should not get married now. For instance, we were told that if a man and a woman want to get marriage they must first test for HIV therefore I am not ready for marriage. (Girl, 15-19, SS+HV+SA, Ndola) 
One girl in Ndola talked about how cultural customs and expectations were shifting, and nowadays men preferred to marry women who have been educated.

Things have changed you can't just get married without doing anything at least two of us are doing something. (Girl, 15-21, SS+HV, Ndola)

These days things have changed because men want to marry ladies that are educated. (Girl, 17, SS+HV, Solwezi)

\section{Support Needed to Delay Marriage}

In light of the pressure within the community to get married, the girls shared that they would be able to remain unmarried if they got support in different forms. Many girls said that advice and caution from their parents and guardians would significantly help them.

My grandmother tells me that if I get married at a tender age I will just find a useless man who will just be beating me, he might kill me so I have to take time and get married at the right time. (Girl, 12-17, SS+HV+SA, Ndola)

They have to help me by giving me good advice so that I should not go astray so that I can also finish school (Girl, 12-17, SS+HV, Chipata / Chazanga)

They could help me by giving me advice of not becoming a prostitute, good advice and not bad advice because that's what causes early marriages. (Girl, 12-17, SS+HV, Chipata / Chazanga)

My friends, mom and my uncle and even my brothers... (They) should be telling me to behave myself. (Girl, 15-21, Control group, Ndola)

Other girls felt that encouragement from family on their future would help them make sure that they do not get married before their desired age. This could be encouragement related to school or to the girls' dreams and aspirations e.g. employment.

They have to be encouraging me to be going to school. (Girl, 12-17, Control group, Ndola)

Just encouraging words to make me focus on positive things in life. (Girl, 15-21, SS+HV, Ndola)

I want to get the support from my parents, they should talk to me about marriage when I finish school and start working. (Girl, 16, SS+HV, Solwezi)

The help that I want to get is to just get educated if I am not educated, then men would take advantage of me and end up treating me badly. (Girl, 12-17, Control group, Solwezi)

Just to help me in school in terms of school fees. (Girl, 18-21, Control group, Chipata / Chazanga)

Other girls stated that they simply would like their immediate and extended family to support their decisions not to get married in the near future.

I would like them to support me in my decisions and not them telling me to do this or that which I do not want... when I say I want to get married at forty they should back me up. (Girl, 12-17, Control group, Chipata / Chazanga)

Although family plays a major role for most girls, some girls did not feel confident that their family could support them.

Not from my family because they might force me...to get married. (Girl, 18, Control group, Ndola) 
A few girls also talked about how some neighbours and other elders from the community show concern and also give support through words of wisdom.

Our neighbour always says that we should not get married soon but we need to wait until we finish school. (Girl, 12-14, SS Only, Chipata / Chazanga)

A number of AGEP girls felt that their school teachers also could play a role in their decision to delay marriage. It was explained that teachers could advise the girls to concentrate on their studies and encourage them on their personal development.

(Teachers) should encourage me to concentrate on school so that I finish. (Girl, 14, SS+HV, Solwezi)

One of the girls said she could also be supported by her church leaders; this might be words of encouragement, especially in times when her family experiences financial difficulty.

Even if there is no money for school, (church leaders) should be encouraging me so that I wait until the right time for marriage comes.(Girl, 12-17, SS Only, Chipata / Chazanga)

A number of the programme girls mentioned that their mentors had played a significant role in ensuring that they didn't get married early. They hoped that their mentors could continue to support them.

I want support from AGEP because they are the only people who encourage me to continue going to school, the rest just tell me to stop and tell me that I am too old to be in Grade 5 but I tell them to let me keep going to school even if I am only in grade 5. (Girl, 12-14, SS+HV+SA, Mumbwa)

\subsubsection{Effect of AGEP on marriage}

Mentors explained that in the AGEP programme, girls had been encouraged to delay marriage and finish school first.

Nowadays girls are having children at 13 or 14 years and they are being married off but these girls in AGEP they have minimize on that because they have an idea of certain things that they are being taught at AGEP... We encourage them to work hard and know why they are going to school and the benefits that they will get out of that so that they will have a good future and they will always remember the teachings that they were taught (Mentor, Solwezi)

Girls who are not married generally felt they had learned quite a bit from AGEP, some of which had changed their perspective on marriage, whether it meant not marrying at all or delaying the thought of marriage. For instance one girl shared that AGEP had taught her to put her education first.

I stopped thinking about marriage now I just think of school that's all. (Girl, 15-21, SS+HV, Ndola)

Another girl had learnt not to rush into marriage but to follow the right steps to marriage such as finishing school and then marriage.

I have learnt that you have to do things correctly so that you do not get married at a tender age. (Girl, 15-21, SS Only, Mumbwa)

From the small sample of selected married girls, some felt that what they had learned at AGEP had contributed positively to their marriages. The quote below suggested that this girl's interpretation of the AGEP teachings was to obey her husband, which notably was not part of the curriculum. 
They teach us how to take care of our husbands, that we should be obedient to our husbands, that we should be soft spoken. (Girl, 18-21, SS+HV+SA, Ndola)

Mentors also shared their thoughts on the effect that AGEP had made on the girls' relationships and marriages. The general view was that the information that the girls had received on contraceptives had contributed to advising and cautioning those girls already in sexual relationships to delay marriage in order to avoid early pregnancies.

I feel there has been positive change in their lives because most of them share their secrets with me and I have noticed that those that were in unhealthy relationships are no longer in them, and if there are those that have continued being in sexual relationships they could be using contraceptives because none of them has ever been pregnant. (Mentor, Solwezi)

Even though girls were encouraged to delay marriage, some of the AGEP girls didn't adhere to this advice and rushed into early marriages regardless.

My daughter... who is in this programme recently got married, you know how children are, and you may be giving them advice without knowing that they are actually not listening. When she used to come for meetings here, she was a very obedient but I do not know what really happened, a month ago she got married... They just ran away together and made a home with her boyfriend. But they brought dowry later and we talked to her and she said she wanted to be married but then she did it the wrong way because she did not wait. (Parent, Ndola)

\subsection{Child-bearing}

A minority of the girls interviewed already had children. Of those interviewed who didn't yet have children, three expressed no desire to have children now or in the near future, neither did they list any specific reasons behind their lack of interest in having children. The rest said that they hoped to have children someday, but were eager to achieve other things first, such as school completion.

\subsubsection{Reasons for wanting to delay having children}

A large proportion of the girls interviewed expressed a desire to have children in the future. Concerns around lack of resources, interest in educational attainment and careers, fear of rejection in society, and marital aspirations were some of the reasons given to delay having children. Girls who desired to have children in the future generally envisioned having children between age 20 and 35 years. Reasons given for the desired age included personal, educational, marital and employment. Some girls felt that there was specific age at which they wanted to have children:

I feel that (25 years) is the right age to have children. (Girl, 18-21, SS Only, Solwezi)

Some girls, especially those from the urban site Ndola, expressed concern around the burden of bringing another dependent into the world, especially when they themselves are still being supported by guardians.

There are a lot of diseases, and also the fear of bringing another child while you are also being kept (supported). (Girl, 12, SS Only, Ndola)

I have decided to continue with my school. I do not wish to have a child while I am still at school and still living at my parent's home because that would a burden to them. (Girl, 15-19, SS+HV+SA, Ndola) 
Girls also expressed fear relating to the possibility of ending up in situations where they would be unable to provide for their child, and might be forced into doing menial jobs in order to survive and feed their baby.

I see how my friends who did not know anything and are not in AGEP are suffering working in gardens because they rushed into having babies. (Girl, 12-14, SS+HV+SA, Mumbwa)

A number of the girls felt that the ideal age to conceive would also be dependent on when they are able to start working and earning a living.

I want to work a bit first before I have a child (at 23years) that's when I can start thinking about children. (Girl, 12-17, SS+HV, Chipata / Chazanga)

I want to finish school and start working. (Girl, 15, SS+HV+SA, Solwezi)

A number of the girls showed keen interest in completing their secondary and tertiary education before having children.

In the future when I finish school I would want to have a child. (Girl, 18-21, SS+HV+SA, Chipata /Chazanga)

The girls who were in school calculated the age at which to conceive a child based on how many years of schooling they had left to go.

(I want to have children) at 25 years... Because l'm calculating my years for me to finish school. (Girl, 12-14, SS Only, Chipata / Chazanga)

One concern expressed by the girls related to the fear of being forced to drop out of school and not being able to achieve one's dreams as a result of having a child too early.

If I have a child now, it would mean my dreams of school being shattered so I would rather wait. (Girl, 12-17, SS+HV+SA, Mumbwa)

It was evident in the respondents' narratives that social expectations and the influence of the community also play a major contributing factor in a girl's decision to delay pregnancy. The fear of being ridiculed by peers and shunned by the community were some of the reasons the girls gave for wanting to delay pregnancy.

If I had to fall pregnant now I will be a laughing stock, because my friends don't have children. (Girl, 12-17, SS Only, Chipata / Chazanga)

My parents also tell me not to be in a hurry to become pregnant, it is very embarrassing, everyone will be saying that one got pregnant at a tender age, so you have to take care of yourself and only become pregnant when you are old enough. (Girl, 12-17, SS+HV+SA, Ndola)

Most of the girls said that they wanted to first mature and grow up before they considered having children. Many of the girls felt that it was appropriate to first get married before they would think about having children.

I want to have children after getting married at 25. (Girl, 12-17, Control group, Solwezi)

Others felt that they wanted to have enough time to learn what they needed to know about life and the world before having children.

I would have known (learned) everything by the time I'm 35 years. (Girl, 12-14, Control group, Mumbwa) 
One girl indicated that she would rather wait until she was older and able to handle difficult and negative situations that could be the result of having a child too early, for example having a sickly child or being rejected by a male partner.

(I want to wait to have a child) because taking care of a child is hard, because maybe the child may get sick or the man can make you pregnant and then refuse. (Girl, 15, SS+HV, Solwezi)

Being made more aware of the responsibilities involved in raising a child, one girl expressed concern at having a child too early in life. She therefore preferred to have her first child at the age of 37 years.

Having a child early can be a challenge. (Girl, 12-17, Control group, Chipata / Chazanga)

One girl alluded to the fact that even though her peers would want to have children immediately after they get married, one would still have to be mindful of how soon after the marriage they have their child. She explained that there are cultural beliefs in her community that having a child too soon after marriage implies that there was pre-marital sex and that the marriage occurred in a hurry because the girl was already pregnant.

I want to have my first born child at 25... some people who have children just after marriage are suspected of getting pregnant before marriage. (Girl, 12-17, Control group, Solwezi)

\section{Support Needed to Delay Child-Bearing}

Most of the girls indicated that they would need advice and support from parents, guardians, aunties and uncles as to when to have children.

They just have to encourage me and tell me the consequences of being found around men by constantly reminding me that a man can ruin a young girl's life. (Girl, 15-21, SS+HV, Ndola)

(They must) continue advising me not to be in relationships before 30 years. (Girl, 12-17, SS+HV, Mumbwa)

They should advise me to concentrate at school and not to involve myself in bad things. (Girl, 12-17, SS+HV+SA, Mumbwa)

One of the girls in the control group suggested that in situations where a married girl is not able to decide for herself when to bear children, her parents can support her by assisting her to raise her children in situations where the age gap between the children is small.

My parents can help me to look after my children more especially when there isn't proper spacing, for instance I get pregnant when the other one is still some months old. (Girl, 12-17, Control group, Solwezi)

Respondents suggested that school teachers could also play a role in educating the girls on how to avoid teenage pregnancy so as to ensure a girl only has a child at her desired age.

The teacher can also advise me on how to take care of myself so that I do not have a child early. (Girl, 15-21, SS+HV, Ndola)

A number of girls in both the control group and intervention arms said that the will power not to have a child early was mainly up to them.

Like I myself, I don't think I would need help in that area to make sure I don't have a child before then. (Girl, 18-21, Control group, Chipata / Chazanga) 
You just have to take care of yourself that's all and avoid hanging out with boys so you don't have a baby to nurse. (Girl, 15-21, SS+HV, Ndola)

I reason on my own by taking care of myself so that I do not have a child early, I would rather take my time because God will see whether it's time for me to have a child or not. If I stay single years after I finish school, I know eventually a man who truly values me will marry me and look after me as opposed to having a man that abuses you. (Girl, 15-21, SS+HV, Ndola)

Self-control of sexual urge and desire was another ability that girls said they would need to have in order to abstain from sex and attain their desired goals of when to have children.

Just to control myself... When you feel like sleeping with a man, you just ignore it. (Girl, 18-21, Control group, Chipata / Chazanga)

Respondents suggested that if a girl is already dating boys, she would benefit from support from her boyfriend to ensure that she doesn't get pregnant until she feels ready.

There is nothing I can do but only to tell that man that I want to have children when I am 26 when me and him are dating and before our parents know. You tell him everything. (Girl, 1217, SS $+H V$, Chipata / Chazanga)

A number of the girls from the control study arms mentioned that the company they kept could influence their ability to achieve their goals as to when to get have children. They explained that it is therefore important that they choose their friendships wisely and correctly, to endeavour not to be jealous or envious of friends, and to stay away from boys.

Not having boyfriends and also not being envious. (Girl, 12-17, Control group, Mumbwa)

Not to be found with your friends who like men... I want to concentrate on my school. (Girl, 15, Control group, Solwezi)

What I am doing now is not to be found with boys at parties, night clubs because they can get you drunk and rape you and you will end up with a child. (Girl, 12-17, SS+HV, Chipata / Chazanga)

One girl suggested that it is important to choose friends who will respect your decision to delay having children, and who will not try to persuade you to stray from your path.

I want to have children at the right time, if I see that my friend is having boyfriends I can stop playing with her, if she is saying I want to have a child, I can stop playing with her and tell her to say "I can't force you not to have a child now, it's up to you". (Girl, 12-17, Control group, Ndola)

\subsubsection{Child-bearing aspirations}

In the interviews, girls were questioned on the number of children that they would ideally like to have. Their responses generally ranged between two and eight children. In most instances the girls were not able to explain how they had arrived at the desired number of children. In some cases the girls suggested that their ability to earn an income would also affect the number of children they would like to have.

I will be able to take care of them especially if am working. (Girl, 12-14, SS Only, Chipata / chazanga)

The vast majority of girls agreed that one's financial ability to look after and provide for their children was a major contributing factor in decisions around how many children they should have. 
You just have to know what you can manage, if you can't manage then there's no need to have a lot of children. (Girl, 12, SS Only, Ndola)

It is not good to have a lot of children, it may be difficult to feed them and take them to school. (Girl, 18-21, SS+HV, Solwezi)

Control girls expressed the same sentiment about the need to plan your family, and limit the number if children you have so that you can afford to provide for them.

When you have a lot of children, it becomes very difficult to solve problems but if they are not many it's very easy to solve. (Girl, 15, Control group, Solwezi)

Because it is easy to look after three children and I can afford to educate them... and also it can be easy to feed them. (Girl, 12-17, Control group, Solwezi, 03)

I want to have five children although marriages differ, you want to have 5 children but you can end up having 10 children, which may even be difficulty to feed them and also provide shelter for them. (Girl, 12-17, Control group, Solwezi)

In some parts of Zambia, particularly the rural areas, it is still viewed that the more children one has, the more assistance parents will have in their old age. Children are viewed as assets one should acquire to reap in future. One girl from a rural site was concerned with having children with disabilities and reasoned that the greater the number of children she has, the better chances she has in having healthy children who would be able to look after her.

Because children are born with different abilities, some may be disabled other might be mentally retarded while others may be very intelligent... I want to have 8 children so that they may look after me in my old age. (Girl, 18-21, SS Only, Solwezi)

\subsubsection{Effect of AGEP on delaying child-bearing}

A number of girls mentioned that their involvement with AGEP has played a major role in influencing their thoughts on whether to have a child, when they should ideally have children, and how many children they should have.

If this programme was not there, I could have children already. (Girl, 15-21, SS+HV+SA, Mumbwa)

One girl mentioned that she initially wanted to have children earlier but after attending Safe Spaces meetings, she had now changed her mind:

Now I don't ever thinking of having children because I haven't finished school (Girl, 12-14, SS Only, Mumbwa)

Another girl mentioned she had learnt that she needed to mature first and also settle down and get married before thinking of having a child:

We have been taught that you're not supposed to have a child because you are also still a child and you don't know how to keep a baby. You shouldn't have a child out of wedlock, you should only have a child when you have waited long enough and feel ready for marriage. (Girl, 15-21, SS+HV+SA, Ndola)

Quite a few AGEP girls, notably those from the rural site Solwezi, alluded to the fact that the nutritional information that they had received through Safe Spaces had helped them to understand that a child needs to be take care of well, and therefore they should only have children when they are able to cater for all the child's needs. 
I should be taking care of them and also feed them very well. (Girl, 14, SS+HV, Solwezi)

I need to take care of them, feed them well and also clothe them. (Girl, 13, SS Only, Solwezi)

Information that the girls had gained regarding family planning was another topic that AGEP girls, particularly those from the two rural sites, commented on. The girls stated that the knowledge they have gained on family planning had influenced their decisions on the number of children they should have and when to have them:

It has helped to think of having the manageable number of children. (Girl, 15, SS+HV+SA, Solwezi)

We learnt that you should have the number of children you know you will able to take care of and even take them to school. (Girl, 12-17, SS+HV, Mumbwa)

When three years has passed then I know that the child has grown then I can have another baby. (Girl, 18, SS+HV+SA, Solwezi)

One girl explained her view that the lessons at AGEP could not influence her fellow peers if they had already decided to have children earlier on in life.

AGEP can't change someone about how you feel on when you want to have a child or not, we are only here on Saturdays when we meet, like that girl she always told us that she would like to have a baby, we would ask her why she wants to have a baby and she would be like I just want to feel how those that have a baby. (Girl, 15-21, SS+HV, Ndola) 


\section{DRIVERS OF TEENAGE PREGNANCY}

One of the sections of the interview guides asked respondents to give their views on the issue of young girls in the communities getting pregnant before they want to. Questions they were asked included how common they thought it was for girls to get pregnant before the age of 18, and if they could provide examples of such situations. They were also asked to list the reasons why girls in their communities got pregnant before they want to. Interviewers probed specifically around economic and educational reasons, pressure from family or peers, lack of knowledge about or lack of access to condoms/contraceptives, and violence. Respondents were also asked to share their views and give suggestions on what they believed could be done to prevent girls from getting pregnant for the reasons that they described.

\subsection{Transactional Sex}

Transactional sex was the most commonly cited causal factor for young women getting pregnant. This was the case across respondents and across study sites. From the narratives of the respondents it appears that often young girls do not fully grasp the implications of their relationships until it's too late. One of the AGEP girls explained that when she was younger, she and her friends believed that if a man gave you money it was a sign of his love for you, so they would accept the man's money, and spend it, only later to realise that they were expected to give him sex in exchange.

We used to think that when a man is giving you money that means he loves you very much, but instead it means that he is after something. When he asks you for sex you will never refuse because you will think of his money that you have already spent... A man once proposed to me and one day he asked for sex because I have accepted and spent his money, so I went and told my mother about it and that's how my mother gave him back his money. (Girl, 16, SS+HV, Ndola)

\section{Transactional Sex and Fear of Violence}

The fear of violence from men was cited as a reason for girls engaging in transactional sex, and getting pregnant.

Having too many sexual partners who are giving her money, it will be difficult to say no to sex because of the favours she is receiving. She may be scared to refuse in fear of being beaten. (Mentor, Solwezi)

Several girls from the urban site Ndola described situations in which girls would be forced to have sex with a man who had given them money before, out of fear of violence.

When the boys give you money then one day he asks you to have sex with him, if you refuse he will start telling you that he will beat you so you will be scared and in the end you will give in and have sex with him. (Girl, 12-17, SS Only, Ndola)

Girls described situations in which they would be violently forced to have sex without their consent, after having accepted a man's money.

When a man is giving you money and his time to have sex with you comes, he would want to sleep with you without your consent, and there are men who can even threaten you with a knife that he would kill you if you don't sleep with him. (Girl, 16, SS+HV, Ndola)

In some situations girls did not have the money to pay back the men to get out of having sex with them. In these cases the men might threaten the girls until they agreed to have sex. 
There was a girl who used to get money from boys but this certain guy used to write down every amount that he would give her, $K 5$ today, tomorrow $K 5$, talk time $K 2$, when he showed her the bill it had reached $\mathrm{K100}$, he removed a screw driver and told the girl that I want my money, if you won't sleep with me I want my money and then she didn't have money. (Mentor, Ndola)

\section{Poverty and Transactional Sex}

Respondents in general described a context of poverty and lack of resources in the study communities. Poverty was one of the key factors in explanation of why girls ended up engaging in transactional sex, which would lead to unplanned pregnancies. One community leader commented that girls agree to have sex in exchange for very little, even just biscuits.

These children need to be empowered because these girls don't get pregnant because they are being given millions but just because of biscuits... where can these small boys find one million? Nowhere, so when these boys want to have sex with these girls, they tell them that they will buy them biscuits, or I will give you K100. (Community leader, Mumbwa)

In fact, sex in exchange for food, most specifically biscuits, was a commonly emerging theme in the data, most notably from the two rural study sites.

When a girl likes money, every time they ask for biscuits from boys and the same boys don't give them for free but ask for sex in return which leads to pregnancy... There are many girls in this area who always ask for money to buy biscuits and other things in this area and when these boys offer money or things to these girls they end up having sex with them which leads to pregnancy... It is very common because many girls love money and things like biscuits. (Parent, Solwezi)

Being young ladies... they don't know anything, someone can be impregnated just because of a biscuit, not something sensible, just buying her a biscuit they even have sex, they think they are just playing when they are actually getting pregnant, just because of a very simple thing. (Community leader, Mumbwa)

Respondents from across all the study communities explained that hunger and lack of food could lead a girl to engage in transactional sex. Some comments regarding hunger being a motivation for engaging in transactional sex came from girls themselves. Narratives on hunger appeared to be very prevalent amongst respondents at the urban Ndola site. A number of girls in both the intervention and control groups from Ndola described theoretical situations of this kind that might be experienced by girls in their community:

(If her parents) don't give her food; she might decide to start sleeping around just to be able to find something to eat in the end she might get pregnant. (Girl, 18-21, SS+HV+SA, Ndola)

You might not be able to provide in your home and now you start going out (to find men) so that you find some money. (Girl, 18, Control group, Ndola)

When there is no food in the home and she wants to find some money to buy relish only to be told that she has to sleep with a man in order for her to get that money. Upon doing that, and without using any protection then she becomes pregnant. (Girl, 15-21, Control group, Ndola)

When someone is too poor and life is too hard it can make someone want to have a boyfriend who can at least help her with money. I have seen situations where a girl ends up going to the club to sleep with any man that she meets so that she can have something to eat, this may make one get pregnant from these men that she may be sleeping with. (Girl, 15-21, SS Only, Ndola)

A range of adult respondents from across the study sites similarly shared the view that hunger and transactional sex are closely interlinked. Some of the respondents described 
the context of poverty in their communities, and the desperation that led young girls into these situations. Respondents from the urban sites described the context:

Poverty has no boundaries, because you would find that when a person is hungry and they do not have any money to buy food and she finds a man who has money and for her to suppress poverty, she to get money from the same man and now that man takes advantage of her and starts to use her in sleeping with her and as a result she falls pregnant. (Parent, Chipata / Chazanga)

You find that this girl has nothing to eat at home the whole day so she starts to think that maybe if she goes out with this big guy who has some money, she will at least have some food on the table. (Mentor, Ndola)

Chazanga is an impoverished community, so there are high levels of poverty, this is actually driving girls to finding other means and one of the means is to indulge in premarital sex and through that they get pregnant. (Community leader, Chipata / Chazanga)

Likewise, respondents from the rural sites described similar contexts of poverty and hunger that could lead girls into transactional sex:

This year our area has experienced a high level of hunger. There is a lot of hunger in the homes which means that at times the child goes without anything to eat all day, when a man who is offering her K10 for her company approaches her, she will lay with him and eventually end up pregnant. (Parent, Mumbwa)

Families in the rural areas that relied on farming for their livelihoods often struggled to meet their needs, and would find themselves without enough food after a poor harvest, so would have to send their daughters to earn a living, which would put them at risk.

There are so many poverty issues in our community... a girl not being provided with things like school fees and food sometimes even the necessities that a girl would want... you find that the girl makes comparison with a girl whose parents are able to provide, or sometimes they make comparisons with friends that have boyfriends who provide for them... At the end of the day you find that poverty leads them into indulging into sex before time... some guy that made her pregnant is the one that used to provide her with some money and some mealie meal for them to eat and this boy, his family had a garden so they could go and get some vegetables just for ends meet for them to have at least a plate of food on the table, so this girl at the end of the day ended up getting pregnant from the same boy... this is the most common reason why girls are getting pregnant is because there is much hard work, looking at also the families that they are coming from, they are peasant farmers who do not even grow enough, sometimes they have nothing to eat with their families, you would find that the food that they have goes up to mid-year and you would find that half of the year they have nothing to eat and you would find that even the girls are sent now to go and work on the farms, girls are sent to go and sell on the streets and by so doing you would find that the girls are now subjected to boys who would want to give them something in exchange with sex. (Mentor, Mumbwa)

One mentor described situations in which girls would seek support, help and food from other people, and then get taken advantage of.

Because of hunger, they would have situations at her home were they would have no food, she would go to her friends place (for food)... her friend would cook and they would eat together, as I am speaking she is pregnant from her friends brother, so the biggest reason is poverty. (Mentor, Chipata / Chazanga)

Some girls who come from poor families in rural areas would rather trade sex for money and support than work in the fields alongside their families.

Poverty can cause a girl to get pregnant if her family is poor, and it is not easy to find some money unless they go in the field. You find that if she is lazy she would refuse to go into the fields, but instead she would want to go in the bars to make fast money. Even her dress code 
will be very bad, she will dressed in short clothes so as to entice men, and she would accept any man so long they give her money... In this community I heard of and saw a girl who was from a poor family but she never wanted to be going in the fields with her parents, she just wanted to be going in the bars. (Girl, 18-21, Control group, Solwezi)

A few of the girls disclosed their own past experiences of having traded sex for basic household necessities such as soap.

It was a kind of thing where you do not have things to use for the child like washing soap. So I met this guy who bought things like that and told me that he wanted to have sex with me and could not just give me for free. So I accepted and that was how I got pregnant (Girl, 15-21, SS Only, Mumbwa)

One explanation given for why girls in the rural areas would end up having transactional sex was in order to pay for transport.

They are walking long distances and their parents do not have money to give them for transport so they just think of... trying to look for money and in the process they get pregnant. (Girl, 17, SS+HV, Solwezi)

\section{Materialism, Peer Pressure and Transactional Sex}

One of the most common themes in relation to why young girls in the community got pregnant due to transactional sex related to materialism, the desire for material items, and wanting to have things that friends have.

When she lusts for things... it will force her to sleep with a man. (Mentor, Mumbwa)

It was apparent in the respondents' narratives that peer pressure, materialism and transactional sex are often closely interlinked.

Group influence, you will find that these girls admire things from their friends and when they are asked how they got them, their friends will tell them to do things like sleeping with men. (Parent, Ndola)

If one for example always lust for things that her friends wear for instance latest fashions and she cannot afford, she can consult her friends on how they get those things and they can share like, "oh I have a boyfriend who gives me money you mean you don't have a boyfriend", that's how that girl can be influenced and also fall in that trap and maybe get pregnant in the end. (Mentor, Mumbwa)

Sometimes a young lady one can be envious of her friends somewhat better lifestyles and what they're able to do and afford eventually she will give in and simply put herself out there trading sex for money. (Community leader, Ndola)

I would say peer pressure and lust go hand in hand, just because my friend has it I should also have it and with peer pressure you would find that they would be four in a group but only one goes to school, you would find that due to pressure the one who goes to school would even succumb to the pressure and stops going to school and might even end up getting pregnant and leaving the ones that don't go to school... when a girl always has money or nice things like clothes, lotion and phones financed by a boyfriend or sugar daddy, the girls that don't have end up being envious and want to follow suit in acquiring those things by similar means. (Mentor, Chipata / Chazanga)

Group influence can cause teenage pregnancy if one person engages in prostitution to acquire material things, a girl will be telling her friends things like "I have a man who provides me with all the things that I need, things like soap, Chitenges and many other things so if you also want you can have men to help you out". (Community leader, Solwezi) 
Some of the adult respondents, particularly from the urban sites, explained that girls envied things that their friends had, and competed with them to have nicer clothes and more expensive items.

I see your gold chain, with nice shoes and a nice bag - where did you get this? Then you say my boyfriend gave me, I will also want to have more than what you have, at least I should have a watch and a phone. (Mentor, Ndola)

Sometimes she may admire something that the friend has and does not have that thing, it might be fashion and the like so she might end up sleeping around with men or maybe stealing so that she has those things also. (Parent, Chipata / Chazanga)

Respondents described that when girls get themselves into situations in which they become dependent on a sugar daddy to buy them what they want, they lose their agency and the power to refuse sex.

If you are lacking and you are getting pressure from the way your friends are looking (dressing), you will definitely find someone to sponsor you (sugar daddy) and in the end you get pregnant because you have no say you will give in and get what you want. (Girl, 18-21, Control group, Chipata / Chazanga)

Competition between girls and between families was a recurrent theme.

Competition comes in mostly because of fashion, more especially what people like wearing like slippers, oh I need to buy that, how am I going to get the money to buy these slippers, I will have sex with a man or I will have a boyfriend, today he will give me money tomorrow the same thing, then he will ask for sex then I won't be able to deny him, I will give in so he can give me money to buy the slippers that I want. (Mentor, Ndola)

One community leader from an urban site explained that sometimes the pressure came from a desire to match your peers and neighbours in providing for and giving gifts to your family.

When they go to their homes there is pressure... here you have a parent, who has got a teenage girl, and the neighbour has got a teenage girl as well, so now... the neighbour's daughter, buys the mother a pair of shoes or chitenge material. And this other neighbour now, tries to praise the neighbour's daughter, to say... "the daughter to such and such has now grown up because she has managed to get the mother a chitenge material" so, now you are praising in the presence of your own children. So now the children are affected, so what they are going to do is, go out and meet a man, who says, "can I have sex with you and I will give you K100.00?", and they will accept. So that they go and have those presents for their mother, so they go and buy a chitenge material and give it to the mother, and the mother will be very happy and say, also look at my child, my child has also grown, she has now managed to get me a chitenge material, so there is that pressure that is also coming in at family level. (Community leader, Chipata / Chazanga)

Respondents in both rural and urban areas explained that many girls were image-obsessed and wanted to look good, wear the latest fashions and have their hair styled. This would lead them into transactional sex relationships.

She will see a latest design of clothes or something like that and she wants to get it, so she will go to her boyfriend to tell him that she wants to go to the salon, for the boy to give her the money, he will want to first sleep with her. (Mentor, Chipata / Chazanga)

For some it is because when they see others buying expensive clothes, they also want to buy. (Girl, 15-21, SS Only, Chipata / Chazanga)

Girls like nice things, when they are at school they like buying things like candies, biscuits from the tuck shops... these girls like smelling good, they like perfumes and doing their hair nicely. When a man comes with money, they will accept because they want all those nice things. They 
love things when they are still young so those men will sleep with them and make them pregnant... we have this young girl who loved things and had high standards. She was a young girl but had so many boyfriends, she had more than four boyfriends; some were older than her and others were her age mates. She used to look so nice that you would think that she works (has a job). But because of that love for money, she got pregnant. (Community leader, Mumbwa)

The desire to be fashionable and look good was a commonly cited reason from respondents across all the study sites.

Girls like to hang out in groups. When she asks a friend where she where she got a skinny jean, she would tell you that she got it from the boyfriend so that makes you want to have a boyfriend. He will not just give you money freely. (Girl, 18-21, SS+HV, Chipata / Chazanga)

There were tops that were out in fashion at that time and she wanted one. So she said that I want to go to the pub so that I can find someone to buy it for me... (My cousin) she was saying that she needed money for a party, so she was going to sleep with someone from the club so that they can give her money. (Girl, 18-21, SS+HV, Chipata / Chazanga)

(One girl) who likes fashion... she doesn't go for second hand clothes like some of us, she goes for JET and others such shops, so when my friend saw that the other girl shoes from jets then she said on, my friend got shoes from JET, I will go and buy shoes from Bata then she will come to church and say oh, is that the shoe you are putting on, I am putting on shoes from Bata.... now because her mother never used to have a lot of money, maybe she could afford to buy her clothes for K35 each but she didn't want to wear K35 clothes, she only wanted expensive clothes now to have those expensive clothes she used to have sex with men to have money for the clothes, she even said it herself money has bought problems for me she talks about it because it has already happened. (Mentor, Ndola)

Girls seeking men with whom to engage in transactional sex to attain their material needs would frequent local bars.

This girl was surprised that her friends always had vanilla biscuits and leggings which she didn't have until she asked how they get those nice clothes. The girl was told that if she also wanted to have then she should follow them where they got those things... there is a bar called Barcelona where every evening girls bath and go there. The very girl went to that bar and she was asked why she goes there even when she was ever home she didn't answer and what we saw after a month was a pregnancy, we asked why? She blamed the friends who found a boyfriend for her. (Mentor, Solwezi)

The love of money was given as a reason why some young girls would choose to engage in transactional sex.

It is the love of money. You find that you are young but you love money so much, meaning in the end you will start having (sex with) men. (Girl, 12-17, SS Only, Chipata / Chazanga)

The love of money... because they want to have the money to buy what they want, and they don't have anywhere to get, as a result they find themselves involved in men and as you know a man cannot be just giving you money without having sex with him. (Girl, 18-21, SS+HV, Mumbwa)

Girls wanting to have toiletry items such as soap, body lotion, facial powder and make-up was also a factor. When their parents didn't provide these kinds of items for them, they would end up trading sex for them, and as a result get pregnant.

If girls are not being helped or given the things that they need (by parents)... Girls who lack things like soap, lotion and other things usually resort to getting those things from boys and men who ask for sex for the things that they give them, and in the end they get pregnant... The girls that get pregnant in this way are many because many families fail to help their daughters with things like soap, lotion and other things... when these girls lack basic needs they engage 
in sexual activities... these men trade material things for sex and girls can end up getting pregnant. (Parent, Solwezi)

Some copy from their friends to have boyfriends. When they have one, the boy will be giving her things, but not for free. They will want to be paid in kind. As a result they end up pregnant... (they want) biscuits, sweets, make up kits and powder so that they look nice and clothes too. (Mentor, Chipata / Chazanga)

Often it seems that parents were oblivious of the situations that their daughter were getting themselves into.

(One girl) she used to like buying nice and expensive things for her to look good... now has a child... parents don't pay attention to what their children want so that they can give them... parents (need) to realize that they are the ones causing this problem (Girl, 18-21, SS+HV, Mumbwa)

Most respondents, as seen above, described theoretical situations of girls engaging in transactional sex for materialistic reasons, or gave examples of girls they knew. Very few of the girls interviewed recounted their personal experiences of engaging in transactional sex. One girl from the control group in the urban site Chipata / Chazanga disclosed that she had engaged in transactional sex in order to purchase something that she desired.

(I had sex) because of money, I wanted to buy something and I didn't have money. In that situation a man can tell you to sleep with him especially when you are assured that he will give you something. (Girl, 18-21, Control group, Chipata / Chazanga)

\section{Transactional Sex and Supporting the Family}

In many cases it was suggested that when girls come from family contexts of poverty and lack of resources, girls end up getting involved in transactional sexual relationships in order to support their families. Notably, the majority of quotes relating to this theme came from respondents at the two urban study sites.

I know two girls who used to stay with their parents, their parents never used to do anything, they just used to depend on hand-outs from people. Now there was this young man who used to help them, and as a result one of the girls fell pregnant as young as 13 years old from the same young man. (Parent, Chipata / Chazanga)

The poverty levels in these homes, you find that the parents are not able to provide for the children, when the child is given a five kwacha by her boyfriend, she tell her mother that I have such an amount and they use that money to buy food they eat. (Mentor, Chipata / Chazanga)

In some cases the impoverished household circumstances might be a result of irresponsible parenting or parental neglect.

For some it's their parents that are the cause, you find that a child comes back home at 10pm, they don't say anything, they are quiet, they even open the door for her. (Mentor, Chipata / Chazanga)

Irresponsible, careless and neglectful parenting was cited as a common reason for girls getting involved in transactional sex, and getting pregnant at a young age.

Parents being careless can be one of the reasons why girls get pregnant... for these who are in boarding school, you would find that you buy things for your daughter and give her pocket money for sustenance. But you would come to learn that when returns from school, she comes back with expensive clothes and instead of the parent questioning where the daughter got these things from, she will stay quiet about it so that people think that she has enough money to give her daughter everything she wants. When it turns out that this girl is pregnant, the father will be annoyed with the mother because the mother has to be very tight with the 
daughter to know all her whereabouts and when she wants lotion for herself or soap as a mother I have to buy for her. She is not supposed to be in possession of anything I have not bought for her. (Parent, Solwezi)

In cases where both parents are alcoholics, and fail to look after their children, the elder daughters have to support and feed their younger siblings with the money they get from transactional sex.

There are parents that don't have time to sit down with their children... Both the mother and father are drunkards, they both reach home at 10pm. Sometimes when they get home they are very drunk and they start fighting, they don't even know whether their child is home or not... the wife drinks, the husband also drinks, as I am speaking right now they are in bars, they just call each other to say we will meet in such and such a bar, when these are married people with teenage daughters! They don't even have time to see and take care of their children, or even provide food for their children, sometimes they would go without leaving anything for the children, you find that the money that the girl got from her boyfriend is what she uses to buy food, she will buy some eggs, they cook nshima for her siblings to eat. When the parents come back they want food to eat even when they didn't leave any food. That's the reason why girls become pregnant... parents should just learn to make time for their children especially the girl child. They should be good example to their children. (Mentor, Chipata / Chazanga)

Alcoholism amongst parents was cited as a problem in the urban sites:

You find that a family would be living in a one-roomed house and sometimes they would have breakfast, miss lunch and have supper if lucky. The parents just drink alcohol, they both do not have a job, so the girl will be forced... she would lust for things that she does not have and she will find friends who will influence her to get involved with men so that she can be receiving money and buy food for the family. (Mentor, Chipata / Chazanga)

Respondents suggested that sometimes parents would even encourage or coerce their daughters to seek out transactional sex partners in order to bring food home to the family.

There is a young girl... who got impregnated... her reasons were that because of poverty her mother was coercing her to go and sleep with this man... sometimes parents coerce their children into do such things. (Girl, 15-21, Control group, Ndola)

There was a girl who used to stay with her parents and one day the father stopped working and because of what was needed at home, the girl started sleeping around with men... sometimes parents coerce their children into doing such kinds of things. (Girl, 16, SS+HV, Ndola)

As a family, maybe due to economic hardships, they can complain about you not being an active contributor to the household and eventually pressure you to exchange sex for say money. That way you end up falling pregnant. (Girl, 10-14, SS+HV+SA, Chipata / Chazanga)

Circumstances in which a girl has a baby, and the baby's father refuses to provide support, may also lead a girl into transactional sex in order to support the child's needs.

I know of girl that got pregnant because things were hard at home and she wanted help, so when she got pregnant she mentioned a certain guy, who refused that it was not his baby because the months she was mentioning were not correct. So what is happening now is that she leaves her child at her grandmother's place, and she goes to sleep around in pubs so that she can take care of her baby. (Girl, 15-21, SS Only, Ndola) 


\section{Transactional Sex for Other Services}

Respondents explained that there were various other items and services that girls would receive in exchange for sex. One AGEP girl explained that she became pregnant by accident after exchanging sex for exam answers.

I had gone out to write my grade nine examination with my friends so I was enticed to have sex with some man so that we can have some examination leakage... he was just some person that we met in the same area we went searching for leakage but now I have a baby... (The men) gave us the (exam papers) leakage in the evenings and told us that we will meet tomorrow. To my surprise they came back and called us to this ramshackle house, thinking that they were giving us leakages... then they had sex with us... they told us to go with them saying that that's where they had left the papers and that's how we went with them. When we got there they gave us the papers, and said now we have sex. (Girl, 15-19, SS+HV, Mumbwa)

Looking at the respondents' narratives, it appears that this exchange of sex for exam answers was not an isolated incident, and may be a common occurrence, especially in the rural areas.

Girls exchange sex for leakages especially those in exam classes e.g. grade 9, they sleep with teachers and some in order for (him) to help first has to sleep with her. (Girl, 17, SS+HV, Solwezi)

One mentor explained that transactional sex also occurs in exchange for school fees.

This girl who may not have support in terms of finances to go to school, may get pregnant if she finds a man who is support her to go to school, and she has to pay by having sex with the man that is supporting her. For example if I want to go to school and my parents don't have money and there is a man who has promised to pay my school fees, I will accept, but the consequences will be very bad, I may get pregnant and many other bad things. (Mentor, Solwezi)

In addition to paying for school fees, some girls might engage in transactional sex to pay for other school necessities, such as books, stationery, uniforms and shoes.

They resort to sexual activities to buy things for school while others that have no parents are just looked at and they involve themselves with men to get money for books. (Mentor, Solwezi)

\section{Death of Parents and Transactional Sex}

Being orphaned was one factor cited by respondents, particularly those in the two urban sites, as being a factor in young girls getting pregnant. It could be that in the rural areas orphaned children get more support from the community and are less vulnerable than those in urban areas.

If the parents die and she is the only elder one then she can start doing prostitution so that she can provide for the others in the family and at the end get pregnant. (Girl, 15-21, Control group, Ndola)

For some, you find that their parents are dead and so they indulge (in sex) to earn a living. (Girl, 15-21, SS Only, Chipata / Chazanga)

Some respondents gave examples of orphaned girls in their community who had ended up engaging in transactional sex.

This girl has lost both parents and is living with the grandmother who is not doing anything. Out of desperation and the will to provide, she sees no way out but to sell her body for money. Sometimes the pain and agony of losing both parents will cause her to go out and look for 
alcohol to drink so that that she may numb the pain and forget her troubles. (Community leader, Ndola)

There is a girl... when her mother died, she did not have any one to look after her and she opted to have a boyfriend who would buy her body lotion and other things in exchange for sex. Unfortunately she got pregnant (Girl, 12-17, Control group, Solwezi)

Some of the respondents described situations in which orphans suffer from maltreatment where they stay, so they are forced to seek shelter elsewhere, making them vulnerable to sexual abuse and transactional sex.

Many people mistreat the orphans... as a result it often leads to pregnancy because those children prefer being with boyfriends than at home... somebody told me about what she is going through... they mistreat her. Somebody one day told me that the same girl was going round knocking at people s homes at the way bridge, she even went to a man s home to ask if she could sleep there because her grandmother was mistreating a lot... it is common and worse nowadays because orphans are now many. (Mentor, Solwezi)

Girls are sometimes also mistreated by step-parents in the case of death of one parent.

She will need a lot of things like food, school, and as a result she will need to have a boyfriend and that can lead her to become pregnant... there was this girl who used to stay with the father and the mother was late (died) so she was being mistreated by her step mother. That's how she ran away to stay with a man but she was already pregnant. (Parent, Chipata / Chazanga)

\section{Transactional Sex and Lack of Information about Contraceptives}

Some of the mentors explained that many of the young girls who end up exchanging sex for material goods do not have information regarding contraceptives, so are unable to protect themselves.

You will be a slave if you have someone else's money, they will give me expensive gifts, jewellery what, what but in the end he will ask for something and that something is sex and then with sex if am young I don't even know that there are even contraceptives, there are condoms and the like, I will fall pregnant and contract STIs and HIV. (Mentor, Ndola)

I may be a good girl very innocent I don't do bad things but once I join bad company I will be compelled to do bad things, these same girls from the group they will be encouraging the other girl to join their bad ways, and when she sees the clothes they are putting on, the food they are eating she will join the group where she will also have a boyfriend who will give her all such things but the end result will be pregnancy because she does not take any precautions like the friends who are already in the system. Usually it's an amateur who gets caught up in the issue of pregnancies. (Mentor, Solwezi)

\section{The Solution}

Some of the mentors explained that when girls are able to save their own money, they are more independent and less likely to resort to transactional sex to survive.

Relationships with men... have even ended because the girls are saying they don't want them, even when (the men) offer them money (the girls) are telling them that they have their own money. (Mentor, Solwezi)

If there are things that she can sell for example if it's the mango season, sweet potatoes she can sell and earn some money or maybe vegetables, she can grow vegetables and sell and earn money from there, we want to teach so that they can be saving their money so that she doesn't depend on men because when she grows up, if she doesn't know how to save then she finds a man who will be giving her money. She will think that money is good money 
because he will be giving her everything that she wants, but from her own money she can get powder. Because as you have seen they have started applying lipstick like me, so they can get powder and all these other things from their own money. (Mentor, Ndola)

Another mentor from Solwezi suggested that men in the communities also need to be engaged in an effort to put an end to transactional sex relationships.

Men should know that the girls can also find their own money, and it they should not be bringing money for the girls... they should just be friends just like they have female friends instead of bringing them money to be intimate friends. (Mentor, Solwezi)

One of the AGEP girls made the suggestion that girls need to be advised not to be materialistic, instead of lusting after things that they don't have and can't afford.

Girls follow men for money... What can be done to prevent girls from getting pregnant for this reason is to advise them not to be admiring whatever clothes they see. (Girl, 15, SS+HV+SA, Solwezi)

One of the community leaders said that girls needed to be warned of the risks of desiring material wealth, and should be advised to be patient and to finish their education before thinking of acquiring things.

I am begging that these girls should be taught even by AGEP that such things come at a later stage in life. And be taught that if they love money so much, it will land them in early marriages. The most important thing is that these girls finish school so that they can be independent. (Community leader, Mumbwa)

One view that was expressed by a variety of respondents, particularly from the Solwezi rural site, was that parents need to make a concerted effort to support their daughters, so that they have no reason to enter into transactional sex relationships to get what they need.

When a girl is asking for what she needs and the answer from parents asking her to fend for themselves; they girls get into bad ways and eventually get pregnant... Parents should make an effort of supporting their daughters. (Girl, 16, SS+HV, Solwezi)

What can be done is the parents and guardians need to help girls with material things and basic needs so that they don't look for men to provide for them because these men trade material things for sex and girls can end up getting pregnant. (Parent, Solwezi)

It's up to parents to work hard so that they can provide for their children, they need to provide things like food, education and other things if they do that children won't be tempted to exchange their bodies for these things. (Mentor, Solwezi)

One of the parents commented that poverty should not have to lead girls into transactional sex if their parents can manage to grow food to feed the family.

Poverty is one of the reasons... This would be reason why some girls leave their homes and end up losing their way in life and fall pregnant. Even though I am old and we live in poverty I am able to farm and grow crops, and as long as we have harvest it will always generate money for us to buy soap or relish. The children would never say that they've sleep without eating. A sensible person would never leave that to go and look for other things elsewhere. (Parent, Ndola) 


\subsection{Peer Pressure}

Besides being influenced by peers and friends to engage in transactional sex, as outlined in the previous section, young girls getting pregnant as a result of other forms of peer pressure was a commonly cited issue in the study communities.

If a girl starts playing with other girls that are naughty, her behaviour will also change even if before at home she used to respect you, she will no longer listen to you when you tell her something because of the friends that she is playing with and because of peer pressure she might fall pregnant. (Parent, Mumbwa)

Some of the adult respondents described how young girls are subject to pressure from their friends to get involved in sexual relationships.

When a girl has lots of friends it's difficult to be focused, because they want to be like this one and that one in the end they get confused and sometimes their friends are the ones that tell them that if you don't have a boyfriend you are backwards... I have a daughter, my fourth daughter... she was only thirteen, little did we realise that as she goes to visit her friends they were influencing her to have a boyfriend, so apparently at the same house there was a boy who was eyeing her, so what happened was that she reached a point where she just disappeared from home, after some weeks we just heard that she was seen at some far away village, so this was all because of peer pressure. After a few months she was pregnant and stayed on that side until she delivered, after some time the boy run away from her and that's how she came back home to plead with us so we can return her home. (Parent, Mumbwa)

Being in bad groups, even if a girl is well behaved, the friends in that group who engage in sexual activities try by all means to make their friend also start doing their ways, which is a very big problem. (Parent, Solwezi)

Peer pressure and lust go hand in hand, just because my friend has it I should also have it. With peer pressure you would find that they would be four in a group but only one goes to school, you would find that due to pressure the one who goes to school would even succumb to the pressure and stops going to school, and might even end up getting pregnant and leaving the ones that don't go to school. (Mentor, Chipata / Chazanga)

As well as pressure from peers and from boys, girls themselves were eager to enter into relationships.

Girls just rush... they just rush, they get excited to get into relationships, as a result the pregnancy comes in. (15-19, Control group, Mumbwa)

Two of the mentors from Ndola explained that the young girls lacked information on sex and contraceptives, and as a result did not take precautions against pregnancy when influenced by peers to engage in sex.

Peer pressure: "oh you don't have a boyfriend, sex is good", you try it, then she will start envying her friends when she doesn't even know what she is getting herself into, she doesn't know the implications... most of them don't know that if I start sleeping with him at this age, I will enter the family life. They don't know because they are young. (Mentor, Ndola)

In a group they all had boyfriends and they would be together everywhere but this girl was the only one who didn't have a boyfriend. Because she followed her friends blindly when she didn't have information, she didn't know how to protect herself, her friends knew how to protect themselves. Maybe they don't even have sex, they just move around, you who is seeing from afar you think they engage in sexual activities, because sometimes when you go for outings as a group, you see people kissing and laughing, you start thinking how come they are kissing, obviously they do everything (have sexual intercourse), you also want to do the same thing. (Mentor, Ndola) 
One commonly emerging theme, particularly from the two urban study sites, related to girls being subject to peer pressure to be sexually active, but not having the same information about how to have safe sex as their friends, so they end up getting pregnant.

They follow what their friends tell them, because they don't want their friends thinking that they are dull. The friend will say "why can't you have a boyfriend, look at me, my boyfriend gave me twenty kwacha yesterday, I used it to plait my hair"... when she sees this she also finds herself a boyfriend just so she can fit in. But because her friend started having sex a long time ago and she knows what to do to prevent pregnancy, she even knows how to use a condom. But this one who is new (to sex) just opens her legs to the fullest without using protection and then she becomes pregnant. (Mentor, Chipata / Chazanga)

One of the girls in the control group explained she succumbed to peer pressure to have sex but was not informed about contraceptives, and got pregnant the first time she had sex.

There are friends that can convince you to sleep with men telling you that you need to experience it. When you follow that, you can end up getting pregnant, whilst they don't because they know the preventative measures they can take. That is what had happened to me. A friend from school would ask me to go with her to try having sex but when I did, that very first time, I fell pregnant. (Girl, 15-21, Control group, Ndola)

A number of the adult respondents from the rural site Solwezi, including parents, mentors, and community leaders, explained that some girls experienced peer pressure to have babies, and others were envious of their friends with babies.

Some girls envy their friends who have babies such that they will start having desires to have babies also. (Community leader, Solwezi)

Some girls admire when a friend is pregnant they also get interested and want to get pregnant and start asking their fellow friend how she got pregnant and she would tell her that if you want you can just sleep with a man and you will get pregnant and in the end she tries and then becomes pregnant. (Parent, Solwezi)

They just admire their friends that have children and then they also decide to have a child... There is a girl who has a friend who got pregnant and had a baby, when the friend delivered she started admiring having a baby. (Mentor, Solwezi)

One girl described how a fellow AGEP group member got pregnant because she wanted to experience what it felt like to have a baby, like those of her friends who were already mothers.

(One girl in our AGEP group who got pregnant) always told us that she would like to have a baby, we would ask her why she wants to have a baby and she would be like I just want to feel how those that have a baby. (Girl, 15-21, SS+HV, Ndola)

One community leader suggested that some girls also envied older women with babies, and this also led to them to engage in unprotected sex.

Most of these girls are just naughty, they don't listen and they like engaging themselves in bad groups (peer pressure), they play with those who take alcohol and also envy those with nice things not knowing that those are elderly people they can afford to have such things... when a girl sees an adult woman who is grown and is pregnant, they usually admire and in the process they also experiment and get pregnant forgetting that they are still young. (Community leader, Solwezi)

Situations also occur in which young girls hang out with much older girls and end up copying their behaviour and getting involved with things that they are not mature enough for.

You would find that a girl is just 14 years and she is playing with people who are older than her, those that have already experienced life and sometimes she is the one whom they send to 
their boyfriends, then in the end she will also follow their style end up having a boyfriend too then she will be pregnant. (Community leader, Solwezi)

One parent disagreed that girls get pregnant due to peer pressure, saying that it was the sole responsibility of the girls if they become pregnant.

Your friends can't lead you to get pregnant, it's your own fault. (Parent, Chipata / Chazanga)

\section{The Solution}

A few adult respondents suggested that in order to mitigate the effects of girls being influenced by peer pressure to become pregnant, they needed to be provided with information on how to protect themselves, and needed to be empowered so that they could be self-confident and independent.

(We should be) teaching them to take care of themselves and not to be copying other peoples lives. (Mentor, Mumbwa)

One mentor commented that if she had been provided with information about contraceptives, and support to be self-confident and independent when she was a young girl, she would not have become pregnant as a result of peer pressure and lack of information.

The most important thing this time is sensitization and giving these girls the information, even if you see your friend doing something, you don't have to follow what your friend is doing, stand on your own, you know what you want, just stand, like I said, when I got pregnant the first time, I was just following what my friends were doing because I thought we were just playing, getting myself in to something that I didn't even know but if I had information I wouldn't have done it. Information can help the girls in the community to stand on their own. (Mentor, Ndola)

\subsection{Bad behaviour / Being naughty}

Mentors and parents explained that some girls just have a naughty nature, and it is in their personality to misbehave, disobey parents, and engage in bad behaviour.

You will find that this person who is naughty will never have self-control, with them whatever man proposes to them they will accept they do not have the word no in their mouth. (Mentor, Solwezi)

(Some girls) are just naughty, just like my daughter, she had everything; food, her own bed but she still went ahead and ran away with a man. Another thing is group influence, playing with many friends because she only listens to her friends. (Parent, Ndola)

There are some that are just naughty, that's just their nature... I can give an example (of one girl)... she is the kind of person that you can't sit down and give her advice and even the mother she does not adhere to her advice. Not even the father, she is just in grade six, but she finds herself in parties, and disco places. Some are just unreasonably naughty to the point that they cannot be controlled. Their lawlessness always ends up leading to pregnancies. (Mentor, Chipata / Chazanga)

Young girls dressing provocatively and indecently was also cited by respondents as a factor leading to men approaching girls and getting engaged in sexual relationships.

If you put on miniskirts and also trousers so when a man sees you like that, he can't hold himself and when he proposes (sex) to you, you can also agree. (Girl, 15, Control group, Solwezi) 
When you are telling them they say that we are old fashioned but that is not the case, the way girls dress up now, you will find that she is only wearing leggings and like that men can't leave you. (Parent, Ndola)

Hanging out with boys too much was listed as one reason for girls getting involved in sexual relationships.

Some girls love so much to hang out with boys so boys take advantage and have sex with them. (Girl, 15-19, SS+HV, Mumbwa)

\subsection{Culture / Tradition}

Some of the community leaders from both urban and rural communities cited traditional cultural values and rituals as being causal factors in young girls getting pregnant. One community leader described a ritual celebration in which community members would gather, including young girls, and the celebrations would often end up in sexual intercourse.

There are certain times of the year when people need to celebrate the culture. It is usually in the night. Because the teenagers can't just sit home they follow adults to go and watch people dancing to the music from the drums that are being beaten. In the process some get involved with men who will impregnate them... there was some traditional gatherings (ceremony) in XXX area, and (the girls) got involved with some men, unfortunately they even got pregnant, and some were forced into marriages. Also among these girls two were nieces to the chiefs and sadly enough they boys responsible are nowhere to been seen in the community. (Community leader, Solwezi)

One community leader from an urban site described how in some areas, due to traditional practices, girls are promised for marriage by their parents to suitors as early as 3 or 4 years of age.

They do not value education and especially girls, so girls are married off at a very tender age... we have heard that within the circles, a girl can be married at actually 3 years. 4 years, and the man keeps waiting for that girl, and then when they reach puberty, they just get that girl. So it is very, very common in this community... Community challenges... religious beliefs, where elderly men marry off young girls... we really need to find some interventions to get to them. (Community Leader, Chipata / Chazanga)

Some of the adult respondents from the two rural sites suggested that the common local practice of building a separate house for their daughters was a leading cause of young women getting pregnant too early.

(Parents) are building their daughters separate housing... once they build that house separate from their own home, it means she has been given freedom to do what she wants to. It seems though that that's the tradition of the lla people who inhabit this land. They think it's a way of showing respect to the young lady. But I feel differently about it, because that puts them at a high risk of getting pregnant. As a young lady one needs to be indoors no later than 7 or 8 pm. But by building her own housing unit you cannot tell who she has over late at night, sometimes all night. (Parent, Mumbwa)

Some respondents felt that this practice of building a separate housing unit for your daughter was a sign of poor parenting.

Some parents have stopped caring about their children and I can give an example where by you would find that someone is 14 or 15 years but they have built a house for them and he/she is sleeping alone in that house and that can cause someone to have more freedom... A child has to be in her parents' house and follow their rules... if the parents are just watching their daughter to do what she wants and they are not even concerned about the time that she 
is getting home, that's also bad... Parents should give rules to the children that they have and also protecting them from getting pregnant at an early age. (Mentor, Solwezi)

One parent in Mumbwa felt that girls' parents needed to keep a closer eye on their daughters, and exert more control over their behaviour, so that they could protect them.

Most parents have given their children too much freedom, and this freedom is the leading cause of underage pregnancy... parents have no direct control over what the girls get up to at night because parents and children live in different housing units. The girl child has her own hut in which she sleeps in at night and no one is there to see which men/boys enter and most of the girls consent for these men to lay down with them since their parents are nowhere in sight to see what's happening. I definitely think parents building separate housing units for their girls is a major contributing factor to teenage pregnancy. (Parent, Mumbwa)

\subsection{Substance Use: Drinking Alcohol}

Alcohol use amongst young girls was cited as a leading factor in young girls getting pregnant. Some of the adult respondents explained that when drunk, girls are unable to look after themselves and make informed decisions about sex.

A girl who drinks beer has no control of herself and men can easily have sex with her... There is a girl in this community who men would pick to drink beer, she was sleeping with any man and eventually ran away from home and ended up being pregnant. (Mentor, Solwezi)

If a girl is lacking in knowledge she may not know the consequences of taking alcohol. Because of this she may end up taking alcohol and getting drunk and the get taken advantage of. (Community leader, Ndola)

The likelihood of having sex without a condom increases when girls are drunk, lose control, and are unable to negotiate condom use with sex partners.

When a girl picks up such a reckless lifestyle they find themselves in situations where they get so drunk and lose control of themselves. This can happen to the point where they are not even aware of the men that pick them up to go sleep with them, without protection in most cases. (Mentor, Chipata / Chazanga)

They go for parties, you find that there are boys there, this one with the boyfriend that one with a boyfriend and this girl doesn't even have a boyfriend, she will also want to have a boyfriend because she has seen that her friends have boyfriends because she doesn't even know what it means to be a boyfriend and has no knowledge, at the end of the day maybe they just give you beer, she will get drunk, as you can see most girls are not strong when they take beer, they will just be taken to places where they can have sex with her, when morning comes she doesn't even know what happened the previous night at the end of it she will fall pregnant. (Mentor, Ndola)

Some of the girl respondents explained that many men in the community take advantage of young girls who are drunk.

If you get drunk men will be touching you. (Girl, 12-17, SS Only, Chipata / Chazanga)

In bars there found a lot of men, different men, and because of you being drunk every time at one you will be drunk and without knowing what is happening you will sleep with a man and become pregnant. (Girl, 12-17, SS+HV+SA, Mumbwa)

Some girls described some kind of 'date-rape' drugging of girls by men at bars.

When you look at these pubs they like going to, there are a lot of drunkards, so when (girls) sneak at night and go there, they find these drunkards who buys them a drink and puts sex 
pills to arouse you and when you take them they take advantage of you and sleep with you. (Girl, 15-21, SS+HV+SA, Mumbwa)

\section{The Solution}

There were a few comments from respondents regarding the necessity of enforcing age limits on purchasing alcohol, and how this could mitigate some of the effects of underage drinking, resulting in pregnancy.

What can be done is to encourage the girls to stop drinking beer and tell the people that sell beer stop selling to the under age children those that are less than 18 should not be sold beer. (Mentor, Solwezi)

I see girls of my age (under 18) in this community drinking beer... The men they go out with buy them beers and when they are drunk the man takes advantage, sleeps with her and she gets pregnant. Just putting restrictions and chasing young girls who go to pubs. Young girls should not be allowed in bars. (Girl, 12-17, SS Only, Chipata / Chazanga)

\subsection{Lack of Information / Education}

A lack of information regarding safe sex, reproductive health and family planning was also given as a reason why young girls in the study communities get pregnant.

Girls don't know that if I have sex just once I am able to get pregnant and I can just say that others have no idea about sex and pregnancy... most of those who fall pregnant it's lack of information about sex matters. (Mentor, Mumbwa)

One young girl illustrated this point, explaining that she had been unaware that she could get pregnant when she first had sex, and ended up having a child.

I: What circumstances led to you having children?

R: I was naughty, I did not know I was going to be pregnant when I have sex. (Girl, 15-21, SS

Only, Mumbwa)

\section{The Solution}

To avoid situations in which young girls would get pregnant due to a lack of knowledge and information, some of the adult respondents suggested that girls need to receive accurate information on sex and reproduction.

Educate them on how one can become pregnant. Some think that they can only get pregnant when they have sex everyday but what they don't know is that even once is enough to get pregnant. Others say when you have sex while standing, one cannot get pregnant. (Mentor, Chipata / Chazanga)

\subsection{Not listening to advice}

Many of the respondents said that one reason for young girls getting pregnant was that they were disobedient, and did not listen to the advice that their parents gave.

Girls that are naughty do not listen to anyone they are always moving up and down with boys and in the end they get pregnant... there is a girl who is naughty and she didn't want to listen to anyone who advised her, as we are talking right now she has a child. (Parent, Solwezi) 
One girl from Ndola gave an example of a friend who got pregnant after refusing to listen to her parents' advice, and expressed regret afterwards.

(Parents) are telling her and she is not listening to them, when her friends say let's do this she follows, and the next thing that will happen is she will get pregnant... We used to play the three of us but when... her parents would be giving her good advice but she wasn't listening to them, then when she become pregnant, and she came to tell us "if I had been listening to my parents I wouldn't have been pregnant right now". So right now we don't even play with her. (Girl, 1217 , SS Only, Ndola)

Some of the parents, especially those from the urban study sites, remarked that norms and behaviours have changed from previous generations; and that nowadays girls 'date' many young men and have casual pre-marital sex partners. Respondents, both girls and parents from the urban sites, commented that if parents try to give advice to their daughters, the girls don't listen to them and accuse them of being old-fashioned and giving out-dated advice. One parent explained that the norm used to be for a suitor to approach your family and express interest in marriage, but now girls date many different men and have casual relationships before getting married.

In my generation there was no such thing as a girl dating or being found with different guys on the streets chatting and what not. If a man wanted to marry you, he would make his intentions know to your family and then you would get marriage. But these girls nowadays are very disobedient and... they consider our advice to be old fashioned. But when we are able to live long because we behaved we are considered to be witches when in actuality such destructive behaviour can lead one to contract diseases. (Parent, Ndola)

There are some who have everything and even admire them and wish to be like them because they do not lack anything, they have everything that they may want but they still get pregnant. I know of a girl that got pregnant because of this, they have everything where she comes from but she stopped school in the 11th Grade because of not listening. The mother just cried because she used to have everything she needs... We have seen how parents talk to their children about taking care of themselves and some girls do not listen until they get pregnant. Then they will start regretting now to say they should have listened to parents' advice and when they realize this it may be too late. (Girl, 15-21, SS Only, Ndola)

Not wanting to listen to the elders... What your mother is telling you not to do is what you always want to do... She would be telling you that if you have sex with a boy you will fall pregnant, you think she is joking with you. (Girl, 10-14, SS+HV+SA, Chipata / Chazanga)

\section{The Solution}

It was suggested by three respondents from the Ndola urban study site that if girls would be more respectful of their parents, and heed their advice, as taught by AGEP, they would avoid having unplanned pregnancies.

Just listening to parents' advice and learning from groups like AGEP which may teach one a lot of things. (Girl, 15-21, SS Only, Ndola)

If you don't listen to your parents they can curse you, that's not a good thing, things wouldn't go well with you... a lot of girls don't listen to their parents... If they start listening to their parents, they won't be getting pregnant at a tender age. (Girl, 12-17, SS Only, Ndola)

One mentor suggested that in order to empower girls, parents need to be upfront, honest and open with their children, and educate them about the realities of society and the risks of sex, instead of hiding the truth from them.

Just to sensitize them and teach them the right things and explain things as they are not what our parents used to do a long time ago telling us that if you start sleeping with men then they just let you grow up thinking that's how things are. No, when I get to a certain stage they have 
to tell me... "what we told you were just lies, we wanted you to take care of yourself... these things that you are seeing on your body you have to take good care of yourself because AIDS is real, unwanted pregnancies are not good no one will keep your child who doesn't have a father, dropping out from school is bad". If there are people that can teach the girls those things, that would be better... We need to teach them that they need to listen to their parents because parents have seen a lot, what I haven't seen my parents have seen, so when they say... "don't move at night there is no good thing found in moving at night", or they say "don't drink alcohol", they have seen what is in alcohol. Or they say "don't go out with sugar daddies", it's because they know that sugar daddies might be infected with a disease or they will just destroy your future. (Mentor, Ndola)

\subsection{Abuse}

One reason cited by some of the community leaders for why young girls got pregnant was that they were subject to abuse, were unaware of their rights, and were unable to refuse a man's advances.

Girl children do not know their rights because they do not know how to say no when a man touches their back or their breasts. They do not know how to refuse... They learnt from AGEP that are able to report such cases but now since most of them lack that knowledge, they suffer. When such men touch them, they end up sleeping with them but if they know their rights they will report and at the end of the day they get protected. (Community leader, Mumbwa)

In our area there was this girl who got pregnant at the age of 10 and it was all over the news. What transpired was the girl's mother was a divorcee and had recently remarried unfortunately to a heavy drinker. Sow what would happen in that home was that her husband would get her drunk so that he could take advantage of his 10-year-old step daughter while she was passed out. This continued to happen over a period of time until the young girl fell pregnant. Had she had knowledge on sexual behaviour such us protective measure to use or to scream and shout and call for help when someone takes advantage of you and even to report this man, this issue would have been prevented... (These situations) happen but is usually kept a secret in many homes out of fear of losing financial support. (Community leader, Ndola)

\subsection{Boredom / Lack of Entertainment / Dropping Out of School}

Respondents explained that girls who could not afford to pay school fees, and didn't have any financial support, would end up with nothing to do, and their lives would end up in a downward spiral, often ending in pregnancy and HIV infection.

The main cause for this is a lack of sponsorship. Because she has no sponsorship, she will drop out of school. Due to a lot of time on her hands she will get up to no good and end up pregnant, eventually contracting HIV/AIDS... (One girl) lost both her parents and started living with her grandmother who was too old to provide for her. In the end she dropped out of school as there was nobody left to support her. She lost track of her life and it resulted in her having a child too soon and because of this lifestyle she contracted HIV/AIDS. (Community leader, Ndola)

One of the explanations given for young girls getting pregnant was that when girls drop out of school, either due to lack of funding, support from parents, or lack of interest, the girls are left with nothing to occupy their time, so they end up getting pregnant.

Some children don't have parents that can care for them so that they can finish their education, then when they go to school they are chased (have to leave). So that's why they just 
decide to get pregnant in the hope that those boys will marry... they have no sponsors to help them pay at school so that's when they decide to just do other things. (Parent, Mumbwa)

One of the mentors at the rural site Mumbwa suggested that young people have no forms of recreation in the community. With nothing else to occupy them, they end up having sexual relationships.

Where a girl has just been dormant in the community not going to school and you would find that in the communities where we live there are no recreational centres, therefore the girls mind becomes dormant and nowhere to go, nowhere to interact from at the end of the day they just decide that if I have a boyfriend, I will have somebody to interact with, that will be like a recreation to them and at the end of the day they fall pregnant, sometimes realising at and sometimes not realising that through sex they will be able to get pregnant... There is a girl that became pregnant... she lives in my neighbourhood and the time l asked her why she got pregnant, she said what else can I do, I do go to school, my parents have failed to pay for me and am just home for the past 3 years and I am now 16 years old, this is why I ended up thinking that maybe that guy would marry me at the end of the day when I told him that I was pregnant he told me that he had nothing to do with the pregnancy, he was not ready to father a baby. (Mentor, Mumbwa)

Another mentor, also in Mumbwa, shared a similar view, suggesting that boredom and lack of entertainment lead the girls to experiment with sex to keep themselves occupied.

When a child is kept busy, they have a lot of things to do they will not think of sex, but like the saying goes an empty mind is the devils playing ground. So, if they have nothing to do they only thing they would think of is sex. But if there are things to do, they won't have time to look for boyfriends... there are a lot of girls who are getting pregnant because of lack of entertainment. (Mentor, Mumbwa)

\section{The Solution}

It was suggested that girls need to be engaged in sociable, productive activities and provided with other forms of entertainment, to ensure that they didn't get bored and resort to having sex just to have something to occupy their time.

At least if there can be games, such as sport, playing football, netball and also forming youth groups, just like that so that they can be playing together. (Mentor, Mumbwa) 


\section{Conclusion}

\section{Summary of Findings}

In general, mentors, community leaders, AGEP girls themselves and their parents, from all four study sites, spoke positively about AGEP, and the impact it has had on girls in the community who have been part of the programme.

The key benefits of the AGEP programme as described by respondents included:

> Health knowledge gains: specifically relating to general health and nutrition, as well as sexual and reproductive health including family planning, contraceptives, STIs, HIV and safer sex;

$>$ Improved motivation and inspiration to attend and complete school, and even pursue tertiary education and a career;

$>$ Positive behaviour changes: including increased respect for elders, more responsible and considerate behaviour, more modest dressing, and avoiding risky behaviours such as drinking alcohol and frequenting bars and nightclubs;

$>$ Increased self-confidence, self-esteem, self-worth, self-belief and self-efficacy, impacting various aspects of life;

$>$ Increased knowledge regarding safety and self-care, and increased awareness of individual rights to bodily integrity, and improved confidence and agency to report cases of abuse and rape;

$>$ Improved health seeking behaviour and medication adherence as a result of increased self-confidence, reduced fear of clinics, and improved experiences at health facilities, particularly for those with Health Vouchers;

$>$ Improved financial sense in terms of earning, budgeting, and saving money. Girls described the ways in which learning how to earn and save money had positively influenced their education and relationships, decreased the risk of getting involved in transactional sex, and increased their financial independence and ability to support themselves and provide for their families;

> Positive impact on social networks and relationships: generally girls reported that they now socialised with friends that who better behaved and were a more positive influence in terms of education, safety, health and delaying sexual debut, pregnancy and marriage;

$>$ Increased sexual agency: girls were more motivated to delay sexual debut, abstain from sex, or to practice safer/protected sex. Additionally, girls generally felt more empowered to withstand peer pressure to have sex, and to refuse unwanted sexual advances from men;

With regards to life goals and planning for the future, in general AGEP girls were motivated by the programme to "dream big", complete their schooling, pursue a career, become financially independent, and delay marriage and child-bearing until they had achieved these goals.

As seen from the comments made by community leaders and parents, community perceptions of AGEP were generally positive. However, there were some negative views of AGEP expressed by respondents. These included widely held views in the community that 
AGEP was Satanist, and perceptions that the programme promoted promiscuity by teaching young girls about sexual and reproductive health, and termination of pregnancy. Some respondents also felt that the programme had failed to meet expectations, especially with regard to the prizes given to group members. However, these negative views came from a minority of respondents.

One key aspect of Safe Spaces entailed informing and empowering girls about their sexual rights. Sexual rights refer to the right of all persons, free of coercion, discrimination, and violence, to the following: access to sexual and reproductive health care and information; respected bodily integrity; the ability to decide whether to be sexually active or not; have consensual sexual relations; consensual marriage; decide whether or not to have children, and if so, when (Collumbien et al., 2012). As a result of their involvement in the programme, AGEP girls demonstrated improved knowledge and awareness of their rights to bodily integrity; were more informed about and empowered to access contraceptives; were more able to stand up themselves; more able to delay sexual debut; more empowered to prevent themselves getting involved in transactional sexual relationships; and more determined to delay marriage until they had attained their education goals.

However, although AGEP mentors felt that they had benefited from the programme, gaining valuable knowledge, life skills and experience, some of the mentors explained that they had found it challenging to provide information to the girls on topics which they disagreed with on a personal level. In other cases girls described messaging from their mentors that was not in line with the core values of information and choice that the program was trying to convey. One example of a challenge for the mentors was having to teach girls, especially those in the younger age groups, about termination of pregnancy. The AGEP health curriculum informed girls of the importance of accessing termination of pregnancy services at a formal health facility. However, from the narratives of some of the girls, it seemed that some of the mentors were displaying judgemental attitudes and instead moralistically condemning abortion. Another example is of girls expressing that their mentors did not think unmarried girls should use contraception or fearing that their mentors would be disappointed if they became pregnant. It would appear that despite values clarification exercises conducted as part of the mentor training, some of the mentors may not have shared the programme's values. Mentors also described some of the logistical challenges related to the programme such as lack of venues, late delivery of prizes and disgruntled group members and parents, and other issues relating to poor meeting attendance and attrition.

From the narratives of girls in the control group, it appears that those control group girls who were engaged in some sort of programme such as a church youth group or NGO activities gained similar kinds of support and encouragement through these groups as AGEP girls did in Safe Spaces, such as encouragement and motivation to attend school and complete education, some sort of moral support and advice, and in some cases information about HIV and other health issues. Within the control groups, there appeared to be a wide variation in terms of girls' knowledge levels, access to social support, levels of self-confidence and agency, and money management behaviour. Some of the girls in the control group exhibited attitudes and experiences similar to those of AGEP girls; others were disadvantaged and lacked the same levels of knowledge, skills and awareness. This is important to keep in mind as the quantitative data will be presenting program impact based on change in the AGEP girls relative to the control group girls.

One noticeable difference between control group girls and programme girls was in relation to access to, and motivation to seek, health services. AGEP girls, most specifically those who received health vouchers, experienced fewer barriers to accessing healthcare namely long queues and waiting times at the clinics-and received free medication and services. Another difference between girls in the control group and those in AGEP related to access to constructive and supportive friendships. Many of the AGEP girls spoke of 
having friends who were supportive, encouraging and trustworthy, especially since being involved in the programme. In contrast, a number of the girls in the control group appeared not to have access to constructive friendships and rather chose not to have any friends, out of concern about destructive peer pressure influences, and being distracted from finishing school.

A wide range of factors were listed by respondents in explanation of the high rates of teenage pregnancy in the communities. Reasons included transactional sex, peer pressure, hunger and poverty, materialism, lack of education and information, bad behaviour including drinking alcohol, poor parenting, abuse, boredom and dropping out of school to name a few.

\section{Limitations}

There is likely to have been an element of social desirability bias present in the interviews. If the interviewees perceived the interviewers to be part of AGEP, they would have been less likely to express negative views about the programme. The social desirability factor may have been enhanced amongst all respondents by the fact that girls had been receiving prizes from the programme, and they may have anticipated that they may benefit from responding positively during the interview. In addition, respondents may have wanted to give positive answers about the programme, with the hope that it would continue for a longer period of time.

Another limitation apparent in the transcripts is that in the interviews, some of the interviewers' questions appeared to be leading respondents' answers, particularly when the interviewers were probing responses to the section on the drivers of teenage pregnancy. This is likely to have influenced respondents' answers. Additionally, in some cases it appeared that the respondents did not fully comprehend the interviewers' questions, which would have affected the quality of the data.

Overall these findings provide valuable insight into the views and experiences of girls who were involved in the AGEP programme, as well as the perceptions of programme mentors, the girls' parents, and community leaders. In addition, these findings highlight the areas in which the experiences of girls in the control groups, who had not been engaged in AGEP's programmes and activities, differed from or were similar to those of the AGEP girls. The findings also highlight issues and factors in the community that contribute to the problem of pregnancies amongst young girls. 


\section{References}

Austrian, K., Jackson Hachonda, N. \& Hewett, P. (2013). The Adolescent Girls Empowerment Program: Lessons learned from the pilot test programme. Lusaka: Population Council.

Basit, T.N. (2003). Manual or electronic? The role of coding in qualitative data analysis. Educational Research, 45(2): 143-154. DOI: 10.1080/0013188032000133548.

Bradley, E.H., Curry, L.A. \& Devers, K.J. (2007). Qualitative Data Analysis for Health Services Research: Developing Taxonomy, Themes, and Theory. Health Research and Educational Trust. DOI: 10.1111/j.1475-6773.2006.00684.x.

Collumbien, M., Busza, J., Cleland, J. \& Campbell, O. (2012). Social science methods for research on sexual and reproductive health. World Health Organization. Geneva: Switzerland.

FHI360. (2014). Zambia National Education Profile: 2014 Update. FHI360.

Gale, N.K., Heath, G., Cameron, E., Rashid, S. \& Redwood, S. (2013). Using the framework method for the analysis of qualitative data in multi-disciplinary health research. BMC Medical Research Methodology, 13:117. http://www.biomedcentral.com/1471-2288/13/117.

Hewett, P.C., Austrian, K., Soler-Hampejsek, E., Behrman, J.R., Kelly, C.A., Kusi-Appouh, D.. Bozzani, F., Mensch, B.S. \& Maimbolwa, M. (2014). Adolescent Girls Empowerment Programme: Research and Evaluation Baseline Technical Report. Lusaka, Zambia. Population Council.

Myers, M. (2000). Qualitative Research and the Generalizability Question: Standing Firm with Proteus. The Qualitative Report, 4(3/4). http://www.nova.edu/ssss/QR/QR43/myers.html.

Pope, C., Ziebland, S. \& Mays, N. (2000). Qualitative Research in Health Care: Analysing Qualitative Data. British Medical Journal, 320(7227): 114-116.

http://www.jstor.org/stable/25186804. 